\title{
Incentives in the diagnosis treatment combination payment system for specialist medical care : a study about behavioral responses of medical specialists and hospitals in the Netherlands
}

Citation for published version (APA):

Hasaart, F. (2011). Incentives in the diagnosis treatment combination payment system for specialist medical care : a study about behavioral responses of medical specialists and hospitals in the Netherlands. [Doctoral Thesis, Maastricht University]. Maastricht University. https://doi.org/10.26481/dis.20111104fh

Document status and date:

Published: 01/01/2011

DOI:

10.26481/dis.20111104fh

Document Version:

Publisher's PDF, also known as Version of record

Please check the document version of this publication:

- A submitted manuscript is the version of the article upon submission and before peer-review. There can be important differences between the submitted version and the official published version of record. People interested in the research are advised to contact the author for the final version of the publication, or visit the $\mathrm{DOI}$ to the publisher's website.

- The final author version and the galley proof are versions of the publication after peer review.

- The final published version features the final layout of the paper including the volume, issue and page numbers.

Link to publication

\footnotetext{
General rights rights.

- You may freely distribute the URL identifying the publication in the public portal. please follow below link for the End User Agreement:

www.umlib.nl/taverne-license

Take down policy

If you believe that this document breaches copyright please contact us at:

repository@maastrichtuniversity.nl

providing details and we will investigate your claim.
}

Copyright and moral rights for the publications made accessible in the public portal are retained by the authors and/or other copyright owners and it is a condition of accessing publications that users recognise and abide by the legal requirements associated with these

- Users may download and print one copy of any publication from the public portal for the purpose of private study or research.

- You may not further distribute the material or use it for any profit-making activity or commercial gain

If the publication is distributed under the terms of Article $25 \mathrm{fa}$ of the Dutch Copyright Act, indicated by the "Taverne" license above,

Download date: 26 Apr. 2023 


\title{
Incentives in the Diagnosis Treatment Combination payment system for specialist medical care
}

\author{
A study about behavioral responses of medical \\ specialists and hospitals in the Netherlands
}

Fleur Hasaart

Juli 2011 
(c) Copyright Fleur Hasaart, Maastricht 2011

Cover design: Jules Wanten

Production: Datawyse | Universitaire Pers Maastricht

ISBN 978-94-6159-089-3 


\title{
Incentives in the Diagnosis Treatment Combination payment system for specialist medical care
}

\author{
A study about behavioral responses of medical \\ specialists and hospitals in the Netherlands
}

\author{
PROEFSCHRIFT \\ ter verkrijging van de graad van doctor aan de Universiteit Maastricht, \\ op gezag van de Rector Magnificus, Prof. mr. G.P.M.F. Mols \\ volgens het besluit van het College van Decanen, \\ in het openbaar te verdedigen \\ op vrijdag 4 november 2011 om 16.00 uur \\ door
}

Fleur Hasaart

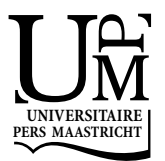




\section{Promotor}

Prof. dr. J.A.M. Maarse

\section{Copromotor}

Dr. J.M. Pomp (onafhankelijk onderzoeker)

\section{Beoordelingscommissie}

Prof. dr. J.G.A. van Mierlo (voorzitter)

Prof. dr. P.P. Groenewegen (Universiteit Utrecht)

Prof. dr. C.R.J. de Neubourg (European University Institute, Italy)

Prof. dr. R.T.J.M. Janssen (Universiteit Tilbug)

Mw. dr. M.I. Pavlova 


\section{Content}

Chapter 1 A Primer on Financial Incentives in Funding Systems for Medical Specialists and Hospitals

Chapter 2 Hospital Funding in the Netherlands: The DTC system unveiled

Chapter 3 The Volume Effect of a New Casemix-based Funding System for Hospital Care on the Behavior of Medical Specialists in the Netherlands

Chapter 4 Does Upcoding occur in the DTC system? An Explorative Analysis

Chapter 5 Fee-for-Service Use of the Dutch Casemix System of DTCs

Chapter 6 Supplier-induced Demand in Dutch Hospital Care: Evidence from a Natural Experiment

Chapter 7 Summary and discussion

Samenvatting

Dankwoord

Curriculum Vitae 



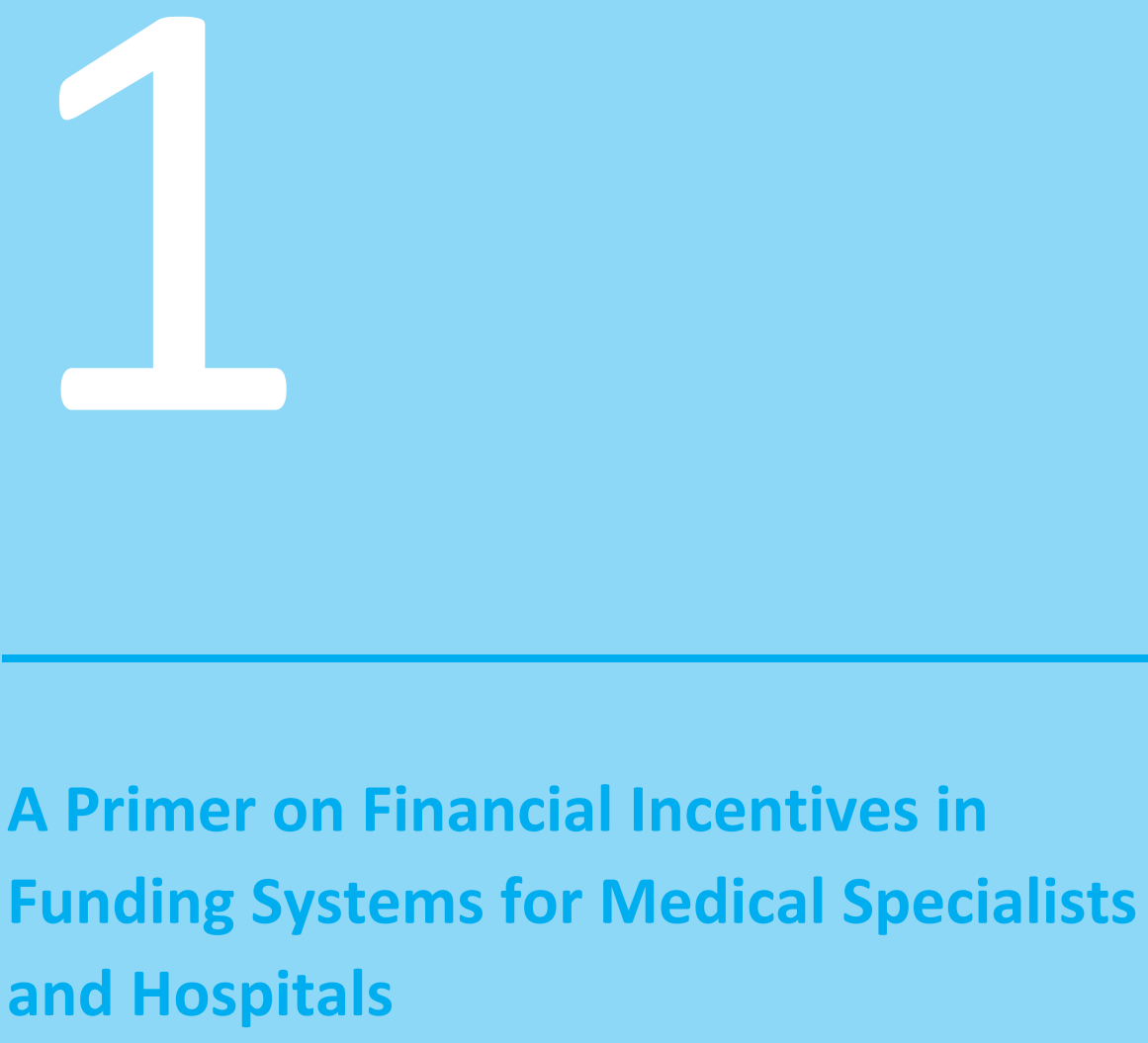




\section{Introduction}

Finding the optimal way to fund hospitals and medical specialists is frequently studied in economic theory and research on hospital care. As health care in general and specifically hospital care consume a considerable and increasing share of the Gross Domestic Product (GDP), policymakers are continuously looking for new payment strategies to ensure that funding and performance are sufficiently linked to each other and that high-quality care is delivered efficiently. One of the most challenging tasks in this strategy is to design hospital funding systems that align patient needs and provider incentives in order to obtain the best possible value for money (Kutzin, 2001). Empirical research can play an important role in the design process.

A new system for funding hospitals and medical specialists was introduced in the Netherlands in 2005: the Diagnosis Treatment Combination - or DTC system (DBC or Diagnose Behandeling Combinatie). This system replaced a fixed budget system that had existed since the early 1980s. The two primary objectives of the new hospital funding scheme were to forge a stronger link between funding and performance and to foster hospital efficiency. The shift to a new funding system was also a key element in the intended transition of a mainly supply-driven type of health care system to a more demand-driven type (Maarse and Paulus, 2011). In this study we present an analysis of some effects of the new funding system's financial incentives on hospital care in the Netherlands. We are interested in behavioral effects (for medical specialists and/or hospitals) that yield extra revenues, either by raising the volume or care, or by what will be termed upcoding or by what will be termed overdeclaration. Upcoding refers to the incentive to choose the most lucrative treatment, even though this is not medically necessary and overdeclaration to the incentive to increase the number of DTCs to increase revenues. Each of these three effects can be conceptualized as a strategic response to the introduction of the new funding system. We do not investigate strategies that yield extra revenues by negotiating higher prices with health insurers.

To understand the role and effects of financial incentives in hospital funding schemes, we begin with a short overview of the theoretical context of physicianinduced demand. We then describe the four most common funding schemes for hospitals and medical specialists, each with their respective incentive-sets. We conclude this chapter with an overview of the empirical work presented in this dissertation. 


\section{Physician-induced Demand}

From an economic perspective the health care market can be conceptualized as a specific market. It has special characteristics that are caused mainly by asymmetry in information in the physician-patient relationship. Another specific characteristic is that 'consumers' usually do not pay directly for the health care rendered to them, but indirectly through a health insurance scheme. Since health care costs do not influence their demand for health care (inelastic demand curve), a moral hazard problem arises. Moral hazard is a common problem for (health) insurance, because the insured may take more risks than they do when they are directly accountable for the costs they incur (Arrow, 1963; Pauly, 1987). The characteristic of the health care market that most interests us in this study is the information-asymmetry in the physician-patient relationship. Information-asymmetry causes a principal-agent problem (McGuire, 2000).

\section{Medical Specialist - Patient}

The most important principal-agent relation in the health care market is the relation between the medical specialist as the agent and his patient as the principal. The medical specialist is a professional who renders health care and has 'an ideology that asserts greater commitment to doing good work than to economic gain and to the quality rather than the economic efficiency of work' (Freidson, 2001). However, from an economic point of view the medical specialist also has preferences about providing health care and earning revenues. As Arrow (1984) notes in regard to the relationship between doctor and patient: 'The physician-patient relation is a notorious case... the very basis of the relation is the superior knowledge of the physician. Hence the patients cannot check to see if the actions of the physician are as diligent as they could be' (p. 1184).

Providers of health care can influence the demand of their patients in their own interest, because patients possess too little knowledge and information to assess what they really need. This is called physician-induced demand, first identified in 1974 by Evans (Evans, 1974). A definition of physician-induced demand is '... the amount of demand created by doctors, which exists beyond what would have occurred in a market in which consumers are fully informed' (Donaldson and Gerard, 2005). In other words, a distinction should be made between useful agency and inducement. There is no physician-induced demand if the specialist influences the patient towards the patient's optimal point. This is merely the specialist acting as a perfect agent. This is also where moral hazard collides with induced demand. Since patients do not pay for health care themselves, they may choose for more care than might be optimal (McGuire, 2000). 
There are widely differing beliefs about the degree to which the medical specialists' role as agent is influenced by the funding scheme. Many health economists believe that the funding scheme has a large influence on behavior, whereas medical specialists more often state that only medical and ethical considerations play a role (Fuchs, 1978; Evans, 1984; Dranove, 1988; Ellis, 2001; Janssen and Soeters, 2010). In economic theory, the utility function of the agent determines his behavior. The theoretical literature on physician agency assumes that the utility of a physician is not the standard utility function, consisting only of leisure and income. For a medical specialist this function also contains medical standards, reputation, ethical considerations and the best interest of the patient (McGuire, 2000; Mot, 2002). This argument was made clear by a rather visual example of Evans (1984): 'Removing healthy organs, or drilling healthy teeth, has a negative impact on the practitioner's overall satisfaction, even if it is profitable and the patients, believing the organs/teeth were diseased, are satisfied' (p. 151). However, there are situations, for example in elective surgery such as a borderline cataract, where a medical specialist will face a trade off between gaining income by an intervention that has either no or only a small (either positive or negative) effect on the welfare of his patient, and not gaining income. No matter what particular model concerning physician motivation is used, the nature of the trade-off to the physician implies that the physician will feel at least some inducement. The same argument is stated by Pauly (1980) as: 'Other things equal, physicians would rather tell the truth, but they would be willing to surrender some accuracy for some amount of income' (page 51). This does not necessarily imply that physician-induced demand is exercised by all specialists, but it does imply that a change in the payment system is likely to have an impact on the aggregated behavior of medical specialists.

\section{Medical Specialist - Hospital}

The institution in which the specialist performs his actions is in most cases and also in this study the hospital. Within the hospital there exists a second agency relationship that may influence the production of hospital services: the relation between the medical specialist and hospital management. In this relationship the medical specialist acts as the agent whose behavior can be suboptimal for the principal (management), depending on the financial incentives in the hospital funding scheme. The basis for this possible strategic behavior is once again the informational advantage the medical specialist has over the other party. Pauly and Redisch claim that in practice medical specialists, not hospital management, determine the policy of the hospital; this type of organization is called a professional organization (Pauly and Redisch, 1973). Medical specialists make the decisions about the exact treatment and hospitalization. However, hospital management can indirectly influence these decisions through the allocation of resources like nurses or time in the operating room. Hospital policy is also part of the set of constraints medical special- 
ists face in optimizing their income, since the hospital always provides logistical support for the actions of the medical specialist and in some cases also pays the medical specialist's salary. The interaction between the incentives of hospital management and the medical specialist also needs to be considered when analyzing the effects of reimbursement schemes upon their behavior (Berenson et al., 2007). In order to optimize cooperation it is therefore crucial that the interests of the medical specialists and the hospital be aligned. If hospitals and medical specialists are paid through separate schemes, non-alignment of incentives may occur.

\section{Differences in practice styles}

As mentioned at the end of the section on the medical specialist-patient relationship, we do not expect all medical specialists to exercise physician-induced demand or practice medicine in the same way. This explains in part the differences in the type and quantity of treatment of a patient, defined as treatment intensity or more broadly as practice style. These differences have been extensively researched by Wennberg, who found differences in practice styles within regions under the same funding scheme (corrected for differences in patient casemix). An example is the difference in incidence of tonsillectomy, which turned out to be three times higher for a specific region in the US in comparison with its neighboring regions. Wennberg attributes these differences in practice style to differences in beliefs among physicians concerning the indications for, and efficacy of the procedure (Wennberg, 1973; Wennberg, 1982). Dranove describes regional variations that are caused by differences in treatment style, which depends on where the physician was educated (Dranove et al., 2006). Overall these differences can be caused by differences in professional training, differences in the levels of uncertainty about the right treatment, but also by differences in reactions to financial incentives (Wennberg et al., 1982). These small area variations have been studied extensively over the last decades and indicate strongly that '. .those physicians' preferences are formed within, and respond to, a local culture' (Evans, 2009). In chapters 4 and 5 we study these differences in practice style in Dutch hospital care.

\section{Funding schemes}

After having established why financial incentives play a role in the physician-patient and physician-hospital relationship, we will briefly describe the basic funding schemes and the financial incentives incorporated in these schemes. Within OECD countries, there are four main funding schemes currently in use for medical specialists and hospitals: 1) budget (or salary), 2) capitation, 3) case-based systems, and 4) fee-for-service. There are also hybrid schemes that we will address later in this introduction. We will describe the funding schemes and their incentives one by one, 
using three dimensions from a typology to classify provider payment systems from an incentive point of view: fixed or variable volume component, relation to actual costs and the unit of reimbursement (Jegers et al., 2002). Note, that our description of each of these models is highly stylized. There is not such a thing as a single budget-model or a single fee-for-service model, to mention only two examples. There are many variations of each model and the way they are combined in practice (hybrid models).

\section{1) Budget (or salary)}

A budget is a funding scheme in which a provider receives a lump sum for the treatment of patients for a given period. This sum is independent of the volume of services provided or number of patients treated. Also, there is no relation to actual costs, since budgets are determined prospectively. The unit of reimbursement is a time period, usually a year for a budget and a month for salaries. Budgets and salaries guarantee cost control, but may cause possible adverse behavior in the provision of care, since extra effort is not rewarded. In a budget system there is no financial incentive to increase volume much beyond the budget ceiling, since this care will not be reimbursed. Furthermore, the budget system provides no financial incentive to work more efficiently, since this will not change the budget. Theoretically there is no incentive to produce at all; however ethical and reputational constraints will prevent this scenario from happening.

\section{2) Capitation}

Capitation is a funding scheme in which a medical specialist or hospital is paid a fixed amount per enrollee to cover a defined scope of services for a defined population for a defined period of time, regardless of the actual number or nature services provided (McGuire, 1988). Capitation rates can be adjusted to specific population characteristics (such as age, gender, chronic illnesses, etc) that better forecast actual costs and at the same time avoid risk selection by the provider. The unit of reimbursement in this scheme is a patient. An advantage of capitation is the scheme's incentive to stimulate prevention and health promotion. Another advantage is that total costs are controlled. A possible risk, apart from the risk selection by the physician (or hospital) already noted, is the under provision of care to some patients.

\section{3) Fee-for-Service}

Fee-for-service reimbursement is the most traditional form of reimbursement for health care services: a fee is paid to a provider according to the service performed, either by the patient or the insurer after the service is rendered (McGuire, 1988). In 
fee-for-service funding there is a direct link between volume and revenues. Payment occurs retrospectively and is related to volume and by implication to actual costs. The unit of reimbursement is a pre-defined service, such as a consultation or an x-ray. The two main advantages of fee-for-service are good access to care and high quality of care. The main drawback of this system is that there is a clear incentive for overproduction (Jegers et al., 2002). A study by Hickson et al. (1987) shows that under less than full capacity, medical specialists who are paid on a fee-forservice basis provide more services than do medical specialists who are paid a salary. In some countries, like Germany, there is a budget cap on a macro-level in combination with fee-for-service funding on micro-level, in order to control costs (Jegers et al., 2002).

\section{4) Case-based system}

Case-based systems are funding schemes in which all health services provided to a patient are bundled and classified into a group according to medical costs. Both the DRG (Diagnosis Related Groups) - and the DTC (Diagnosis Treatment Combinations) system are examples of case-based funding systems (Swan et al., 2010). Reimbursement per case is fixed, but more cases do lead to more revenue. The payment per DRG is set prospectively and bears no relation to actual costs. The unit of reimbursement is a specific case (Jegers et al., 2002). The advantages of this system are that within a given case there are no incentives to provide unnecessary services, and therefore there is strong cost control per case (although there may still be an incentive to produce an unnecessary case, e.g. unnecessary hospitalization). There are also possible adverse effects such as an incentive to choose the most lucrative treatment even though this is not medically necessary. This phenomenon is called upcoding (Simborg, 1981; Silverman and Skinner, 2001; Psaty et al., 1999). Another incentive is to select the most profitable patients. In this case the provider organization engages in patient selection to avoid high-risk patients (Ellis, 2001; Lakerveld, 2001). A last incentive that leads to a risk is to lower the quality of care within a certain code in order to save costs (quality skimping) (Glaser, 1987; Siciliani, 2008; Busse et al., 2006).

Figure 1 gives a visual comparison of the different funding schemes on the main incentive we are interested in: the incentive to either increase or decrease the total volume of care. 


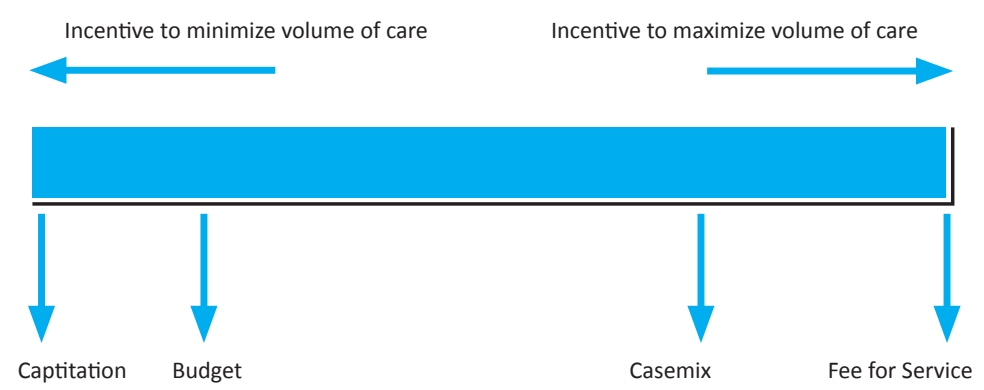

Figure 1: Schematic overview of different payment systems

\section{Hybrid funding schemes}

Hybrid funding schemes are schemes that combine different types of funding systems. For instance, hospitals may be funded by means of case-based payment scheme and physicians by means of a salary scheme or, to give another example, hospitals may receive a fixed budget whereas physicians are paid on a fee-forservice basis. In other words, hybrid schemes use different schemes for different types of providers or apply different types of funding systems to different payers (Jegers et al, 2002). Table 1 gives an overview of the outcomes of combining two payment schemes in one organization. Alignment occurs only if hospital and physicians are funded through the same (type of) payment scheme (cells 1, 6, 11 and 16). We also classify models which either combine a hospital budget with capitation payment of physicians (cell 2) or capitation funding of the hospital with salary-paid physicians (cell 5) as aligned. The argument for this classification is that the incentives in these funding models do not really conflict with each other. Therefore, both funding models can co-exist in a hospital without great practical problems. The situation is totally different in cell 3 , cell 4 , cell 7 , cell 8 and cell 12 . Here, physicians are paid according to a casemix or fee-for-service model, whereas the hospital is funded through a budget, a capitation model or a casemix-based model. Whereas physicians have an incentive to increase their revenues by rendering extra services to patients, the hospital does not have such an incentive (in cell 12 hospitals have an incentive to restrict the services per case). Hospital management has only a weak instrument to influence the behavior of their physicians, namely persuasion.

In principle one may also consider the combinations in cell 9, cell 10, cell 13, cell 14 and cell 15 as non-aligned. In each of these cells hospitals have an incentive to maximize their production, whereas specialist are not exposed to such an incentive. However, we prefer to classify the combinations of payment schemes in these cells as moderately aligned. The argument for this classification is that hospital management has effective instruments to re-align the incentives structures by introducing 
hospital-specific schemes to establish a link between the salary, capitation payment or casemix-based payment of physicians and their production volume.

Table 1: Hybrid schemes

\begin{tabular}{lllll}
\hline $\begin{array}{l}\text { Doctor } \rightarrow \\
\text { Hospital } \downarrow\end{array}$ & Salary & Capitation & Casemix & Fee-for-Service \\
\hline Budget & 1 Aligned & 2 Aligned & 3 Non-aligned & 4 Non-aligned \\
\hline Capitation & 5 Aligned & 6 Aligned & 7 Non-aligned & 8 Non-aligned \\
\hline Casemix & 9 Moderately aligned & 10 Moderately aligned & 11 Aligned & 12 Non-aligned \\
\hline Fee-for-Service & 13 Moderately aligned & 14 Moderately aligned & 15 Moderately aligned & 16 Aligned
\end{tabular}

As we will explain in greater detail in Chapter 2, hospital funding in the Netherlands under the regime of fixed budgets represents a clear example of a non-aligned funding scheme. Whereas hospitals were paid a fixed budget set prospectively, selfemployed ${ }^{1}$ specialists continued to be paid through a casemix system. The shift from a fixed budget funding scheme to a case-based funding scheme can be seen as an attempt to better align the incentives of hospital management and medical specialists. However, as we will see in Chapter 2, the realignment was only partial.

\section{Outline of the study}

This thesis consists of seven chapters. In Chapter 2 we will present a brief description of hospital funding in the Netherlands and how it changed following the transition of the fixed budget funding scheme to a case-based funding scheme. Chapters $3,4,5$ and 6 are empirical chapters that contain analyses of responses to the financial incentives of hospitals and medical specialists in the Netherlands. In Chapter 3 we analyze whether the introduction of market competition has led to an increase in the volume of care. We do this by comparing the growth of the newly introduced liberalized segment of hospital care with the growth of the still budgeted segment of hospital care. Chapter 4 is an explorative analysis of upcoding, which is a common risk in case-based funding systems. In Chapter 5 we analyze a financial incentive typical of the Dutch DTC system, namely the fee-for-service use of the case-based DTC system. In Chapter 6 supplier-induced demand in the Netherlands is analyzed by relating the number of specific procedures (surgeries) per capita to the number of both salaried and self-employed medical specialists per capita. Chapter 7 provides an overall conclusion of the different analyses of the Dutch DTC system and discusses policy recommendations.

\footnotetext{
${ }^{1}$ About 70 percent of medical specialists are self-employed. The other 30 percent are employed and are paid a salary.
} 


\section{References}

Arrow, K. J. (1963). "Uncertainty and the welfare economics of medical care." The American Economic Review 53(5): 941-973.

Arrow, K.J. (1984). The Economics of Agency. Staford University institure for Mathematical Studies in the Social Sciences, technical report.

Berenson, R.A., Ginsburg, P.B. and May, J.H. (2007). " Hospital-Physician Relations: Cooperation, Competition, or Separation?" Health Affairs 26(1): 31-43

Busse, R., Schreyögg, J. and Smith P.C. (2006). "Hospital case payment systems in Europe." Health Care Manag Sci 9(3): 211-213.

Cutler, D. M. and R. J. Zeckhauser (1999). The anatomy of health insurance, National Bureau of Economic Research Cambridge.

Donaldson, C., K. Gerard, et al. (2005). Economics of health care financing: the visible hand, Palgrave Macmillan.

Dranove, D. (1988). "Demand inducement and the physician/patient relationship." Economic Inquiry 26(2): 281-298.

Dranove, D., Ramanarayanan, S. and Rao, H. (2006), "The Substance of Style: A Study of Small Area Variations in the Practice Styles of Ob/Gyn Specialists in Florida" Working Paper, Stanford University.

Ellis. R.P. (2001), "Hospital Payment in the United States: An overview and conclusion of curent policy issues." Colloque International International Conference on Setting prices for disease: lessons from foreign experience. Paris, France.

Evans, R. G. (1974). Supplier-induced demand: some empirical evidence and implications. In Perlman, M.

(Ed.), The Economics of Health and Medical Care. New York: John Wiley and Sons.

Evans, R. G. (1984). Strained mercy, Toronto: Butterworth.

Evans, R. G. (2009). "There's No Reason for It, It's Just Our Policy." Healthcare Policy 5(2): 14.

Freidson, E. (2001) Professionalism: the third logic. San Francisco: Polity Press.

Fuchs, V. R. (1978). The supply of surgeons and the demand for operations, National Bureau of Economic Research Cambridge, Mass., USA.

Glaser, W. A. (1987). Paying the hospital: the organization, dynamics, and effects of differing financial arrangements, San Francisco: Jossey-Bass.

Hickson, G. B., Altemeier, W.A. and Perrin, J.M. (1987). "Physician reimbursement by salary or fee-forservice: effect on physician practice behavior in a randomized prospective study." Pediatrics $\mathbf{8 0}(3)$ : 344.

Janssen, R.T.J.M. and Soeters , P. (2010). “DBC's in de GGZ , ontwrichtende of herstellende werking?” GZ Psychologie 7: 36-45

Jegers, M., Kesteloot, K., de Graeve, D. and Gillles, W. (2002). "A typology for provider payment systems in health care." Health Policy 60(3): 255-273.

Kutzin, J. (2001). "A descriptive framework for country-level analysis of health care financing arrangements." Health Policy 56(3): 171-204.

Lakerveld, A. (2001). Financiële Prikkels in het DBC-systeem: upcoding en afwenteling. Maastricht, University of Maastricht. Master's thesis.

Maarse, H. and A. Paulus (2011). "The politics of health-care reform in the Netherlands since 2006." Health Economics, Policy and Law 6(01): 125-134.

McGuire, A., Henderson, J. and Mooney, G. (1988). The economics of health care: an introductory text, London: Routledge.

McGuire, T. G. (2000). "Physician agency." Handbook of health economics 1: 461-536. Elsevier.

Mot, E. (2002). Paying the medical specialist: the eternal puzzle: experiments in the Netherlands. Amsterdam: University of Amsterdam. Dissertation

Pauly, M. (1980). Physician information and the consumer's demand for care, University of Chicago Press.

Pauly, M. V. and M. A. Satterthwaite (1981). "The pricing of primary care physicians services: a test of the role of consumer information." The Bell Journal of Economics: 488-506. 
Pauly, M. and M. Redisch (1973). "The not-for-profit hospital as a physicians' cooperative." The American Economic Review 63(1): 87-99.

Pauly, M. V. (1987). "Nonprofit firms in medical markets." The American Economic Review 77(2): $257-262$.

Psaty, B. M., Boineau, R., Kuller, L.H., and Luepker, R.V. (1999). "The potential costs of upcoding for heart failure in the United States." The American journal of cardiology 84(1): 108.

Siciliani, L. and Hafsteinsdóttir, E.J.G. (2008). "DRG prospective payment system: refine or not refine?" Discussion Papers. 08/29 Department of Economics. York: University of York.

Silverman, E. and Skinner, J.S. (2001). Are for-profit hospitals really different? Medicare upcoding and market structure, National Bureau of Economic Research Cambridge.

Simborg, D. W. (1981). "DRG creep." New England Journal of Medicine 304(26): 1602-1604.

Tan, S. S., van Ineveld, M., Redkop, K. and Hakkaart-van Roijen, L. (2010) "Structural reforms and hospital payment in the Netherlands." EuroObserver 12(3): 7-9

Wennberg, J. and Gittelsohn, A. (1973). "Small area variations in health care delivery." Science 182(4117): 1102.

Wennberg, J. E., Barnes, A.B. and Zubkoff, M. (1982). "Professional uncertainty and the problem of supplier-induced demand" Social Science \& Medicine 16(7): 811-824. 



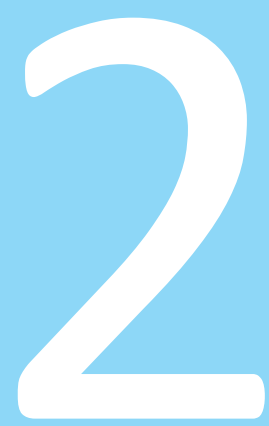

Hospital funding in the Netherlands:

The DTC system unveiled 


\section{Introduction}

In 2005 a new model for hospital funding, based on Diagnosis Treatment Combinations or DTCs (DBC in Dutch: Diagnose Behandel Combinatie), was introduced in the Netherlands. The new funding or reimbursement model meant a switch from a fixed budget model to one in which hospitals are paid a casemix-based tariff for the entire treatment of a patient in the hospital. The DTC model was introduced as a tool to support market competition (Maarse and Bartholomée, 2007; van de Ven and Schut, 2008).

The purpose of this chapter is threefold. First, there is a short descriptive overview of the history of hospital funding in the Netherlands, the reasons for switching to the DTC model and the main elements of this model. To understand its specific structure better, we will compare the DTC model to the model of hospital funding by means of diagnosis related groups (DRGs) which is currently used in the United States, Germany and Australia (second purpose). The third purpose is to systematically compare the incentives and problems of the DTC model and the DRG model.

\section{A short history of hospital funding in the Netherlands}

In the 1970s hospital care was funded by means of a fee-for-service arrangement consisting of two distinct regimes. In the first part hospitals charged insurers for surgical procedures, outpatient services, laboratory tests and a few other medical services. The tariffs of these services were regulated by the national tariff agency (Centraal Orgaan Ziekenhuistarieven) which was established in 1965 under the Hospital Tariffs Act (Wet Ziekenhuistarieven). However, per diem rates operated as the main unit of payment for sickness funds and private insurers (second regime). To calculate these rates, the revenues of the aforementioned services were subtracted from the approved hospital budget. The per diem rate was found by dividing the remaining part of the budget by the projected number of patient days. The government introduced several instruments to control hospital outlays. One of these instruments was hospital planning. The Hospital Planning Law of 1971 entitled the Minister of Health to fix the number of beds of each hospital as well as the size and composition of the medical staff. Hospitals needed a government license to expand their staff or extend their range of medical services. Another instrument for cost control was to regulate hospital expenditures by means of guidelines for hospital reimbursement. There were dozens of such guidelines regulating, for instance, the maximum amount spent per patient-day for nursing staff; the maximum number of occupied beds per nurse or the maximum number of administrators per 100 occupied beds (Maarse, 1996). The guidelines also created an 'iron wall' between personnel and non-personnel expenditures. 
Neither instrument was very effective for cost control. As an instrument for bed reduction, hospital planning largely failed (Roemer once wrote 'a built bed is a filled bed', taken from Van Doorslaer and Van Vliet, 1989). In practice, bed reductions were mainly brought about by requiring a bed reduction plan in order to approve a hospital construction plan: a hospital construction plan was approved by the Minister of Health only if it included a sizeable bed reduction. The regulation of hospital expenditures by reimbursement guidelines had several drawbacks. First, the guidelines created an open-ended funding model, because they did not control the volume of hospital services, but only set a maximum on expenditures given the volume of services. In fact, the guidelines had the perverse effect of giving each hospital an incentive to provide a high level of services in order to maximize its revenues. For instance, there was no incentive to discharge patients as soon as possible. Second, the hospital funding scheme lacked strong incentives for cost control and did not encourage hospitals to provide services more efficiently. A third problem was the labyrinth of guidelines which strongly restricted the autonomy of hospitals (Maarse, 1996).

In the 1980s, cost control rapidly developed as a top priority in Dutch health care policy-making, particularly after the first oil crisis in the early 1970s (Van het Loo et al., 1999). The percentage of health care in the GDP (Gross Domestic Product) grew from $6.9 \%$ in 1972 to $7.4 \%$ in 1980 (OECD Health Data, 2010). There was great concern that universal access to health care would be jeopardised, if health care costs were not controlled effectively. Not surprisingly, hospital care became an important target in the government's cost control programs.

In 1983 a radical change took place in hospital funding. More or less overnight, the open-ended funding model was replaced with a global budgeting model (Glaser, 1987). In this model each hospital received a prospective global budget to cover most of its expenses. To calculate a hospital budget, the year 1982 was taken as baseline year (historical budgeting). Every year, the budget was adjusted for some changes, including the projected growth in demand for hospital care and expenditure cuts. If a hospital managed to realize a budget surplus at the end of the year, it was allowed to retain that surplus. Conversely, when it incurred a deficit, it had to find ways to cover the deficit. In principle, budget adjustments to relieve financial problems were no longer allowed. A fundamental assumption of the new funding model was that the budget ceiling would enforce hospitals to control their costs effectively and encourage them to achieve greater efficiency.

As noted, the hospital budget did not cover all costs. Interest and depreciation costs largely remained subject to full (retrospective) reimbursement. More important, however, hospital budgets included the fees only of salary-paid specialists (about 
$30 \%$ of all specialists), but not the fees of the self-employed ('free') specialists who were paid a fee-for-service (about $70 \%$ of specialists). This remarkable arrangement was a clear political compromise. The National Association of Medical Specialists (Landelijke Specialisten Vereniging) opposed the introduction of fixed budgets, but eventually accepted it under the condition that the fee-for-service payment scheme remained in place. In the association's view, the new funding model would restrict the professional autonomy of its members. Furthermore, it would certainly reduce their income and undermine their status as 'free entrepreneurs' in the hospital. However, the compromise had a serious disadvantage. Whereas hospital management had an interest in avoiding cost overruns by reducing its activity volume, medical specialists had the opposite interest. The incentives of hospital management and medical specialists were no longer aligned as they had been under the previous funding model.

The model of historical budgeting was practical and relatively easy to implement, but it was also crude. The choice of 1982 as baseline year implied that hospital spending in 1982 was arbitrarily taken as the spending norm. It favoured hospitals with a relatively high spending level in 1982 over hospitals which happened to have a relatively lower spending level in that year. Its fundamental deficiency, however, was that it lacked objective and transparent norms for setting a hospital budget. A related problem was the absence of norms for adjusting a hospital budget for an approved extension of its medical services.

A major change took place in 1988 with the development of what was termed a functional funding or budget model. The essence of the new model was to relate a hospital budget to its functions. Hospitals should be paid an equal budget for performing equal tasks. The model distinguished three budget components: an availability component, a capacity component and a production component. The availability component was measured as the size of the clinical catchment area of the hospital, and the capacity component as the number of authorized specialist units and then number of beds. The production component required annual negotiations between hospital management and health insurers about the volume of care. Production or volume contracts had to be made regarding the number of hospital admissions, inpatient days, first outpatient visits and day care visits. Additional contracts were required for some high-cost treatments. In 1992, the availability component accounted for $15 \%$ of the aggregate budget for hospital care, the capacity component for $34 \%$ and the production component for $51 \%$. The hospital budget was calculated by multiplying the parameter value (for instance number of beds or the number of inpatient days agreed upon in the volume contract) with the corresponding tariff set by the national tariff agency. The tariff varied per hospital size (the bigger the hospital, the higher the monetary value). The availability and capacity component were assumed to cover the fixed part of hospital expenditures and 
the production component the variable part (Maarse, 1996). As had also been the case for the historical budgeting model, the functional budgeting model did not include all hospital expenditures. Several expenditures continued to be reimbursed on a retrospective base.

The functional model signalled a radical change in comparison with its predecessor, because the hospital budget was no longer based upon history but on objective spending guidelines. After its introduction in 1988 the model underwent various technical changes. For instance, to make the budget more production-bound and to better adapt it to the changing demands for hospital care, the fraction of the production component gradually increased to about $60 \%$ of the budget. Furthermore, the scope of the model was extended by developing spending guidelines for expenses which after the introduction of the functional budgeting model were still reimbursed on a retrospective base (for instance the costs of small hospital reconstructions). However, the costs of rent and depreciation of major (re)construction works never became part of the hospital's prospective budget.

The functional budgeting model did not include changes in the payment regime of self-employed medical specialists. They continued to be paid on a fee-for-service base. As a consequence, the model did not resolve the fundamental problem that the incentives of hospital management and self-employed medical specialists were opposed. And there was another problem as well. Various efforts of the government in the 1980s and early 1990s to curb the growth of the specialists' compensation had not seen much success, even though they rested upon a negotiated agreement between the government and the national association of specialists (Lieverdink and Maarse, 1995; Lieverdink, 1999). An interesting development took place in 1995, when, after lengthy negotiations with the specialists' association, the government introduced a lump-sum payment scheme for the self-employed medical specialists. Each hospital received a history-based lump sum. The new arrangement guaranteed each specialist his (or her) historical income. However, the lump sum arrangement had a major drawback - if a specialist had reached his (or her) limit, (s)he had no financial interest in rendering care to patients during the rest of the year resulting in waiting lists. To combat this problem, from 2001 onwards a small production incentive was introduced. The production parameters of the hospital were also used to calculate the yearly increase of the lump sum (Janssen et al.,2003).

At the turn of the century, it became increasingly clear that the functional budgeting model had many problems. A major problem was that the total sum of hospital expenditures in a given year frequently exceeded the total budget for hospital care set by the Minister of Health. These cost overruns had to be offset by tariff adjustments in a subsequent year. Apart from the macro adjustments, individual cost 
overruns by hospitals were also offset by budget cuts. On a more fundamental level, the model of functional budgeting had outlived itself. Hospital expenses had not kept pace with the growing demands for health care. The tariff of the parameters of the functional budgeting model did not bear any relation to the real costs of hospital services. Furthermore, the model lacked powerful incentives for improving efficiency: good performance was not rewarded enough and poor performance not punished enough. It could even be counterproductive to invest in innovative care (SEO, 2006). Other deficiencies were that differences in case-mix had not been taken into account adequately and that the quality of hospital care did not play any role in the budgeting process. There was a complete lack of transparency. Finally, policymakers realized that the introduction of market competition into hospital care required another model of hospital funding. It was time for a new funding model.

\section{Hospital funding by means of DTCs}

In 1994 the national associations of hospitals, university hospitals, medical specialists, health insurers and the Ministry of Health started a common project for a fundamental revision of hospital funding, based upon the principle of case-mix based funding. The project, which reflects the Dutch style of shared decision-making or concerted action, eventually led to the introduction of a unique new model, based upon Diagnosis Treatment Combinations (Diagnose Behandeling Combinaties or DBC's). In 2005 the DTC model was introduced in general hospitals, specialty hospitals, university hospitals and independent treatment centers.

The idea of a case-mix based hospital funding model was not new. The first model based upon Diagnosis Related Groups (DRGs) was introduced in US health care in the 1970s. In 1985 Nederstigt had already developed a similar model for the Netherlands. He used Dutch hospital data and interviews with model specialists to create DRG profiles. His aim was to create more transparency for better hospital comparison, planning, medical audits and budgeting (Nederstigt, 1985). However, the aforementioned five parties decided not to choose the DRG-model, but to develop an alternative model. An important argument for this decision was that the DRGmodel did not include treatment of patients in an outpatient setting. Another problem was the absence of the specialists' fees in the DRG-model (Klompenhouwer and Vos-Deckers, 2005).

The new hospital funding model has to support the introduction of market competition in hospital care. Market competition requires clear 'products' to enable health insurers and hospitals to negotiate on price, volume and quality of care. DTCs must also improve the possibilities for comparing the performance of hospitals and introduce a clear link between revenues and performance. Furthermore, a case-mix 
based funding model is expected to be a powerful incentive for increasing efficiency and stimulating innovation (NZa, 2006).

A DTC is defined as the whole of activities and services of hospital and medical specialists stemming from the demand for care for which the patient consults the specialist. It covers the complete process of care: from the first consultation of the medical specialist until the completion of the treatment. At the moment there are approximately 29,000 DTCs. Each DTC consists of two parts: the first part encompasses the component of the hospital and the second part the fee of the medical specialists. The price of DTCs is set either by the Dutch Healthcare Authority (NZa) and in these cases is uniform across the country, or it is the result of bilateral negotiations between each hospital and insurer. Medical specialists' fees are regulated by the national tariff agency to avoid specialists abusing their market power to negotiate higher fees following guidelines from the Minister of Health. The fee is based on a norm time for each specific DTC, multiplied by a fixed fee per hour. At the moment of introduction the hourly fee was 140 Euros (DBC Onderhoud, 2006a).

\section{Coding}

Every DTC has a unique performance code that includes all information. The performance code consists of 14 digits and contains information about the type of care, the demand for care, the diagnosis and type of treatment. The performance code has the following structure:

Table 1: Performance code 01110005540031

\begin{tabular}{|c|c|c|}
\hline performance code & explanation & translation \\
\hline $01-\ldots-\ldots \ldots-\ldots$ & specialty & ophthalmology \\
\hline$\ldots-11-\ldots . \ldots-\ldots$ & type of care & regular care \\
\hline$\ldots-. .00-\ldots . . .$. & demand for care & no defined demand for care \\
\hline$\ldots-. . .-0554-\ldots$. & diagnosis & cataract \\
\hline$\ldots-\ldots-\ldots . .-0031$ & treatment & treatment outpatient department \\
\hline
\end{tabular}

The medical specialist decides on the choice of the DTC to be assigned to a patient upon first contact. The choice for a DTC is made by using a set of guidelines on how to open, close and determine the type of DTC. Every specialty has its own set of instructions, which are updated if necessary. In 2007 a new set of instructions was formulated to harmonize the guidelines of all specialties. There are general rules concerning the opening and closing a DTC (see below). The data that have to be registered per DTC are the following (DBC Onderhoud, 2006b):

- Opening date of the DTC.

- The specialty, the type of care, the demand for care (when relevant), the diagnosis and treatment that typifies the DTC.

- Closing date of the DTC. 
The first part of the DTC is the specialty code of the main specialist seeing the patient. The second part of a DTC is the type of care. A new, also called initial, DTC is opened when (a) a patient visits a medical specialist for the first time with a new demand for care, (b) when the patient consults a specialist from a different specialty, (c) when a patient is transferred to another provider organization or (d) when a new demand for care arises that will lead to substantially higher costs and effort. When a new demand for care arises it is possible to open a second DTC if the extra costs and/or effort of treatment are at least $40 \%$ of the initial DTC. If the extra costs and/or effort are less than $40 \%$ of the initial DTC, the opening of a new DTC is not allowed: the treatment must be continued within the initial DTC. A DTC is closed when either the whole treatment has come to an end or after 365 days. After an initial DTC, a chronic periodical check-up care DTC can be opened to monitor the patient after treatment. This type of care is the second part of the DTC.

The third part of the DTC code is the demand for care which has not been defined for all specialties, but contains the initial complaint(s) that motivated the patient to see a medical specialist. The fourth part is the diagnosis part of the DTC and obviously stands for the diagnosis made by the medical specialists and is an important element of the performance code. Finally the fifth and last part is the treatment code which reflects the procedures performed and the treatment setting of the care. The combination of diagnosis and related treatment is the distinct characteristic of the DTC system.

The choice of DTC is initially made by the medical specialist, who has to choose the most appropriate DTC. This choice can be adjusted during the process, if for example the treatment setting of a patient changes from outpatient treatment into clinical admission. In this case the initial DTC should be adjusted to the most serious treatment setting used. An often performed but not permitted strategy action is to close the initial DTC and open a new DTC. This strategy contradicts the intention of the DTC system and is for that reason forbidden by the instructions.

After the medical specialist has closed a DTC it must be validated in the hospital so that it can be sent to the health insurer for reimbursement. The validation process is performed by an internal control procedure in the hospital. In this procedure the treatment activities performed are matched with the assigned DTC to determine whether the right DTC has been assigned. If there is no match, validation will not be given. For example a DTC with a clinical episode requires a hospital admission in order to be validated. The IT-systems used to validate DTCs are not standardized and can differ substantially between hospitals. The hospital board is obliged to produce a yearly statement of the functioning of its internal control system with verification by an external accountant. 


\section{Maintenance of DTCS}

As noted before, all interested parties including the medical societies were closely involved in designing the DTC system. Under the current regulations the Dutch Healthcare Authority (Nederlandse Zorgautoriteit, NZa) checks whether the DTC system indeed serves public interests such as transparency, an efficiently functioning health care market and quality of care. The Health Insurance Board (College voor Zorgverzekeringen or (VZ) is in charge of deciding upon whether the DTC is in the benefit package of the basic health insurance scheme (CVZ, 2009). Furthermore, a new and independent organization, named DBC Onderhoud, was created in order to maintain the DTC system. This new organization is in charge of creating new DTCs and revising existing DTCs. Another task of this new organization is to inform the users of DTCs and answer their questions (NZa, 2006).

\section{The distinction between the A segment and B segment in hospital funding}

The new hospital funding model consists of two parallel regimes, corresponding with the so-called segment $A$ and segment $B$. In segment $A$ the tariffs of the DTC are regulated by the national tariff agency. As a consequence, price competition between hospitals is absent in this segment. Another distinct characteristic of segment A concerns the continuation of the budget model. Hospitals cannot spend beyond their budget ceiling. If they do, the extra spending has to be offset. Conversely, they can retain the surplus if they spend less than the budget ceiling allows them to do. DTCs in segment A are used only for administrative reasons.

The funding regime is different in segment $B$. In this segment, hospitals and insurers can negotiate the price of DTCs (on a bilateral basis). Officially, there is no budget ceiling but, as we will see below, the situation appears to be somewhat more complicated. The contract between insurers and hospitals may include agreements on the volume of medical care and how to proceed if the actual volume of medical care exceeds the volume agreed upon in the contract. Although hospitals and insurers are allowed to negotiate on all prices of all DTCs in segment B, they don't do so. In practice, they often select a number of 'target DTCs' for bilateral price negotiation. Other strategies for reducing transaction costs are to agree upon an average price or an average price increase. Market share and market structure are important elements for insurers in deciding which strategy to pursue.

A further difference between both segments concerns the regime of rent and depreciation costs. Whereas in segment $A$ these costs are still reimbursed on a retrospective basis, insurers and hospitals negotiate a normative mark-up upon the DTCprice to cover these costs in segment $B$. The implication of this regime is that hospitals incur a financial risk in segment $B$. There exists a transition regulation for seg- 
ment $B$ where hospitals can choose for full risk bearing over segment $B$ or a phased introduction per year. A similar risk does not yet exist in segment A (NZa, 2009).

The distinction between segment $A$ and segment $B$ has been used for a stepwise introduction of price competition in hospital care. In the period 2005- 2007 segment $B$ represented about $10 \%$ of hospital production (by value). It contained 1246 DTCs. Most of these DTCs were clear-cut and relatively simple routine procedures such as cataract, inguinal hernia, varicose veins, total hip and total knee replacement. Diabetes was also included in segment B. In 2008 segment B was extended to about $20 \%$ of hospital production (including 4921 DTCs) and in 2009 to about $34 \%$ (including 7028 DTCs).

So far, however, the actual size of segment B has always been significantly smaller than these percentages (see table 2). At this moment the ultimate size of segment $B$ is still uncertain. Hospitals call for a substantial extension. The maximum size is expected to be between 50-70\%. Recently (2011), the Minister indeed announced a further extension to about $70 \%$ in 2012.

Table 2: Actual size of B segment (in revenue)

\begin{tabular}{|ccc|}
\hline year & Official size & Real size \\
\hline 2005 & $10 \%$ & $4.1 \%$ \\
\hline 2006 & $10 \%$ & $6.0 \%$ \\
\hline 2007 & $10 \%$ & $5.9 \%$ \\
\hline 2008 & $20 \%$ & $13.3 \%$ \\
\hline 2009 & $34 \%$ & $19.9 \%$ \\
\hline
\end{tabular}

Source: Gupta Strategists (2010), "De donkere kamer van Damocles"

Increasing the size of segment B has always been a politically sensitive affair. It is the task and responsibility of the Minister of Health to decide. But since market competition in health care has remained controversial, the Minister has to maneuver carefully and demonstrate that free pricing works as intended (lower prices, no unwarranted volume effect) (Maarse, 2011). For this reason, the Dutch Healthcare Authority regularly publishes a monitoring report on the effects of free pricing.

Price liberalization in segment B has led to some variation in DTC-prices. Interviews with insurers and hospitals indicate that insurers with a large market share are able to negotiate lower prices than insurers with a relatively small market share. However, the opposite is also suggested; insurers can depend so much on a hospital in which they have a large market share that they have to accept higher prices. Which effect dominates is still unclear; analysis of the first period (2005/2006) shows that insurers with small market shares have to accept higher prices (NZa, 2007). 
The funding regime in segment B can be conceptualized as an open-ended regime. The revenues of each hospital are the product of volume and prices. What does this mean for the effectiveness of cost control? The advocates of market competition assume that competition will compel hospitals to operate more efficiently and that health insurers will act as a countervailing power on the market by negotiating favorable prices and volumes. They believe that more efficient delivery of hospital services will offset the increase of hospital expenditures due to a possible higher volume of services. Furthermore, the Minister of Health has the formal competence to impose expenditure cuts in case of cost overruns in segment A. One would expect a similar competence does not exist in segment $B$.

However, the 'real world' of hospital funding is more complicated. In 2008 and 2009 there were substantial cost overruns in hospital care. According to the Minister of Health, in 2008 hospitals spent 512 million Euros more than the total budget for hospital care, and in 2009 they overspent by 549 million Euros. Consequently, the Minister announced a generic budget cut affecting all hospitals (Ministerie VWS, 2010).

The Minister's reference to a total budget for hospital care is of course remarkable, given the open-ended structure of hospital funding in segment B. But even more remarkable is that in his calculation of the cost overrun, the Minister did not make a distinction between segment A and segment B. In the view of the National Hospital Association (Nederlandse Vereniging van Ziekenhuizen) this line of action violated the principle of open-ended funding in segment $B$. When the association and a few hospitals appealed the Minister's decision, it was negated by the court. The court reasoned that a generic budget cut to offset cost overruns in previous years contradicted the open-ended structure of hospital funding in segment B. In its view, one cannot opt for an open-ended model of hospital funding, but not accept its consequences for total hospital care expenditures! However, later in 2010 the Minister's line of action was approved in an appeal by the Minister, after which the hospitals are now appealing for cassation of this verdict. The conflict illustrates the hybrid structure of the current hospital funding model consisting of two separate segments each with its own regulations and incentives.

Similar problems are manifest in the payment of medical specialists. The introduction of the new payment model using an hourly tariff turned out to be significantly flawed because of technical failures in estimating the time needed for a medical treatment. Some specialists, including radiologists, pathologists and microbiologists, managed to realize a much higher personal income without working one minute longer. The technical failures have been recognized by the specialists, but the issue has not yet been settled. The problems in the payment of specialists are further evidence of substantial flaws in the new hospital funding systems. 
We conclude that the funding of hospital care has remained hybrid and confusing. The scope of free pricing (segment B) is still restricted. The dual structure of hospital funding (segment $A$ and segment $B$ ) creates administrative complexity because of the necessary clearance of segment $A$ every time segment $B$ is extended. The dual structure also implies two different regimes: the regulations and incentives in segment $A$ (no free pricing, collective bargaining on the budget and no incentive to produce extra because of the budget ceiling) are different from the regulations and incentives in segment $B$ (free pricing, bilateral bargaining, incentive to increase production). Offsetting cost overruns by tariff cuts hitting all hospitals appear a source of great trouble including appeal procedures in court.

The current hybrid situation means, according to the present Minister of Health, that 'we are stuck in the middle' (Ministerie VWS, 2011a). To overcome this problem, she decided to accelerate market competition by a significant further liberalization of hospital care, including an extension of segment B to about 70\% in 2012. Only hospital services for which free pricing is considered to be unfeasible or undesirable remain to be funded by means of a fixed budget (e.g. trauma care, some topclinical care, donor teams, helicopter services). In 2011 she signed an agreement with the representative associations of hospitals (including the association of the independent treatment centers) and health insurers on this strategy ((Ministerie VWS, 2011b). An important element of this agreement, apart from the extension of segment B to about $70 \%$, is that health insurers have accepted the obligation to do their very best to restrict the annual growth of the volume of hospital care to $2,5 \%$. If they are not successful, the Minister retains a macro instrument to offset overproduction. Another important agreement is to replace hospital funding by DTCs with hospital funding by DOTs (DTCs on their way to transparency). This transition is topic of discussion in the next two sections.

\section{Problems with the DTC-system}

Since its implementation in 2005 the DTC system has been considered to be too complex. The level of detail is so high that 100,000 different DTCs can be construed. However, if we look at the actual use of the DTCs, only 30,000 of them are used in practice. Furthermore, only 3,000 DTCs account for $90 \%$ of all costs (own research). Despite the high number of DTCs the system still does not meet the criterion of 'medical recognizability'. In order to avoid skyrocketing transaction costs, DTCs are clustered in so-called product groups that consist of up to 100 DTCs, which all belong to the same specialty and are cost homogeneous. However, these groups are not medically homogeneous, making them unfit for use in negotiations between provider and insurer. 
Another problem is that the coding schemes of the DTC system are not harmonized across specialties. The coding is not based on an internationally recognized classification system, but on 24 different systems of diagnosis classification, developed by different specialist medical communities. This results in 24 product structures that cannot be compared amongst each other. In practice this means that a medical procedure that can be performed by different specialties can have a completely different DTC in coding as well as costs for each specialty. This leads not only to lack of clarity and uncertainty for medical specialists and hospitals on how to code DTCs, but also makes it difficult for health insurers to perform their control task and to predict costs. Finally, not using an internationally recognized classification system makes international comparisons on health data very difficult (DBC Onderhoud, 2010).

A third major problem concerns the rules for opening a second DTC. As mentioned earlier, a new DTC is opened when a new demand for care arises. However, in the case of an already existing DTC for the same specialty an additional second rule applies: the costs of the second DTC need to be at least $40 \%$ more than the costs of the first DTC and/or the treatment must lead to a $40 \%$ increase in the workload of the medical specialist. This second rule has been the subject of heavy disputes between hospitals and medical specialists on the one side and health insurers on the other side. The dispute was based on the 'and/or' and even at this time no official decision has been made by a government body on whether or not it is correct to declare a second DTC (also termed parallel DTC) without $40 \%$ more costs. This situation is a source of confusion and uncertainty for both providers and insurers.

A final problem is that the validation process of the DTC system - the module in the hospital that states whether a DTC fit for declaration- is neither uniform nationally nor very strict. Validation can be manipulated manually. The motivation for careful and complete registration is therefore not very high and there is ample room for risks like upcoding or under -registration.

\section{From DTCs to DOTs}

The specificity of the DTC-system has many benefits. Detailed products give a high level of transparency on diagnoses, processes and costs, providing feedback to hospitals to redesign their processes and develop efficiency and quality interventions. Strong involvement of the medical profession in the design of the system increased insight into the effects of medical decisions on the system's costs. Information on the whole episode of care provides an incentive to increase efficiency by substituting day- and outpatient care for inpatient care. However, fundamental changes are needed to fix the problems mentioned previously. These changes are to be implemented in a revision of the DTC system that will be introduced in the coming years 
(DCB Onderhoud, 2010). Exactly when is still unclear because of political decision making. The new system is called DOT: DTCs On their way to Transparency.

The goals of DOT are to achieve the original goals of the DTC system, namely increased transparency, medical recognizability, stability and openness to innovation, but also to reduce the complexity of the current DTC system. The renewal is based on three important pillars. The first pillar is that in the new system, the care products will be deducted from registered activities by a web-based grouper ${ }^{2}$ instead of being selected by the medical specialist and then validated. This change is intended to solve the problems of the first-generation validation modules and to lighten the administrative burden of medical specialists and hospitals.

The second pillar is reducing the number of DTCs to approximately 3,000 DTC care products. These new care products will contain medically recognizable products that can support negotiations between care providers and health insurers. The instructions will be uniform for all specialties. The patient's case-mix will be measured, as is common in the DRG system to ensure fair compensation for every patient.

The last pillar is that the classification of the DTC care products will be based on the uniform ICD10 coding system, making international exchange of data possible. Apart from exchangeability the new coding system also reduces complexity, because all 24 different specialties will now use the same coding system. Multiple specialties that can treat the same diagnosis will be combined into the same DTC care products and multidisciplinary diseases can be captured in a single DTC care product as well. And, even though there will be many changes, the second generation DTC system will keep combining diagnosis and treatment as its unique feature.

\section{Diagnosis-related groups}

The development of systems of case-mix based hospital funding models has its origins in the 70s in the USA. DRGs were intended as a prospective payment system. The aim was to be able to better calculate health care costs by grouping cases into various categories with the same costs. Diagnosis Related Groups (DRGs) have been used in the US by Medicare and Medicaid since 1983. All cases within a DRG should incur the same medical costs, so that the fixed charge for the DRG reflects the average costs of the cases within the DRG. DRGs include only the costs of inpatient care. DRGs have been introduced as a system for hospital reimbursement in many countries worldwide. Two countries which implemented an adjusted form of DRGs are Germany and Australia (Hensen et al., 2005; Duckett, 2000).

\footnotetext{
${ }^{2}$ A grouper is an algorithm that combines all activities and information on a patient into a billable care product. (DBC Onderhoud, 2010).
} 
DRGs are formed by classifying database-stored cases into homogenous groups according to medical costs. In order to avoid grouping distinct categories of patients into a single DRG, an initial partitioning is made into surgical and medical treatments. The crucial criterion is whether a surgical procedure is performed or not. Within the distinction surgical/medical there are 25 different major diagnostic categories (MDCs), arranged mainly according to organ systems. To approach incurred costs, a grouper or computerized algorithm assigns a case to a specific DRG, based mainly on recorded nursing days. This focus on costs (and not mainly on procedures) is the factor that allows DRGs to categorize all cases and greatly reduces the number of DRGs (CMS, 2006).

When a specialist has the first face-to-face contact with the patient the diagnosis and the related treatments are decided upon. Afterwards a medical coder, employed by the hospital, checks if the DRG assigned by the grouper is correct, on the basis of the medical records (Steinbusch et al., 2006). Only one DRG can be attributed per patient, even when the patient needs extra care due to complications or a new diagnosis. Co-morbidity and possible complications are taken into account when attributing a DRG to a patient. This forms a control system for the severity of the patient's needs and adjusting reimbursement to the patient's condition.

\section{United States}

In 1983 the US started using a case-mix system for hospital reimbursement as an antidote to the fee-for-service system of hospital reimbursement which had been used since 1965 . The main reasons for introducing the (inpatient) prospective payment system were to better control costs and improve effectiveness. Health care provided to patients insured with Medicare and Medicaid was reimbursed based on DRGs. Since the introduction of the HCFA-DRG (Health Care Financing Administration DRG) other private companies have developed their own set of DRGs, as for example the AP-DRG (All-Patient DRG), in order to address the rather narrow ageand consequently disease-spectrum of Medicare's mainly elderly population (Busse et al., 2006).

Before 1983 hospitals set prices for their services to cover whatever costs they incurred plus a mark-up to expand their capacity. Insurers paid these prices and year after year prices rose and hospital services expanded. This approach to payment was known as 'cost reimbursement' (Coffey, 1999). To ease the transition to the new system, payments were initially a blend of the new national rates and the old hospital-specific costs per average case. In 1987 the new nationally fixed rates took full effect. The prices of the different DRGs are determined by the use of relative pricing. This means that the nationally set DRG prices are expressed in a nationally 
determined relative cost-weight and a base-rate. The base-rate is corrected for regional differences (CMS, 2006).

Revisions of the DRG definitions are made continuously by ProPAC (the Prospective Payment Assessment Commission) and CMS (the Center for Medicare and Medicaid Services/ previously HCFA). In 2007 Medicare Severity DRGs (MS-DRGs) were introduced with new adjustments for the case-mix index (Mitchell, 2007). The latest version of the MS-DRG (version 27) contains 999 DRGs (Tricare, 2010). Through public meetings, health care providers are given an opportunity to influence the classification to avoid unintended effects on patient care. The federal government has charged independent organizations with guaranteeing and checking the quality of care. These peer-reviewed organizations (PROs) have a two-year contract with the HCFA and control all Medicare hospitals utilizing the treatment standards developed by the HCFA. PROs fulfill several tasks: monitoring the use of resources, testing the quality of care and controlling the process of declaration. This is done through visitations and mapping the coding behavior of hospitals. Errors may have various financial consequences. To control the behavior of the PROs, CMS has put a Super-PROinto place (Carter et al., 1990).

\section{Australia}

Australia introduced the DRG classification system in 1992, originally as a modification of the US system. Since 1998 it has its own locally developed system. Before the introduction of the DRG system, hospital care was funded based on input, and subject to fixed budgets. In the mid 80 s waiting lists and costs grew, and the first steps towards reform using a DRG type system were made. The main goals were to reduce waiting lists, reduce hospital expenditures, improve the efficiency of public hospitals and to provide an expansion in the number of patients treated (Department of Health and Aging, 2006).

In 1992 the US version of the DRG was introduced in Australia. However, it was soon seen as inadequate due to differences between US and Australian clinical practice. In addition, the HCFA-DRG had been developed for the population eligible for Medicare, which made it unsuitable for all-patient use. The first Australian DRG classification system (Australian National DRGs, AN-DRGs) was developed in 1998 in close consultation with Australian clinicians; it was based on the use of ICD-9-CM to code diagnoses and procedures. A commitment was made during development to update the system regularly to recognize the changes in clinical practice. Since then the system has been revised over time and has now evolved into the Australian Refined DRG (AR-DRG), which currently contains 665 DRGs. The Australian Refined DRG, as the name already suggests, can more specifically express the diagnosis and patientrelated variables. The AR-DRG takes into account the cumulative effect of a pa- 
tient's complications and complexity, whereas HCFA-DRG considers only the presence of a complication and does not categorize them. In the Australian system, clinicians are extensively involved in the classification process to ensure that the system is clinically meaningful. The funding model of the AR-DRG consists of two parts: the relative weight of the DRGs and a base rate. Both are set at the state level (Duckett, 2000).

Several instruments have been developed to monitor the coding behavior of Australian hospitals, such as the Australian Coding Benchmark Audits, Performance Indicators for Coding Quality and health audits performed by the Health Departments of state governments (Steinbusch et al., 2006).

\section{Germany}

In 2004 DRGs were introduced in Germany, based on the Australian AR-DRG. Prior to 2004, a prospective payment system, replacing a full cost-reimbursement system, had been introduced to reimburse hospitals. In the German prospective payment system, hospitals were reimbursed by a mix of per-diem rates, per-case rates and special reimbursements for expensive procedures (Busse and Riesberg, 2004). The main goal behind the introduction of DRGs was to curb cost increases in the German health care system. A second goal of the DRG system was to improve the quality of health care services, because DRGs require documentation and coding which leads to increased transparency and allows for external comparison of services rendered (Böcking et al., 2005).

Based on documentation from pilot hospitals, the AR-DRGs were recalculated by the Institute for the Payment System in Hospitals. This recalculation led to the development and introduction of the G-DRG in 2005. In addition to the diagnosis and its clinical severity, co-morbidity and age of the patient, the G-DRG attaches special importance to the medical procedures performed. By 2007, this increased the number of G-DRGs to 1082 (G-DRG, 2006).

Since 2004 all hospitals have been required to document their activities in terms DRGs, although they are still financed based on negotiated budgets. The reimbursements units of these budgets are DRGs, for which the relative weights are determined nationally. For each hospital a hospital-specific case-mix index is calculated by dividing the sum of the relative weights by the number of cases treated. This index varied substantially between hospitals in 2005 and will be gradually equalized to state-wide base rates towards 2009 (Schreyögg et al., 2006). The German DRG Institute is responsible for maintaining the system, i.e. adjusting DRG codes, providing guidelines for declaring DRGs, determining the relative weights and budget deficits or overruns (G-DRG, 2006). 


\section{DTCs and DRGs compared}

There are substantial differences between the DTC and the DRG systems. They vary in starting point and intention, in build-up and structure, and in financial incentive. In this section we will outline the main differences between the two case-mix systems.

\section{Starting point and intentions}

The main reason for introducing the DRG system in the US, Australia and Germany was to curb the rise of health care expenditures. In the Netherlands, however, the DTC system was primarily introduced as a tool to introduce market competition, instead of merely being a tool for cost control. The prices of DTCs are free in segment B of hospital care. However, free-pricing is expected to make hospital care more efficient, which may help to reign in the growth of health care expenditures.

The starting point of the new hospital reimbursement schemes varies substantially across the four countries. The Netherlands and Australia introduced the new hospital funding model as an alternative to the fixed budget model. In the US, however, the DRG model was intended as an antidote to the existing cost-reimbursement system. In Germany the DRG model had to replace a mixed system which combined elements of a prospective payment system with cost-reimbursement.

The DTC differs not only in name from the DRG but also reflects a completely different approach. In the DRG system a patient is assigned a DRG ex post mainly based on costs, whereas the DTC system looks at the complete process of health delivery stemming from the demand for care.

\section{Structures and procedures}

There are some differences in the structure of the DTC and DRG systems. A first important difference concerns the build-up of the DTC. The key characteristic of a DTC is the combination of diagnosis and treatment. As a result, the DTC system is highly complicated and much more detailed than the DRG system. There are around 100,000 different performance codes from which a DTC can be selected, versus around 600 to 1000 DRGs, depending on the version.

The large amount of DTCs relative to DRGs is due not only to the inclusion of the treatment component. The DRG system takes only inpatient clinical care into account, whereas the DTC system includes both inpatient clinical and outpatient clinical care. This was done consciously, in recognition of the rapidly increasing impor- 
tance of outpatient care. Furthermore, there are now integrated care DTCs, including primary health care. Diabetes is an example of such a DTC.

The role of the medical specialist also differs in both systems. Whereas a DTC is coded prospectively by the medical specialist during the first face-to-face contact with the patient, a DRG is registered retrospectively by a medical code clerk on the basis of incurred costs and the procedures performed.

Another difference relates to the payment of the medical specialists. The tariff of each DTC includes the payment to the medical specialist, irrespective of whether (s)he is a salary-paid physician or a self-employed physician. The purpose of this arrangement is to ensure that the financial incentives of hospitals and medical specialists are aligned. In the DRG-system the tariff does not cover the fee to the physician. There are two distinct arrangements, one for paying the hospital and the other one for paying the physician.

The DTC system offers the opportunity to open more than one DTC at the same time for the same patient. The rules on when to open and close a so-called parallel DTC are described in the instructions per specialty. Earlier, we saw that these instructions are somewhat ambiguous and leave room for differences in interpretation. Officially, a second DTC can be opened only if the extra costs are at least $40 \%$ higher than the costs of the initial DTC and/or the treatment leads to a $40 \%$ increase in the workload of the medical specialist. Not surprisingly, there has been much uncertainty on when it is permitted to open a second DTC. A frequently mentioned example is the case of an ophthalmologist who opens a DTC for both the left eye and another one for the right eye during a regular exam. This problem does not exist in the DRG-system since it is only possible to attribute one DRG per patient. Of course it is possible that during the care episode the patient needs extra care due to complications or co-morbidity. These circumstances are taken into account retrospectively when attributing a DRG to a patient.

A final difference between the two case-mix systems concerns the level of centralization. In the US, the HCFA is in charge of all DRG pricing and indexation leading to a high degree of centralization. In Australia, DRG pricing is somewhat less centralized, since prices are set at the state level. In Germany the relative weight of each DRG (the point value) is set nationally, whereas the base rate of the DRG (the monetary value) is set at the state level. Whichever model applies, the key element is that prices are regulated and that price competition does not exist. This is different in the Netherlands, where price regulation exists only in segment A of hospital care but not in segment $B$. 


\section{Financial incentives}

A case-mix system to reimburse hospitals has its own set of financial incentives. First, in the absence of a budget restraint, it is profitable to maximize the number of patients treated (assuming that the costs of treatment are less than the tariff of the DTC/DRG). Second, there is an incentive to choose the most lucrative DTC or DRG even though this is not medically necessary. This phenomenon is referred to as upcoding (Simborg, 1981). Other incentives are to select profitable patients (cream skimming) and to skimp on the quality of care to reduce costs (Lehtonen, 2007; Glaser, 1987; McGuire, 2000).

Even though both are case-mix systems, the DTC and DRG system differ in the incentives given to hospitals and/or medical specialists. There are two main causes for these differences in financial incentives: the specificity of the system and the possibility to declare more than one DTC per patient.

The first difference between the two systems, the level of specificity, leads to a higher risk of the incentive to upcode and to a lower risk of patient dumping and skimping. In general a case-mix system with broad diagnosis groups minimizes the scope for data manipulation, whereas a detailed case-mix system induces overtreatment of patients or upcoding (Busse et al., 2006). Given that the DTC system is much more detailed than the DRG system, the risk of upcoding - defined as a deliberate and systematic shift in a hospital's reported case-mix in order to improve reimbursement - is theoretically higher in the DTC-system. Upcoding (also termed DRG-creep) in the DRG system can take place only by upcoding the diagnostic category or the complication level. For the DTC system it is possible to upcode along the diagnosis axis or to upcode along the treatment axis. The Australian and German versions of the DRG-system include more possibilities for complication levels and thereby have a higher risk for upcoding. Research by Steinbusch et al. (2006) states that upcoding depends on the characteristics of the case-mix system used. Some case-mix systems are more prone to upcoding than others, depending on certain factors such as market, control and case-mix characteristics. They claim that fewer opportunities for upcoding occur in the DTC system, since its classification is medically meaningful, there is no for-profit ownership (yet) in the Dutch hospital market, there is no possibility to make use of secondary diagnoses in the DTC system, as the classification is made at the point of registration/initial contact and not afterwards. However, there are also characteristics that increase the risk for upcoding in the DTC system, such as the fact that the coder's (the medical specialist's) income depends on the DTC chosen ${ }^{3}$. Overall we find the risk of upcoding to be higher in the DTC system, in comparison with the DRG system.

\footnotetext{
${ }^{3}$ In the DRG system the coder is an administrative clerk instead of the medical specialist.
} 
The risk for patient dumping is lower in more detailed case-mix systems, since the patients within a group are more homogenous, making the chance of unprofitable patients smaller. Therefore the risk for patient dumping is lower in the DTC system, in comparison with the broader DRG system (Ellis, 1998; Lakerveld, 2001).

The risk of skimping can be reduced by negotiating the exact content of a care product. These negotiations make sense only if they are done for a product group that contains homogenous care. In the DTC system, negotiations on care content per DTC are possible in segment B, which theoretically reduces the risk of skimping ${ }^{4}$. In the DRG system, the exact content of a DRG can differ significantly between patients, which increases the risk of skimping (Siciliani and Hafsteinsdóttir, 2008; Busse et al., 2006).

The second difference is the incentive to increase the number of DTCs per patient. This risk is unique to the DTC system, since it is not possible to assign more than one DRG per patient. There are two different ways to maximize the number of DTCs per patient: the first option is that multiple DTCs are open at the same time, which is referred to as parallel DTCs. The second option is that DTCs are opened and closed shortly after each other, which is referred to as serial DTCs. According to the instructions, it is possible in some cases to declare multiple DTCs per patient, for example, for chronic care or if continued monitoring is necessary. However, unjustly declaring multiple DTCs per patient is potentially one of the largest problems of the DTC system in its current form. The DTC system is then used as a type of fee-forservice system, which obviously has never been the intention of the new system. During the introduction phase of the DTC system, the average number of DTCs per patient has been very high, which could be an indication of unjust use of the DTC system which we call overdeclaration. Until now the financial consequences of this were limited because the bulk of overdeclaration took place in segment $A$, as this contained both the majority and the more complex part of hospital care, where a budget ceiling applies (NZa, 2006). The incentive for overdeclaration does not exist in the DRG system since it is only possible to declare one DRG per clinical episode (CMS, 2006).

\footnotetext{
${ }^{4}$ In practice there are so many DTCs that transaction costs are too high to negotiate on the content of care for every DTC.
} 


\section{Conclusion}

This article shows that the DTC and the DRG systems are very different. The differences can be divided into three main categories: differences in starting point and intentions, differences in structure and procedures and differences in financial incentives. An important distinction between the two systems is the wider scope of the DTC system; the treatment axis and outpatient clinical care are included in the DTC, which increases the potential for upcoding. Another difference is that the DTC includes the fee of and is coded prospectively by the medical specialist instead of retrospectively by a hospital administrator. Another disparity is that DTCs were not introduced mainly to control costs but as a tool to support market competition in the Dutch hospital market, with partly liberalized prices. The last contrast is the possibility of using more than one DTC per patient in the DTC system and the corresponding incentive to maximize the number of DTCs per patient. Even though there are many differences, there have also been calls in the Netherlands for convergence towards a DRG- type system, in order to simplify the highly detailed DTC system. 


\section{References}

Böcking, W., Ahrens, W., Kirch, W. and Milakovich, M. (2005). "First results of the introduction of DRGs in Germany and overview of experience from other DRG countries." Journal of Public Health 13(3): 128137.

Busse, R. and Riesberg, A. (2004). "Health care systems in transition: Germany." Copenhagen, Denmark: WHO Regional Office for Europe on behalf of the European Observatory of the Health Care Systems and Policies.

Busse, R., Schreyögg, J. and Smith P.C. (2006). "Hospital case payment systems in Europe." Health Care Manag Sci 9(3): 211-213.

Carter, G. M., Newhouse, J.P. and Relles, D.A. (1990). "How much change in the Case Mix Index is DRG creep?" J Health Econ 9(4): 411-428.

CMS (2006). Acute Inpatient PPS- Overview, Centers for Medicare and Medicaid Services.

Coffey, R. M. (1999). "Casemix information in the united states: Fifteen years of management and clinical experience." Casemix Quarterly 1(1): 7-16.

College voor zorgverzekeringen, CVZ (2009) Corporate Brochure 2010 "Van zorg verzekerd Informatie over het College voor zorgverzekering".

DBC Onderhoud (2006a), Vragen over DBC's, http://www.dbconderhoud.nl/client/1/?websiteid=$1 \&$ contentid=163\&hoofdid=103\&pagetitle=Wat_is_een_DBC?. Accessed 11 January 2008.

DBC Onderhoud (2006b). Instructies per specialisme. http://www.dbconderhoud.nl/Rechts/Documenten/DBCs-ziekenhuizen-en-zelfstandige-klinieken/Meest-recente-documenten/Instructiesper-specialisme accessed October 102006.

DBC Onderhoud (2010), DOT in Grote Lijnen, www.DBConderhoud.nl/Ontwikkelen-van-de-DBCsystematiek/Cure/DOT-implementatie/DOT-in-grote-lijnen/Grouper, Accessed on January 12th 2011.

Department of Health and Aging (2006). Casemix Glossary. Casemix Data Collections, Australian Government.

Duckett, S. (2000). "The development of Australian refined diagnosis related groups: the Australian inpatient casemix classification." Casemix 2(4): 115-120.

Ellis, R. P. (1998). "Creaming, skimping and dumping: provider competition on the intensive and extensive margins." J Health Econ 17(5): 537-555.

G-DRG (2006). Weiterentwicklung des G-DRG Systems für das Jahr 2007, Klassifikation, Katalog und Bewertungsrelationen, G-DRG Spitzenverbände der Krankenkassen.

Glaser, W. A. (1987). Paying the hospital: the organization, dynamics, and effects of differing financial arrangements, Jossey-Bass San Francisco.

Hensen, P., Fürstenberg, T., Luger, T.A., Steinhoff, M. and Roeder, N. (2005). "Case mix measures and diagnosis related groups: opportunities and threats for inpatient dermatology." Journal of the European Academy of Dermatology and Venereology 19(5): 582-588.

Janssen, R.T.J.M., Leers, T., Meijdam, LC. and Verbon, H.A.A. (2003) "Bureaucracy versus Markets in Hospital Care, the Dutch case." Public Choice 114: 477-489

Klompenhouwer, J. and Vos-Deckers, G. (2005). De DBC-methodiek. Haarlemmerolie of een werkzaam geneesmiddel voor de Gezondheidszorg? iBMG. Rotterdam, Erasmus University. Master's thesis.

Lakerveld, A. (2001). Financiële Prikkels in het DBC-systeem: upcoding en afwenteling. Maastricht, University of Maastricht. Master's thesis.

Lehtonen, T. (2007). "DRG-based prospective pricing and case-mix accounting--Exploring the mechanisms of successful implementation." Management Accounting Research 18(3): 367-395.

Lieverdink, H. and Maarse, H. (1995). "Negotiating fees for medical specialists in the Netherlands." Health Policy 31(2): 81-101.

Lieverdink, H. J. (1999). "Collectieve besluiten, belangen en wetgeving: de totstandkoming van tarieven voor medisch specialisten in Nederland tussen 1986 en 1992." Maastricht: Maastricht University. Dissertation 
Maarse, H. (1996). "Fixed budgets in the inpatient sector: the case of the Netherlands." Fixing Health Budgets: Experience from Europe and North America. Chichester: John Wiley.

Maarse, H. (2011). Markthervorming in de zorg. Maastricht, the Netherlands: Maastricht University.

Maarse, H. and Bartholomée, Y. (2007). "A public-private analysis of the new Dutch health insurance system." The European Journal of Health Economics 8(1): 77-82.

McGuire, T. G. (2000). "Physician agency." Handbook of health economics 1: 461-536. Elsevier.

Ministerie van Volksgezondheid, Welzijn en Sport (2010), "Waardering voor Betere Zorg IV", Kamerstuk CZ/TSZ 2973145

Ministerie van Volksgezondheid, Welzijn en Sport (2011a), Betreft Zorg die werkt: de beleidsdoelstellingen van de minister van Volksgezondheid, Welzijn en Sport , Kamerstuk MC-U-3048431

Ministerie van Volksgezondheid, Welzijn en Sport (2011b), Hoofdlijnen Kostenontwikkelingen Ziekenhuiszorg, convenant

Mitchell, K. (2007). "Understanding the financial impact of MS-DRGs." Healthcare financial management: Journal of the Healthcare Financial Management Association 61(11): 56.

Nederlandse Zorgautoriteit (Nza) (2006), Declaraties Beter Controleerbaar.

Nederlandse Zorgautoriteit (Nza) (2007), Ziekenhuiszorg 2007: Analyse van de marktontwikkelingen in het segment in 2007.

Nederlandse Zorgautoriteit (Nza) (2009), Overgangsregeling Kapitaallasten.

Nederstigt, P. F. P. M. (1985). Diagnosis related groups: een patiënt-georiënteerd kosteninformatiesysteem, Nationaal Ziekenhuisinstituut.

OECD Health Data (2010). Accessed on 15th of March 2011 through http://stats.oecd.org/index.aspx

Schreyögg, J., O. Tiemann, et al. (2006). "Cost accounting to determine prices: How well do prices reflect costs in the German DRG-system?" Health Care Manag Sci 9(3): 269-279.

Siciliani, L. and Hafsteinsdóttir, E.J.G. (2008). "DRG prospective payment system: refine or not refine?" Discussion Papers. 08/29 Department of Economics. York: University of York.

Simborg, D. W. (1981). "DRG creep." New England Journal of Medicine 304(26): 1602-1604.

Sociaal Economisch Onderzoek, SEO (2006). Kosten en baten van zorgvernieuwing. Amsterdam.

Steinbusch, P. J. M., Oostenbrink, J.B., Zuurbier, J.J. and Schaepkens, J.M. (2007). "The risk of upcoding in casemix systems: A comparative study." Health Policy 81(2-3): 289-299.

Tricare (2010). Fiscal Year 2010 DRG Weights and Rates for All DRG Numbers. www.tricare.mil/drgrates accessed October 102010.

Van de Ven, W. P. M. M. and Schut, F.T. (2008). "Universal mandatory health insurance in the Netherlands: a model for the United States?" Health Affairs 27(3): 771.

Van Doorslaer, E. K. A. and Van Vliet, R. (1989). "A built bed is a filled bed? An empirical re-examination." Soc Sci Med 28: 155-164.

Van het Loo, M., Kahan, P., Okma, K. (1999). Developments in health care cost containment in the Netherlands. Union, Aldeshot: Ashgate: 573-604 


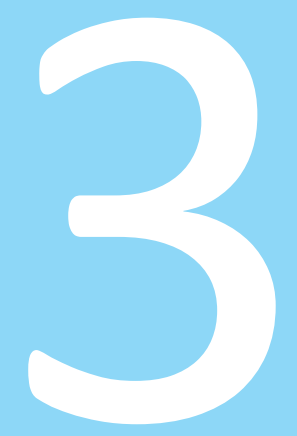

The volume effect of a New Casemixbased Funding System for Hospital Care on the Behavior of Medical Specialists in the Netherlands 


\section{Introduction}

In 2005 a new system for the reimbursement of hospitals was introduced in the Netherlands. The new system is based on so-called Diagnosis Treatment Combinations $^{5}$ (DTCS). It constituted a switch from a fixed hospital budget model (Maarse, 1993) to a casemix-based funding model. DTCs were intended not only to establish a clear link between hospital production and hospital revenues, but also to stimulate competition in hospital care as a tool for controlling costs (Ministerie VWS, 2006; Maarse and Normand, 2008).

A change in the hospital funding model can be conceptualized as a change in the financial incentives for medical specialists and hospital management (McClellan, 1997). This chapter presents a case-study testing of the effects of the incentives of payment of provider systems in the context of price competition in the delivery of health care. We investigate the impact of the new funding model on the behavior of hospitals and doctors. In particular, we analyze the effect on the volume of services provided. Our hypothesis is that the new funding model elicits an increase in the volume of hospital care, because under the new funding system a higher volume means more revenues for both hospitals and doctors, whereas under the old system revenues were only partially dependent upon volume of care, because the so-called production or volume contracts between hospitals and insurers, which put a cap on payment for care, prospectively, were an important element in determining a hospital's budget (Maarse, 1993). The co-existence of the old model for one part of hospital budgets (segment $A$ ) together with the new funding system (segment $B$ of hospital production) since 2005 has created a natural experiment (where segment $A$ functions as a control group) in the Netherlands whereby we can test our hypothesis.

\section{The Dutch context: hospital funding and Diagnosis Treatment Combinations}

DTCs are the cornerstone of the new funding model of hospital care. A DTC is defined as the entire range of activities (procedures) and services (consultations) of a hospital and a medical specialist stemming from the demand for care for which the patient consults the specialist (DBC Onderhoud, 2006). It entails the activities and services of the complete care process in the hospital, starting with the first consultation of the medical specialist and ending with the completion of the treatment in

\footnotetext{
${ }^{5}$ In Dutch: DBC or Diagnose Behandelings Combinatie.
} 
the hospital ${ }^{6}$. Hospitals receive a payment for each DTC whereby the payment varies with the type of treatment and casemix. Therefore, one may speak of a casemixbased funding model.

In practice there are approximately 30,000 DTCs. ${ }^{7}$ Each DTC consists of two parts: the price component to be paid to the hospital and the fee component to be paid to the medical specialists. The fees of medical specialists are based on a norm time for each specific DTC multiplied by a fixed fee per hour. The fees of medical specialists are centrally regulated by the Dutch Healthcare Authority, and therefore fall beyond the scope of price competition. The reason for this arrangement is the fear that a general scarcity of medical specialists would cause a cost explosion.

The objective of the new funding model is not only to introduce pay for performance, but also to encourage price competition in hospital care. However, the use of DTCs for price competition has been introduced only gradually. Over the period 2005-2007 only $10 \%$ of hospital production was opened to price negotiations between hospitals and insurers. The scope of price competition was enhanced to $20 \%$ in 2008 and $34 \%$ in $2009 .{ }^{8}$ An important reason for the government's cautious implementation strategy was the need for policy learning not only by the government, but also by hospitals and insurers. Another reason was to avoid disruptive effects of the new funding model on the financing and delivery of hospital care (Maarse and Bartholomée, 2008). Any further expansion of the scope of price competition is to be considered only after the effects of price competition so far on prices, volume, total hospital expenditures and so on have been considered. ${ }^{9}$ One of the policy lessons is that the present DTC-system requires a substantial reduction in complexity to function as a robust and stable funding model for hospital care (Maarse, 2011).

The part of hospital care open to price competition is called segment $B$ of the hospital budget. Over the period 2005-2007, our research period, it contained 1246 DTCs. ${ }^{10}$ Most diagnoses in this segment correspond with elective and high-volume routine procedures such as the treatment of cataracts, inguinal hernia, varicose veins, total hip replacement, total knee replacement and diabetes.

\footnotetext{
${ }^{6}$ Presently, there are also experiments with integrated DTCs in diabetes care, consisting of bundled payment contracts that also cover consultations by (but usually not treatment by) secondary care specialists (Struijs et al,.,2010).

${ }^{7}$ The theoretical number of DTCs is estimated at about 110,000 .

${ }^{8}$ According to Gupta the real size of segment B, although increasing, has so far always been smaller: 4.1 $\%$ in $2005,6.0 \%$ in 2006, $5.9 \%$ in 2007, $13.3 \%$ in 2008 and $19.9 \%$ in 2009 (Gupta, 2010).

${ }^{9}$ The ultimate scope of price competition measured by the size of segment $B$ is uncertain yet.

${ }^{10}$ In 2008 and 2009 the number of DTCs in segment B increased to 4921 and 7028 respectively.
} 
An important characteristic of segment B concerns the direct link between hospital production (volume) on the one hand and hospital revenues and the personal income of medical specialists on the other hand. This is a radical breach with the past, when hospital revenues and the specialists' incomes were capped due to the fixed hospital budget model (see below). An important implication of price competition is that the prices of DTCs negotiated between a hospital and an insurer can and do vary. There is some empirical evidence that insurers with a large market share are able to negotiate lower prices than insurers with a relatively small market share. An analysis of the first period (2005/2006) indicates that insurers with small market shares have to accept higher prices (NZa, 2007a).

For the remaining $66 \%$ of hospital production, so-called segment A, the DTC funding model is used only as an administrative tool. Hospitals receive a fixed budget which is paid to them by means of DTCs, the prices of which are centrally regulated by the Dutch Healthcare Authority. An important element of the funding procedure is that each hospital makes an agreement with insurers on the volume of hospital admissions, inpatient days, first policlinic visits, day treatments and a number of specific medical procedures (Maarse, 1993). Cost overruns in a given year due to a higher production volume than agreed upon are offset by a lower budget in a subsequent year. The NZa found that over the period 2005-2007 the average price increase of the DTCs in segment B has been less than the price increase of the DTCs in segment A ( $0 \%$ versus $1,5 \%$ in 2006 and $2,1 \%$ versus $2,5 \%$ in 2007) (NZa, 2008).

Medical specialists in Dutch hospitals are either paid a salary (about 30\%) or work on a fee-for-service basis (70\%). Until 1995 the latter category of specialists had a clear interest in maximizing production. By implication there was a conflict of interest between hospital management and medical specialists paid on a fee-for-service basis, because management's interest in keeping production in line with the fixed hospital budget conflicted with the specialists' interest in maximizing production. This conflict of interest was substantially mitigated in 1995 by the introduction of an income ceiling for medical specialists that was related to the volume (production) agreement of the hospital with the insurers. If a specialist reached his (her) annual ceiling, there was no longer a financial interest in producing more. This is the socalled lump-sum model for payment of medical specialists (Folmer and Mot, 2003).

The reform of 2005 was to some extent a return to the pre-1995 situation. Following the introduction of two different segments in hospital funding in 2005, specialists who are paid on a fee-for-service basis and producing DTCs in segment B have a renewed interest in increasing production because their personal revenue will be increased accordingly. Assuming that the revenues per DTC exceed production costs, the incentives of medical specialists and hospital management are aligned in segment $B$, since both gain from extra production. Higher production also reinforces 
the market position of the hospital (note that this is also in the interest of specialists who are paid a salary). In fact, they were aligned in segment A as well. Because of the budget cap and lump-sum payment model in place between 1995 and 2005, neither specialists nor hospital management had an interest in producing beyond the cap/lump sum. This situation came to an end in 2008 with the abolition of lumpsum payments to medical specialists. With the new system, higher DTC-production in segment A may increase the specialist's income, but not hospital revenue.

Table 1: Segment A and B as two alternative instutional settings for funding hospital care

\begin{tabular}{|c|c|}
\hline Segment $\mathrm{A}$ & Segment B \\
\hline $\begin{array}{l}\text { DTC prices centrally regulated by NZa; no price compe- } \\
\text { tition }\end{array}$ & $\begin{array}{l}\text { Price competition; prices negotiated by hospi- } \\
\text { tal and insurer }\end{array}$ \\
\hline $\begin{array}{l}\text { Budget cap by production agreement. Cost overruns in } \\
\text { year } t \text { are compensated retrospectively by a budget } \\
\text { reduction in year } t+1\end{array}$ & $\begin{array}{l}\text { No budget cap but insurers may negotiate a } \\
\text { production agreement with a hospital. No } \\
\text { compensation for cost overruns }\end{array}$ \\
\hline Specialist hour tariff centrally regulated by NZa & Specialist hour tariff centrally regulated by NZa \\
\hline $\begin{array}{l}\text { Impact on production: neither hospital management } \\
\text { nor medical specialists have an interest to produce } \\
\text { beyond the budget cap }\end{array}$ & $\begin{array}{l}\text { Impact on production: hospital management } \\
\text { and medical specialists have an interest to } \\
\text { maximize production }\end{array}$ \\
\hline
\end{tabular}

Segments A and B in hospital funding can be conceptualized as two alternative institutional settings with one common and some different rules of the game for funding (see table 1). The split between the segments creates a natural experiment whereby the volume development in segment $A$ (control group) is compared with the volume development in segment $B$ (experimental group). We test the hypothesis that the introduction of the new rules for funding will elicit a volume growth in segment $B$ that exceeds the volume growth in segment $A$.

\section{Theoretical background}

Every reimbursement system creates its own set of financial incentives (McClellan, 1997). Upcoding (Silverman and Skinner, 2004), patient selection or 'creamskimming' (Barros, 2003) and quality skimping (Ellis, 1998) are frequently mentioned forms of hospitals' and specialists' strategic behavior induced by paying hospitals by means of a casemix-based reimbursement system. In this article we focus on another important incentive, namely increasing the number of per-case reimbursed procedures relative to budgeted procedures.

The goals of physicians are important in order to understand why the payment system is likely to play a key role in their decisions when making diagnoses and prescribing treatments. Physicians influence the demand of the patient through the 
agency role physicians have with their patients, possibly leading to supplier-induced demand. In economic theory, the goals of physicians depend on the utility function of the agent. Theory on physician agency assumes as the standard utility function of physicians that they seek to maximize their net income and leisure. In addition, professional standards and ethical considerations play a role (Mot, 2002). This argument was made clear by a rather visual example of Evans (1984): 'Removing healthy organs, or drilling healthy teeth, has a negative impact on the practitioner's overall satisfaction, even if it is profitable and the patients, believing the organs/teeth were diseased, are satisfied' (p. 151). Physicians do not act as perfect agents for their patients, but rather as incomplete agents. There are opportunities for the physician to act in his own interest within the DTC system without harming the patient.

In segment B of hospital care, DTCs function as a per-case reimbursement, because extra production leads to extra revenues for the hospital and extra income for specialists (Aas, 1995). Because of this link between the provider's activity and his income, it is expected that medical specialists have a strong incentive to increase production (Jegers et al., 2002). A systematic international review of the impact of payment methods on the behavior of health care providers found that providers paid on a fee-for-service basis provide more services than those paid by salary or within a budget (Custers et al., 2008).

However, extra production is possible only if there is room for the extra capacity required (e.g. in terms of hospital beds, surgery theatres, nursing staff) (Robinson, 2001). Since segment B comprised only $10 \%$ of hospital care over the period $2005-$ 2007- and in practice even less as mentioned in footnote 8-, we assume that there were no serious capacity constraints to increasing production. The situation is different for segment A of hospital care. Here, paying by DTCs does not encourage hospitals to raise production because there is a budget limit and a cap on the income of medical specialists. Extra production generates extra costs but no extra revenue. The strategic interest of the hospital is to slightly overproduce because that is expected to reinforce the position of the hospital in the budget negotiations with the insurers. For the same reason, underproduction has to be avoided (Folmer and Westerhout, 2002). This leads to the hypothesis that the volume of hospital care in segment $B$ increased more than in segment $A$ after the DTC system was introduced.

The possibilities for strategic behavior on the part of medical specialists also depends on the type of diagnosis. Procedures that can be regarded as relatively 'elective procedures' are presumed to provide physicians with greater flexibility in this respect. The possibility for induced demand varies across treatments, because the underlying production functions and relative demand for various treatments vary 
(Mitchell, 2000). Therefore, we expect that the volume growth of DTCs in segment B occurs only with elective treatments.

\section{Methodology and Data}

For our analysis we used data from the national LMR-database (Landelijke Medische Registratie) which comprises national medical data from all hospitals in the Netherlands. These data, which have been collected since 1963, are derived from medical records by the administrative staff in hospitals and are periodically sent to a national centre (currently Prismant). Each record consists of one day-treatment or clinical admission with accompanying variables such as age, sex, admission and discharge dates. Unfortunately, outpatient care is not included in the LMR-data. This implies that we must exclude outpatient care from our analysis.

The data used for the analysis include all hospital discharges for the years 2003, 2004 and 2005 for the southern part of the Netherlands (provinces Limburg, Zeeland and Noord-Brabant). The years 2003 and 2004 represent the period before the DTC system was introduced, which we will compare with the year 2005 in which the new payment scheme was introduced. This comparison is possible since the registration parameters were the same before and after DTC was introduced. Unfortunately, the registration of LMR data has no longer been obligatory since 2006 . As a consequence, the registration quality has significantly decreased (IGZ, 2010). For this reason, 2006 and later years were not included in our analysis. The dataset contains the following variables: discharge International Classification of Diseases diagnosis code, (admission) specialty, type of hospital ${ }^{11}$ (regular hospital, top clinical hospital, university hospital or categorical hospital), age and sex of the patient, type of care (clinical admission or day treatment), admission date and discharge date.

We had to split the LMR-data into a segment A and B to perform our analysis. We did so by converting the ICD diagnosis codes to DTCs. For that purpose we used a procedure developed by Prismant for performing budget recalculations (Prismant, 2004). In addition we asked the expert opinion of medical specialists on how to separate the data into two segments ( $A$ and $B$ ).

Segment B contains 23 diagnoses divided over 14 specialties that are shown in table 2. Segment A contains all other forms of hospital care, including complex care such as cardiac surgery and intensive care.

\footnotetext{
${ }^{11}$ The data does not have information about he exact hospital of discharge; only the type of hospital is known.
} 
Table 2: Overview of the specialties and diagnoses in segment B (2005)

\begin{tabular}{|c|c|}
\hline Specialty & Diagnosis \\
\hline Ophthalmology & Cataract \\
\hline \multirow[t]{2}{*}{ Surgery } & Inguinal Hernia \\
\hline & Varicose veins \\
\hline ENT & Disease of adenoid and tonsils \\
\hline Dermatology & Varicose veins \\
\hline \multirow[t]{2}{*}{ Gynaecology } & Cervix abnormality \\
\hline & Pelvic organ prolapse \\
\hline \multirow[t]{3}{*}{ Urology } & Bladder neoplasm \\
\hline & Kidney stones \\
\hline & Urethra stones \\
\hline \multirow[t]{3}{*}{ Orthopaedics } & Total hip \\
\hline & Total knee \\
\hline & HNP surgery \\
\hline Neurology & HNP \\
\hline Neurosurgery & HNP surgery \\
\hline Pneumology & Lung fibrosis \\
\hline Internal Medicine & Diabetes type II \\
\hline \multirow[t]{2}{*}{ Gastroenterology } & Heartburn \\
\hline & Dyspepsia \\
\hline Paediatrics & Diabetes type II \\
\hline Plastic Surgery & Breast reduction \\
\hline \multirow[t]{2}{*}{ Rheumatology } & Gout \\
\hline & Spondylitis \\
\hline
\end{tabular}

Our dataset contains 2,143,598 ICD discharge diagnoses of which 255,847 diagnoses (12\%) belong to segment B DTCs. The number of day treatments is 951,199 observations and the number of clinical admissions is $1,192,399$ observations. To compare the change in volume in segment $B$ with that in segment $A$ of hospital care, we used a difference-in-difference analysis, where we assume that without the changes in reimbursement model, differences in volume growth between the two segments in 2004 would have continued in 2005. DD analysis is commonly used to evaluate the impacts of policy, using the assumption that the growth of the group subject to policy change versus the growth of the control group would otherwise have remained unchanged (Farrar et al., 2009).

Box 1: Definition of Difference-in-difference

Difference-in-difference $(D D)$ estimate of impact of financial incentives = (growth rate segment B in 2005 - growth rate segment $A$ in 2005) - (growth rate segment B 2004 growth rate segment $A$ in 2004). 
In implementing this approach, only those DTCs from segment B were selected where a reimbursement-driven volume increase is likely to be present. For this selection we conducted interviews with medical specialists from every specialty present in segment $B$, leading to the selection of all elective procedures in segment B. We compared the growth of these elective procedures with the growth of similar procedures in segment $A$. This selection is based mainly on type of care; thus the growth of e.g. cataract treatments, which take place in day treatment setting, are compared to the growth of other day treatment procedures in ophthalmology. Table 3 shows the diagnoses in our analysis with their control groups.

Table 3: Overview of the analysed segment $B$ diagnoses and their segment $A$ comparison group

\begin{tabular}{ll}
\hline Segment B & Segment A \\
\hline Inguinal Hernia & Day treatments surgery \\
\hline Varicose veins & Day treatments surgery \\
\hline Cataract & Day treatments ophthalmology \\
\hline HNP surgery (neurosurgery) & Clinical admissions neurosurgery \\
\hline Total hip & Clinical admissions orthopaedic surgery \\
\hline HNP surgery ( orthopaedic surgery) & Clinical admissions orthopaedic surgery \\
\hline Total knee & Clinical admissions orthopaedic surgery \\
\hline Breast reduction & Clinical admissions plastic surgery \\
\hline Pelvic organ prolapse & Clinical admissions gynaecology \\
\hline Disease of adenoid and tonsils & Day treatments ENT
\end{tabular}

\section{Results: The impact of DTCs on volume}

As can be seen from Table 4, the growth rates of the analyzed specialties differ between segment $A$ and segment $B$. Eight out of ten DDs are positive, meaning that for the same speciality the growth of the number of diagnoses in segment $B$ outstripped the growth of the number of diagnoses in segment $A$. The aggregate DD estimate of the impact of financial incentives, combining the effects of all 10 diagnoses, is $8 \%$, meaning that the introduction of the DTC system has led to a volume increase of $8 \%$ in segment $\mathrm{B}$, corrected for the expected trend growth had there not been a change in the payment system (Table 5).

Table 4: Growth rates and difference-in-difference of day-care treatments in 2004 and 2005 in segment A and segment B of hospital care.

\begin{tabular}{lccc|}
\hline Segment of care & $2003 / 2004$ & $2004 / 2005$ & Difference \\
\hline Segment B & $2 \%$ & $3 \%$ & $1 \%$ \\
\hline Segment A & $8 \%$ & $1 \%$ & $-7 \%$ \\
\hline Difference & & & $8 \%$
\end{tabular}


Table 5: Growth rates and diff-in-diff of analysed treatments in 2004 and 2005 in segment A and segment B of hospital care - per diagnosis

\begin{tabular}{|c|c|c|c|c|c|}
\hline Specialty & Segment & Diagnosis & $\begin{array}{c}\text { Growth percentage } \\
2003 / 2004\end{array}$ & $\begin{array}{c}\text { Growth percentage } \\
2004 / 2005\end{array}$ & Dif-in-Dif \\
\hline \multirow[t]{3}{*}{ Surgery } & A & segment $A$ & $6 \%$ & $1 \%$ & \\
\hline & B & inguinal hernia & $2 \%$ & $2 \%$ & $5 \%$ \\
\hline & B & varicose veins & $-1 \%$ & $7 \%$ & $12 \%$ \\
\hline \multirow[t]{2}{*}{ Neurosurgery } & $A$ & segment $A$ & $10 \%$ & $7 \%$ & \\
\hline & B & HNP surgery & $0 \%$ & $11 \%$ & $14 \%$ \\
\hline \multirow[t]{2}{*}{ Ophthalmology } & A & segment $A$ & $14 \%$ & $-12 \%$ & $25 \%$ \\
\hline & B & cataract & $3 \%$ & $2 \%$ & \\
\hline \multirow[t]{4}{*}{ Orthopaedics } & $A$ & segment $A$ & $11 \%$ & $3 \%$ & \\
\hline & B & total hip surgery & $5 \%$ & $9 \%$ & $12 \%$ \\
\hline & B & HNP surgery & $10 \%$ & $11 \%$ & $9 \%$ \\
\hline & B & total knee surgery & $9 \%$ & $15 \%$ & $14 \%$ \\
\hline \multirow[t]{2}{*}{ Plastic Surgery } & $A$ & segment $A$ & $17 \%$ & $-5 \%$ & \\
\hline & B & mamma reduction & $3 \%$ & $12 \%$ & $31 \%$ \\
\hline \multirow[t]{2}{*}{ Gynaecology } & $A$ & segment $A$ & $4 \%$ & $-1 \%$ & \\
\hline & B & pelvic organ prolapse & $20 \%$ & $5 \%$ & $-10 \%$ \\
\hline \multirow[t]{2}{*}{ ENT } & $A$ & segment $A$ & $4 \%$ & $4 \%$ & \\
\hline & B & $\begin{array}{l}\text { disease of adenoid } \\
\text { and tonsils }\end{array}$ & $-8 \%$ & $-8 \%$ & $-1 \%$ \\
\hline
\end{tabular}

Unfortunately, it is not possible to test the significance of the DDs for each distinct diagnosis. The reason for this is that we have only four relevant growth percentages per diagnosis. However, it is possible to test the significance of the aggregate DD. For this purpose we performed a regression analysis with as variables a dummy for segment (A or B), a dummy for before and after the introduction of the DTC system (2003-2004 and 2004-2005) and an interaction term between the two. The growth percentage per diagnosis and period was the dependent variable leading to 40 observations.

$G_{i j}=0+\beta 1 \times S_{i}+\beta 2 \times T_{j}+\beta 3 \times\left(S_{i} \times T_{j}\right)$

$\mathrm{G}_{\mathrm{ij}}=$ Growth percentage for diagnosis $\mathrm{i}$ and period $\mathrm{j}$

$\mathrm{S}_{\mathrm{i}}=$ Segment for diagnosis $\mathrm{i}$ and period $\mathrm{j}$

$\mathrm{T}_{\mathrm{j}}=$ Period for diagnosis $\mathrm{i}$

It can be inferred from the outcomes of this regression (Table 6) that the interaction term had a positive coefficient (0.0864) significant at the 0.05 level. The Rsquare of the model is 0.15 . The interaction term does not change if we include dummies per diagnosis. In conclusion, we can say that there is a significant difference between the growth of the selected specialties in segment $A$ and segment $B$. 
Table 6: Regression results testing the significance of the aggregated DD.

\begin{tabular}{lcrr} 
Variable & Parameter Estimate & standard error & $\operatorname{Pr}>|\mathrm{t}|$ \\
\hline Intercept & 1,0779 & 56,32 & $<0,0001$ \\
\hline Segment $(\mathrm{A}=0 ; \mathrm{B}=1)$ & $-0,0355$ & $-1,3$ & 0,2019 \\
\hline Time dummy (Before DTC =0; DTC =1) & $-0,0634$ & $-2,35$ & 0,0242 \\
Interaction term Segment* Time dummy & 0,0864 & 2,26 & 0,0302
\end{tabular}

We investigated whether this difference is sensitive to a number of potentially confounding factors. First, we considered the impact of age. Over the period 2004 and 2005 the average age of patients in segment $B$ increased less than in segment $A$ (the average age increased by $1.27 \%$ between 2004 and 2005 for segment B and by $1.42 \%$ for segment $A$ ). This makes it very unlikely that age explains our finding. $A$ second potential confounding variable concerns the government's policy to reduce waiting times and waiting lists. However, this policy targeted the entire hospital care sector. It did not exclusively target segment B.

A third confounding factor relates to the activities of the so-called independent treatment centres (ITCS). These centres perform high-volume and routine medical procedures in both segment A and segment B. The number of ITCs increased remarkably in the early 2000s. The Dutch Healthcare Authority counted 130 ITCs in 2005 against 31 in 2000 (NZa, 2007b). Unfortunately, their production is not registered in the LMR data set. It is plausible to assume that some of the production growth of elective treatments in segment A and B has 'leaked away' to ITCs. However, there is no reason to assume that ITCs have systematically and significantly disturbed the pattern of growth rates, particularly because their fraction in total expenditures for hospital care was very limited in 2005 (less than 1\%) (NZa, 2007b). There is even the possibility that they have caused an underestimation of the autonomous growth in segment $B$, since the procedures placed in segment $B$ are frequently performed in ITCs.

A final confounding factor concerns the role of insurers. Theoretically, they may have influenced our results by making lower production agreements with hospitals in segment A. We have no information whether this is true. Insurers may also have sought to mitigate the growth of production in segment $B$ by negotiating volume agreements with hospitals. If they did so, the autonomous growth of $8 \%$ is even more remarkable and a clear confirmation of our hypothesis.

In summary, we conclude that in the first year that DTCs and segment B were introduced (2005), the relative volume growth of elective treatments in segment B was higher compared with similar procedures in segment $A$. This finding points to a growth in segment $B$ attributed not to a growth trend, but to the change in financial incentives; this is in accordance with our hypothesis. 


\section{Discussion}

This study investigates the effect of a new funding model on the behavior of medical specialists in Dutch hospitals. We analyzed the volume effect of the partial shift (establishing segment B) from the former fixed budget model to the casemix model. Here, we found an autonomous growth of the elective treatments in the first year after the introduction of DTCs and of segment B (2005). This result is in accordance with our hypothesis, which was based upon the notion that the new hospital funding in segment $B$ gives medical specialists (and hospital management) an incentive to increase production to raise the specialists' personal income and hospital revenues.

A shortcoming of our study is that it includes only the first year (2005) after the introduction of DTCs and segment B. Since LMR registration was no longer obligatory in 2006, it was impossible to use this set for measuring volume effects in later years. This makes it difficult to assess whether the autonomous growth measured can be considered a lasting effect of the new funding model or if there is mainly a catch-up effort due to existing waiting lists. An investigation over a longer period of time is required to draw more definite conclusions on this topic. Such an analysis is also needed to detect a potential time lag in the impact of the new funding model. Because 2005 was the first year of experience with the new model, it may have taken some time for hospitals to fully adjust to the change in hospital funding. Another limitation of our study is that we have included only the southern part of the Netherlands. However, we have no reason to assume that the effect for other parts of the Netherlands would be different.

An important assumption made in this study is the profitability of extra production. We assume that both the fees of the medical specialists and the price charged by the hospitals are higher than the costs. There is no reason to assume this is not the case, but our hypothesis of an incentive to increase production would not hold without this assumption.

Our results suggest a volume effect of the new reimbursement model for hospital expenditures. It is difficult, however, to evaluate this effect. The growth of production may point to overproduction, but another explanation may well be that it helped to solve the underproduction effect of the previous funding model by shortening waiting times and reducing waiting lists. In other words, the welfare implications of the new funding model are not clear. In combination with our earlier observation that the analysis in this chapter only includes the first year of experience with the new funding model, there is good reason to be very careful with drawing policy conclusions from our study and formulating policy recommendations. 
In order to assess the effects of market competition and the DTC system on total expenditures on hospital care, it is also important to take price effects into account. The Dutch Healthcare Authority found that price competition has led to lower price increases in the segment $B$ than in segment $A$. For several years, it even measured price decreases (NZa, 2011). However, our analysis indicates an upward volume effect. If the volume effect outweighs the price effect, the new funding model will boost the growth of hospital expenditures, which undermines the government's policy of cost control. It is therefore important to take both effects into account when assessing the effects of market competition and the DTC system. This is also stated in Custers et al (2008); single policy recommendations around incentives are inappropriate because of the complexity of health care systems.

\section{Conclusion}

This chapter presented a country case-study of the effect of provider incentives on the volume of care. Our findings are based on a dataset of over 2 million inpatient hospital discharge diagnoses show that in the first year after DTCs and segment B were introduced (2005), the relative volume growth of elective treatments in segment $B$ was higher in comparison with similar procedures in segment $A$. This finding points to a growth in segment $B$ which can be attributed not to a general trend in growth, but plausibly to the change in financial incentives. The welfare implications of our finding are unclear, however. 


\section{References}

Aas, I. (1995). "Incentives and financing methods." Health policy 34(3): 205.

Barros, P. P. (2003). "Cream-skimming, incentives for efficiency and payment system." J Health Econ 22(3): 419-443.

Custers, T., J. Hurley, et al. (2008). "Selecting effective incentive structures in health care: A decision framework to support health care purchasers in finding the right incentives to drive performance." BMC health services research 8(1): 66.

DBC Onderhoud (2006), Vragen over DBC's, http://www.dbconderhoud.nl/client/1/?websiteid=$1 \&$ contentid=163\&hoofdid=103\&pagetitle=Wat_is_een_DBC?. Accessed 11 January 2008

Ellis, R. P. (1998). "Creaming, skimping and dumping: provider competition on the intensive and extensive margins." J Health Econ 17(5): 537-555.

Evans, R. G. and S. Mercy (1984). "The economics of Canadian health care." Toronto: Butterworth \& Co.

Farrar, S., D. Yi, et al. (2009). "Has payment by results affected the way that English hospitals provide care? Difference-in-differences analysis." BMJ: British Medical Journal 339.

Folmer, K. and E. Mot (2003). "Diagnosis and treatment combinations in Dutch hospitals." CPB Report.

Folmer, K. and E. Westerhout (2002). Financing medical specialist services in the Netherlands: Welfare implications of imperfect agency, CPB Netherlands Bureau for Economic Policy Analysis.

Gupta Strategists (2010), "De donkere kamer van Damocles".

IGZ, Inspectie voor de Gezondheidszorg (2010), "Veiligheidsindicatoren ziekenhuizen 2010 t/m 2012; Toezicht op het VMS Veiligheidsprogramma "Voorkom schade, werk veilig"

Jegers, M., Kesteloot, K., de Graeve, D. and Gillles, W. (2002). "A typology for provider payment systems in health care." Health Policy 60(3): 255-273.

Maarse, J. A. M., A. v. d. Horst, et al. (1993). "Hospital budgeting in the Netherlands." The European Journal of Public Health 3(3): 181-187.

Maarse, H. and Y. Bartholomée (2008). "Course and Impact of Market Reform in Dutch Health Care Uncertain." Intereconomics 43(4): 189-194.

Maarse, H. and Normand, C. (2009) "Market competition in European hospital care." Investing in hospitals of the future: 103. European Observatory on Health Systems and Policies.

Maarse, H. (2011). Markthervorming in de zorg. Maastricht, the Netherlands: Maastricht University.

McClellan, M. (1997). "Hospital reimbursement incentives: an empirical analysis." Journal of Economics \& Management Strategy 6(1): 91-128.

Ministerie van Volksgezondheid, Welzijn en Sport (2006). "Ruimte voor Betere Zorg", Kamerstuk CZ/IZ2695262

Mitchell, J. M., J. Hadley, et al. (2000). "Physicians' responses to Medicare fee schedule reductions." Medical care 38(10): 1029.

Mot, E. (2002). Paying the medical specialist: the eternal puzzle: experiments in the Netherlands. Amsterdam: University of Amsterdam. Dissertation

Nederlandse Zorgautoriteit (NZa) (2007a), Ziekenhuiszorg 2007: Analyse van de marktontwikkelingen in het B-segment in 2007.

Nederlandse Zorgautoriteit (NZa) (2007b), De rol van ZBCs in de ziekenhuiszorg.

Nederlandse Zorgautoriteit (NZa) (2008), Ziekenhuiszorg 2008: Analsyse van de marktontwikkelingen in het B-segment.

Nederlandse Zorgautoriteit (Nza) (2011), Marktscan Medisch specialistische zorg: Weergave van de markt 2006-2010

Prismant (2004). Landelijke volumebepaling potentiële B-segment DBC's op basis van LMR 2002.

Robinson, J. C. (2001). "Theory and practice in the design of physician payment incentives." Milbank Quarterly 79(2): 149-177.

Silverman, E. and J. Skinner (2004). "Medicare upcoding and hospital ownership." J Health Econ 23(2): 369-389.

Struijs, J.N., van Til, J.T. and Baan, C.A. (2010) Experimenting with a bundled payment system for diabetes care in the Netherlands. The first tangible effects. Bithoven: RIVM. 


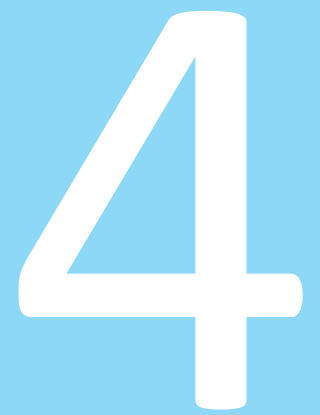

Does upcoding occur in the DTC system? An explorative analysis 


\section{Introduction}

In 2005 a new model for hospital funding was introduced in the Netherlands. The new model is the Dutch version of a casemix system and is called the Diagnosis Treatment Combination model. The change of funding model was not purely administrative. It was also closely connected to a shift from a supply-oriented hospital funding model in which hospitals receive a prospective fixed functional budget (the so-called function-based hospital budget), towards a more demand-oriented approach with partly negotiable (free) prices and volumes (Ministerie VWS, 2006a; Maarse and Normand, 2009). The DTC system introduces a new set of financial incentives for hospitals and medical specialists. One of these is the incentive to upcode, which can be described as choosing a specific DTC for financial reasons rather than medical necessity (McClellan, 1997; Simborg, 1981). In this chapter we explore whether there is evidence for upcoding in the declaration pattern of hospitals and medical specialists following the introduction of the DTC model in Dutch hospital care.

For our explorative analysis we look at the first three years of the DTC system (20052007) and analyze declarations of five pairs of DTCs. Each pair consists of two interchangeable options which offer an opportunity for upcoding by declaring the DTC with the higher reimbursement. All five pairs are part of the freely negotiable segment of hospital care, the so-called segment B in hospital care (see below). The pairs of DTCs are: diabetes mellitus, varicose veins treated by a dermatologist, varicose veins treated by a surgeon, pelvic organ prolapse and inguinal hernia. Large differences in practice style between hospitals may be interpreted as an indication of upcoding. We control for differences in patient casemix to test whether the differences in practice between hospitals can indeed be interpreted as upcoding. Second, we test whether these differences are specialty-specific or hospital-specific. Finally, upcoding is often linked to differences in relative prices between two related diagnostic groups. Since prices of DTCs in segment B are negotiable in the Netherlands, this can be used to explore whether, when hospitals have a choice between two alternatives, they choose the one with the higher price. Put differently, do price differences induce upcoding?

\section{Hospital funding in the Netherlands}

Upcoding, defined as 'a deliberate and systematic shift in a hospital's reported casemix in order to improve reimbursement' (McGuire, 2000), is a financial incentive specific to casemix-based systems. To assess whether and how upcoding may occur in the DTC system we first present an overview of its origins and specifics. 
Next, we discuss the phenomenon of upcoding and its possible occurrence in the Netherlands.

In 2005 a casemix system, the so-called Diagnosis Treatment Combination model, was introduced for the funding of all medical specialist care. The choice to create a new funding model instead of using the already developed DRG system was deliberate. Two important arguments for this decision were the fact that the DRG-system did not include medical activities in the outpatient treatment setting, nor was there a separate fee for the medical specialist (Klompenhouwer and Vos-Deckers, 2005). The objective of introducing a casemix system in the Netherlands for reimbursing hospital care was to support market competition as a new tool to contain costs, due to expected gains in efficiency. In order to introduce market competition, it is necessary to develop clear products so that health insurers and health care providers are able to negotiate on price, volume and quality. The introduction of the DTCs also allowed for better benchmarking of hospitals and introduced a clear link between the costs and performance of health care. Finally, a casemix system is expected to increase the incentive for efficiency and stimulate innovation (Folmer and Mot, 2003).

\section{Segment A and Segment B}

The definition of a DTC is the whole of activities and services of hospital and medical specialists stemming from the demand for care for a given condition for which a patient consults the specialist. A DTC encompasses the complete care process: from the first consultation with the medical specialist until treatment is completed. There are approximately 100,000 unique DTCs, of which 30,000 are actually used. A DTC consists of two parts: the first part is the component of the hospital and the second part consists of the fee of the medical specialists. DTCS are used for hospital funding. The revenues of a hospital consist of two segments. In the A segment, the DTCs' tariffs are regulated by the Dutch Healthcare Authority (fixed tariffs). In the B segment, health insurers and hospitals are permitted to negotiate on tariffs (free prices) and on the volume of services contracted. As a consequence, the tariffs in the $B$ segment and the volume of services contracted in this segment vary among hospitals and health insurers (DBC Onderhoud, 2006). The fees of the medical specialists are regulated in both segments by the Minister of Health and are similar in both segments (see below also).

In 2010 about $34 \%$ of hospital production was reimbursed on the basis of negotiated DTC-prices for the hospital component, which contains around 6,000 DTCs. Most diagnoses chosen for the $B$ segment are clear-cut routine procedures as cataract, inguinal hernia, varicose veins, total hip replacement and total knee replacement. Some chronic conditions including diabetes and COPD are also included in the 
B segment. The size of the B segment increased gradually from about $10 \%$ in 2005 to about $20 \%$ in 2008 and about $34 \%$ in $2009 .{ }^{12}$ The aim of the present government is to further increase the size of the B segment to about $70 \%$ in 2012 . The main reason for the stepwise increase of the $B$ segment in the past was to avoid market distortions in the form of unwanted volume and price increases. Another reason for cautious implementation was to enable insurers and hospitals to become acquainted with price/volume negotiations (learning effect) (Ministerie VWS, 2007). The main arguments for extending segment B from $34 \%$ to $70 \%$ is that the coexistence of two distinct funding segments, each with its own regulations and incentives, leads to high administrative complexity and, hence, higher administrative costs. The extension of the $B$ segment is expected to reduce administrative complexity. In the remaining $30 \%$ market competition is assumed to be either unfeasible or undesirable (examples are trauma and emergency care, donor teams and some top-clinical functions) (Maarse, 2011).

In the A segment, DTCs are used only as an administrative tool to reimburse hospitals. The former system of functional budgeting together with its annual budget ceiling is still in place. The co-existence of the A segment, which is related to the former system, and the B segment implies that there are two parallel systems for hospital funding, each with its own incentives (Maarse and Bartholomeé, 2008). We could call this a double hybrid system since there exist differences in funding hospital care between segment $A$ and $B$; and within segment $A$ medical specialists are funded differently from hospitals.

In both the A segment and the B segment the fee of the medical specialist is based on a norm time per specific DTC, multiplied by a fixed fee per hour (DBC Onderhoud, 2006). This fee was negotiated between the Ministry of Health and the Association of Medical Specialists and is uniform for each hospital and medical specialist.

Until 2008 the total revenues of medical specialists were also subject to a ceilingthe so-called lump sum arrangement. The rationale of this arrangement was to control total expenditures for specialist care. In this respect, it is important to note that about $70 \%$ of the specialists working in hospitals are paid by means of a feefor-service system (the remaining $30 \%$ is salary-paid). Also note that the lump-sum arrangement was combined with the fee-for-service system. This combination worked as a disincentive, because medical activities beyond the revenue ceiling were no longer paid. In 2008 the lump sum arrangement was also abolished for the

\footnotetext{
${ }^{12}$ According to Gupta (a consultancy firm) the real size of the B segment has so far always been smaller: $4.1 \%$ in $2005,6.0 \%$ in 2006, $5.9 \%$ in 2007, $13.3 \%$ in 2008 and $19.9 \%$ in 2009 (Gupta, 2010).
} 
A segment, leading to complete pay-for-service for medical specialists ${ }^{13}$. This means that medical specialists have an incentive to increase their income by means of extra production in the A segment and B segment, whereas the hospital shares the incentive for extra production only in the B segment. In other words, the incentives of medical specialists and hospital management are not aligned in the A segment. The medical specialists are paid per DTC and thus have an incentive to maximize their revenues by either treating more patients, declaring multiple DTCs or upcoding. However, the hospital still has to stick to its functional budget in segment $A$.

\section{Coding}

As mentioned earlier, there are around 100,000 different DTCs. In practice, however, $90 \%$ of total expenditures are explained by only 3,000 DTCs (data from health insurer). Every DTC has a unique performance code that reflects all information concerning that particular DTC. The performance code consists of 14 digits and contains information about the type of care, the demand for care, the diagnosis and type of treatment. An example of a performance code for the diagnosis cataract is shown in Table 1. In order to keep the system manageable there are groups of performance codes within a specific specialty that are cost-homogeneous and are therefore bundled into one product group code with a single tariff (DBC Onderhoud, 2006).

Table 1: Performance code 01110005540031

\begin{tabular}{lll} 
performance code & explanation & translation \\
\hline $01-\ldots-\ldots \ldots-\ldots \ldots$ & specialty & ophthalmology \\
$\ldots-11-\ldots . \ldots . \ldots$. & type of care & regular care \\
$\ldots-. .00-\ldots \ldots \ldots$ & demand for care & no defined demand for care \\
$\ldots-\ldots-. .0554-\ldots$. & diagnosis & cataract \\
$\ldots-\ldots-\ldots . .-0031$ & treatment & treatment outpatient department
\end{tabular}

\section{Upcoding}

Upcoding is a behavioral effect of a reimbursement system. The concept of upcoding was first introduced by Simborg in 1981 as a new type of 'disease' in U.S. hospitals: upcoding or so-called DRG creep. It is defined as 'a deliberate and systematic shift in a hospital's reported casemix in order to improve reimbursement' (Simborg, 1981). A distinction should be made between two types of upcoding. The first type

\footnotetext{
${ }^{13}$ As of 2012 medical specialists will once again receive a lump sum payment that is distributed per hospital and then divided between the different specialties.
} 
is upcoding by classifying a patient into a DRG or DTC with a higher reimbursement, although the actual treatment a patient undergoes does not significantly change. $A$ second type of upcoding occurs when the shift to a DRG or DTC with a higher reimbursement also implies a different type of treatment. In the latter case upcoding occurs because the demand of patients is induced/influenced by the medical specialist (physician-induced demand) (McGuire, 2000).

There are a number of different empirical studies in the US that test for the presence of upcoding, such as Carter et al. (1990), Psaty et al. (1999) and Silverman and Skinner (2001). These studies all focus on the first type of upcoding, i.e. upcoding by classification. Silverman and Skinner found that the occurrence of a more expensive DRG is higher in for-profit hospitals. Psaty found that the costs of upcoding the DRG heart failure can amount to $\$ 993$ million per year.

The second type of upcoding coincides with studies about differences in treatment intensity. Differences in treatment intensity between hospitals can be an indication for upcoding, if the differences are not merely a reflection of differences on the demand side. Variations in treatment intensity have been studied extensively by Wennberg and his colleagues. After having corrected the differences found for demand factors, they attribute these differences to variations in practice style between physicians or hospitals. An example is the difference in incidence of tonsillectomy, which is three times higher for a specific region in the United States in comparison with its neighboring regions. These differences are attributed to differences in beliefs among physicians concerning the indications for and efficacy of the procedure (Wennberg and Gittelsohn, 1973; Wennberg et al., 1982). Research by Dranove describes regional variations that are caused by differences in treatment style, which depend on where the physician was educated (Dranove et al., 2006). Whereas financial incentives embedded in funding schemes influence treatment within a whole region, the clustering of behavior or practice style within parts of a region that has the same reimbursement system indicates 'strongly that physicians' preferences are formed within, and respond to, a local culture' (Evans, 2009).

The actual occurrence of upcoding depends on the characteristics of the casemix system used. We have already noted that the DTC system is different from the DRG system. This also affects the probability that upcoding will occur. Steinbusch et al. (2007) stated that some casemix systems are more prone to upcoding than others, depending on certain characteristics such as market, control and casemix characteristics. Fewer opportunities for upcoding occur in the DTC system, since its classification is medically meaningful, there is no for-profit ownership (yet) on the Dutch hospital market, there is no possibility to make use of a secondary diagnosis in the DTC system, and the DTC is registered at initial contact instead of after treatment. However, there are characteristics that increase the risk for upcoding in the DTC 
system, such as the fact that the coder's (medical specialist's) income depends on the DTC chosen ${ }^{14}$ (Steinbusch et al., 2007). It has also been argued that a casemix system with broad diagnosis groups minimizes the scope for data manipulation, whereas a detailed casemix system induces overtreatment of patients or upcoding (Busse et al., 2006).

\section{Exploration of upcoding within the DTC system}

In the introduction we sketched the institutional settings in the Netherlands. Upcoding is most likely to occur in segment $B$, since higher reimbursement will directly increase revenues for both hospitals and medical specialists. From 2008 onwards (when the lump sum arrangement was abolished), upcoding has also been profitable for medical specialists in segment A. Our analyses are from the years 2005$2007 .{ }^{15}$ Therefore the five selected pairs of DTCs are all from segment B. To determine which DTC pairs from segment B to select, we interviewed medical advisors from a health insurance company (from which we also use the data) and medical specialists. ${ }^{16}$ These five pairs of DTCs were selected from the list provided during the interviews; their substantial volume was a factor in their selection. For each pair the DTC system provides two interchangeable options, with a consequent opportunity for upcoding to the DTC with the higher reimbursement. For these five pairs, from different specialties, we seek answers to a number of explorative questions:

- Is there variation between hospitals in the proportion of the DTC with the higher reimbursement?

- Is there variation within hospitals for the different specialties in the proportion of the DTC with the higher reimbursement?

- Can this variation be explained by casemix differences between the hospitals?

- Are there unobserved hospital-specific effects?

- Are there unobserved specialty-specific effects within a hospital?

- Do specialty effects differ between hospitals?

- Can differences in the proportion of the DTC with the higher reimbursement between hospitals be explained by differences in relative prices?

\footnotetext{
${ }^{14}$ In the DRG system the coder is an administrative clerk instead of the medical specialist.

${ }^{15}$ There might be an incentive for upcoding in segment $A$ as well. Even though extra revenues do not directly lead to extra income, medical specialists might have indirect beneficial effects such as, for example, a better bargaining position with the hospital for resources.

${ }^{16}$ We interviewed 12 medical specialists from the specialties: opthalmology, ENT, gynaecology, surgery, pediatrics, dermatology, internal medicine, neurology, neursurgery and urology.
} 


\section{Data}

We used hospital declarations from a large insurance company to analyze the possibility of upcoding. Our dataset includes declarations from the years 2005, 2006 and 2007. We included only those hospitals with whom the health insurance company negotiates on volume and prices in segment B. Furthermore, we imposed a minimum number of 50 observations per specific DTC pair combined for all years per hospital. This resulted in a dataset including 61,638 declarations from 39 different hospitals. Table 2 provides an overview of the selected DTCs.

Table 2: Overview of selected DTCS

\begin{tabular}{|c|c|c|c|}
\hline Diagnosis & Lower reimbursement & Higher reimbursement & Total \\
\hline $\begin{array}{l}\text { Varicose veins } \\
\text { (by surgeon) }\end{array}$ & $\begin{array}{l}\text { Day treatment } \\
\mathrm{N}=7483\end{array}$ & $\begin{array}{l}\text { Clinical admission } \\
\mathrm{N}=1092\end{array}$ & $N=8575$ \\
\hline Inguinal hernia & $\begin{array}{l}\text { Day treatment } \\
\mathrm{N}=8777\end{array}$ & $\begin{array}{l}\text { Clinical admission } \\
\mathrm{N}=5543\end{array}$ & $N=14320$ \\
\hline $\begin{array}{l}\text { Varicose Veins } \\
\text { (by dermatologist) }\end{array}$ & $\begin{array}{l}\text { Outpatient 'large' treatment } \\
\mathrm{N}=5759\end{array}$ & $\begin{array}{l}\text { Outpatient complex treatment } \\
\mathrm{N}=14288\end{array}$ & $N=20047$ \\
\hline Pelvic organ prolapse & $\begin{array}{l}\text { Operative group } 2 \\
\mathrm{~N}=3916\end{array}$ & $\begin{array}{l}\text { Operative group } 3 \\
\mathrm{~N}=3198\end{array}$ & $N=7114$ \\
\hline Diabetes Mellitus & $\begin{array}{l}\text { Without secondary complications } \\
N=4437\end{array}$ & $\begin{array}{l}\text { With secondary complications } \\
N=7145\end{array}$ & $N=11582$ \\
\hline
\end{tabular}

These five pairs of diagnoses differ from each other in the type of upcoding that can occur. As explained earlier, a distinction needs to be made between simply classifying a patient into a DTC with higher reimbursement (different diagnosis - similar treatment), and actually changing the treatment setting to get a higher reimbursement on the other hand (similar diagnosis - different treatment). In the first two pairs, varicose veins by a surgeon and inguinal hernia, the treatment setting can be upcoded from a day treatment to a clinical admission. This type of upcoding actually leads to a different treatment (upcoding along the treatment axis), which was described as the second type of upcoding in the previous paragraph. It leads not only to more revenues, but also to higher costs for the hospital. ${ }^{17}$ Apart from higher costs for the hospital, upcoding to a clinical admission also has effects on the logistics of the hospital; to place a patient in an overnight bed requires a lot of input from the hospital and other resources. This also implies that this type of upcoding will be attractive for the hospital only if the difference in price is larger than the

\footnotetext{
${ }^{17}$ We assume that the extra reimbursement for a clinical admission outweighs the extra costs. Clinical admission is thus more profitable than day treatment.
} 
difference in costs between the two DTCs. This in contrast to the first type of upcoding, which will always be attractive to the hospital.

The third and fourth pairs of DTCs have a different possibility for upcoding. For varicose veins by a dermatologist and pelvic organ prolapse, the difference between the two treatment settings is only a matter of treatment time. The DTCs with the longest treatment time thus lead to higher reimbursement (upcoding on the treatment axis). Classifying the patient into this DTC does not necessarily lead to extra work and costs, but it does lead to more revenue. These two pairs are a mixed form of the two types of upcoding, since extra treatment time is indeed a different treatment but is manipulated more easily than upcoding from day treatment to a clinical admission.

The possibility to upcode in the fifth pair of DTCs is an example of upcoding by classification (upcoding along the diagnosis axis). According to the DTC instructions and an interview with an internal medicine specialist, the actual treatment performed by the internal medicine specialist for diabetes mellitus does not change for the DTC 'DM with secondary complications' in comparison with the DTC 'DM without secondary complications'. The difference is merely a matter of classifying the patient (ZN Inkoopgids, 2004; DBC Onderhoud, 2007).

Figures 1 to 5 show the differences in proportion of the DTC with the higher reimbursement compared to the DTC with a lower reimbursement. In the graphs the $y$ axis shows the proportion of the more complex DTCs for each hospital (x-axis) for each DTC pair and over the period 2005-2007 For all five DTC pairs there are hospitals billing only the less complex DTC (DTC with the lower reimbursement rate) and hospitals billing only the more complex DTC (DTC with the higher reimbursement rate). It may be that the latter hospitals only treated patients who need extra care, for example because the hospital is located close to an independent treatment centre (ITC). These ITCs typically treat patients with a less severe casemix, so only patients with a more severe casemix go to a hospital in that area for treatment.

Accordingly, differences in the proportion of the DTC with a higher reimbursement in comparison with the DTC with a lower reimbursement do not necessarily constitute evidence for upcoding. However, since the variation is so large and occurs for every pair of DTCs, it is not very likely that variations this large are solely due to differences in casemix. For this reason, we interpret differences in the proportion of the DTC with a higher reimbursement in comparison with the DTC with a lower reimbursement as a 'soft' indicator of upcoding. 


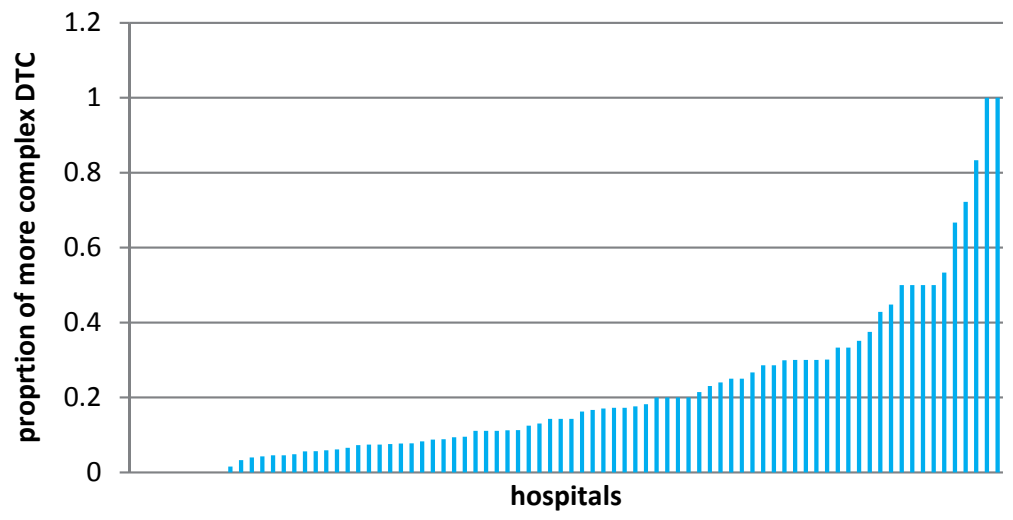

Figure 1: Varicose veins by surgeon

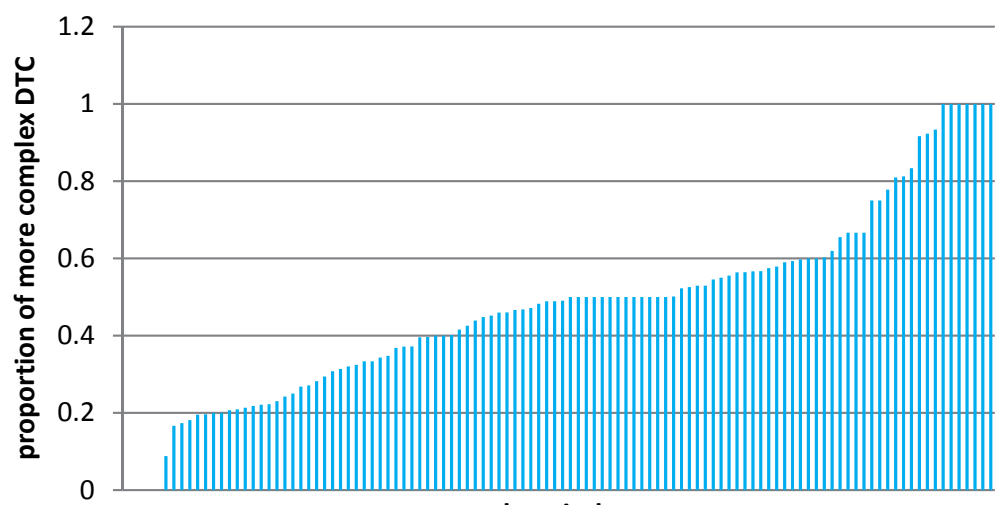

hospitals

Figure 2: Inguinal hernia

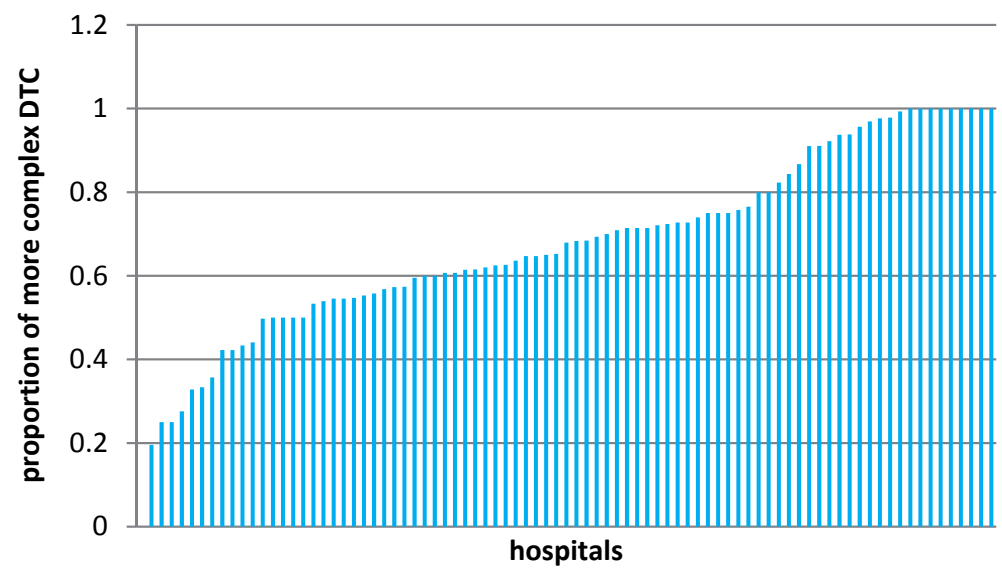

Figure 3: Varicose veins by dermatologist 


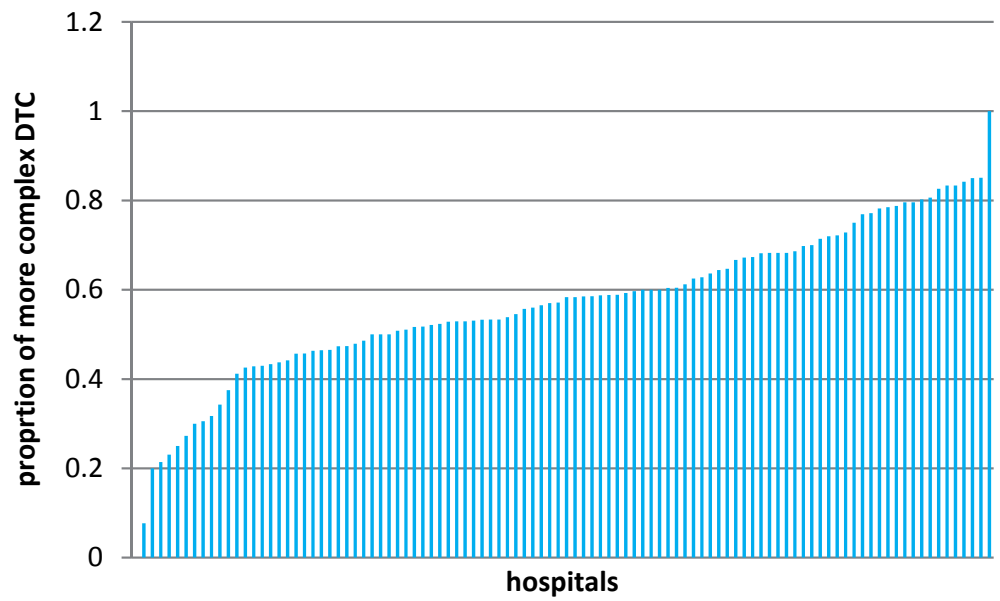

Figure 4: Diabetes Mellitus

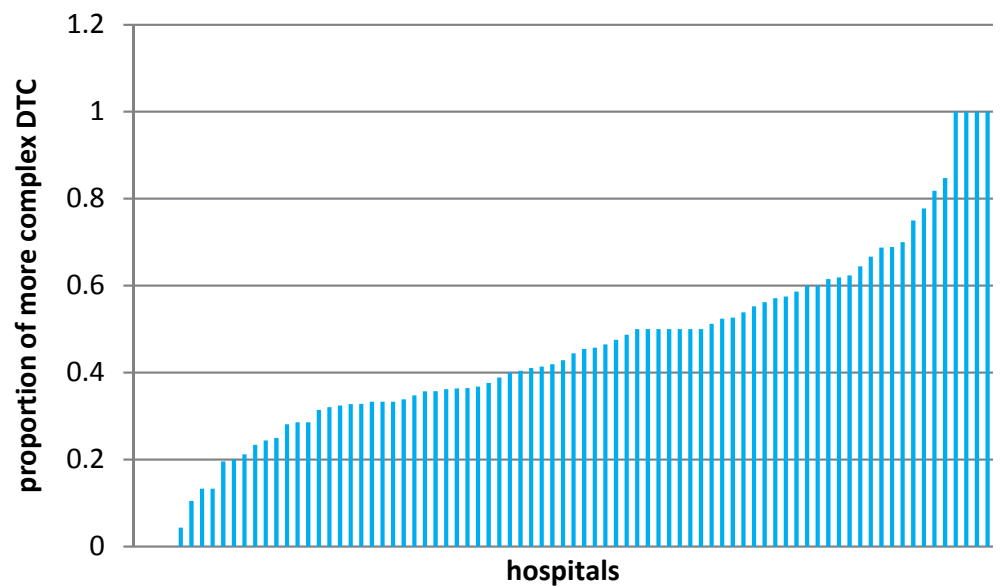

Figure 5: Pelvic organ prolapse

Figures 1-5 provide an answer to our first research question: Is there variation between hospitals in the proportion of the DTC with the higher reimbursement? The research findings clearly indicate a wide variation between hospitals regarding the proportion of the DTC with a higher reimbursement. As stated earlier, we consider the great variation found as a 'soft' indicator of upcoding

\section{A closer look at hospital effects}

In this section we aim to analyze whether the differences observed between hospitals are caused only by differences in casemix, or if they point to upcoding. We have done this by performing a logistic regression analysis, where we estimate whether the chance that the more complex DTC is chosen depends on the hospital the pa- 
tient is treated in. To correct for differences in patient population we have added a number of control variables: type of hospital, age of the patient and patient comorbidity. Type of hospital is included, since top clinical and university hospitals typically have a more severe casemix, which could explain the differences in treatment intensity (RVZ, 2003). Co-morbidity is controlled for by including 20 pharmaceutical and 13 diagnostic cost-groups that are also used as cost estimators in the calculations of risk adjustment schemes (Douven, 2004; Ministerie VWS, 2006b).

We first estimate the probability that the DTC with a higher reimbursement is chosen with only control variables in Model 1 (see also Table 3). Next, we compare Model 1 with Model 2, in which we add dummies per hospital. If Model 2 is a significant improvement in comparison with Model 1, we conclude that unobserved hospital-specific effects play a role in explaining upcoding (see annex for an overview of the equations used).

Table 3: Overview Regression Models 1 and 2

\begin{tabular}{|c|c|}
\hline Model 1 & Model 2 \\
\hline Logit indication more or less complex DTC $=$ & Logit indication more or less complex DTC $=$ \\
\hline $\begin{array}{l}2 \text { dummies for hospital types 'top clinical' and } \\
\text { 'university' in comparison with 'general' }\end{array}$ & $\begin{array}{l}2 \text { dummies for hospital types 'top clinical' and } \\
\text { 'university' in comparison with 'general' }\end{array}$ \\
\hline Age of patient & Age of patient \\
\hline $\begin{array}{l}2 \text { dummies for years } 2006 \text { and } 2007 \text { in comparison } \\
\text { with } 2005\end{array}$ & $\begin{array}{l}2 \text { dummies for years } 2006 \text { and } 2007 \text { in comparison } \\
\text { with } 2005\end{array}$ \\
\hline 19 dummies for pharmaceutical cost groups & 19 dummies for pharmaceutical cost groups \\
\hline 12 dummies for diagnostic cost groups & 12 dummies for diagnostic cost groups \\
\hline
\end{tabular}

We can see from Table 4 that the likelihood ratio $(-2 L L)$ decreases in magnitude as we add the hospital dummies to the model. With a likelihood ratio test we test whether this decrease in the likelihood ratio is a significant decrease given the number of variables we have added. The outcome of this test is for all analyzed diagnoses larger than the critical value. From this result we infer that adding all hospital dummies significantly contributes to the explanatory power of the model. These results indicate that there exist unobserved hospital-specific effects that have an effect on the level of upcoding. 
Table 4: Results of Regression Models 1 and 2

\begin{tabular}{|c|c|c|c|c|c|}
\hline Diagnosis & & Model 1 & Model 2 & $\begin{array}{l}\text { Computed } \\
\text { Chi Square }\end{array}$ & $\begin{array}{r}\text { critical value } \\
\text { Chi Square } \\
(0,001)\end{array}$ \\
\hline \multirow[t]{2}{*}{ Inguinal hernia } & DF & 33 & 61 & & \\
\hline & $-2 \log L$ & 6,208 & 5,586 & 622 & 56,89 \\
\hline \multirow[t]{2}{*}{ Diabetes mellitus } & DF & 35 & 66 & & \\
\hline & $-2 \log L$ & 14,649 & 13,443 & 1,206 & 59,70 \\
\hline \multirow[t]{2}{*}{ Varicose veins by surgeon } & DF & 35 & 71 & & \\
\hline & $-2 \log L$ & 17,321 & 16,124 & 1,197 & 59,70 \\
\hline \multirow[t]{2}{*}{ Varicose veins by dermatologist } & DF & 34 & 64 & & \\
\hline & $-2 \log L$ & 23,260 & 20,604 & 2,656 & 59,70 \\
\hline \multirow[t]{2}{*}{ Pelvic organ prolapse } & DF & 33 & 59 & & \\
\hline & $-2 \log L$ & 9,688 & 8,761 & 927 & 54,05 \\
\hline
\end{tabular}

After having estimated per DTC pair in Models 1 and 2 we also estimate a pooled regression in which we add dummies per DTC pair. The aim of this regression is to find out whether upcoding is hospital-related or specialty-related (within a hospital). To test this we compare the outcomes of a regression (Model 3) with the DTC pair dummies with a model (Model 4) with both DTC pair- and hospital dummies, and with a new model (Model 5), in which we also add interaction terms between the DTC pair- and the hospital dummies. Model 4 tests whether in addition to hospital effects there are also specialty effects. Model 5 allows these specialty effects to differ between hospitals. Table 5 gives an overview of these three models with a pooled regression analysis.

Table 5: Overview of Regression Models 3, 4 and 5

\begin{tabular}{|c|c|c|}
\hline $\begin{array}{l}\text { Model } 3 \\
\text { Logit indication more or less } \\
\text { complex DTC = }\end{array}$ & $\begin{array}{l}\text { Model } 4 \\
\text { Logit indication more or less com- } \\
\text { plex DTC = }\end{array}$ & $\begin{array}{l}\text { Model } 5 \\
\text { Logit indication more or less com- } \\
\text { plex DTC = }\end{array}$ \\
\hline Age of patient & Age of patient & Age of patient \\
\hline $\begin{array}{l}2 \text { dummies for years } 2006 \text { and } \\
2007 \text { in comparison with } 2005\end{array}$ & $\begin{array}{l}2 \text { dummies for years } 2006 \text { and } \\
2007 \text { in comparison with } 2005\end{array}$ & $\begin{array}{l}2 \text { dummies for years } 2006 \text { and } 2007 \\
\text { in comparison with } 2005\end{array}$ \\
\hline $\begin{array}{l}19 \text { dummies for pharmaceutical } \\
\text { cost groups }\end{array}$ & $\begin{array}{l}19 \text { dummies for pharmaceutical } \\
\text { cost groups }\end{array}$ & $\begin{array}{l}19 \text { dummies for pharmaceutical cost } \\
\text { groups }\end{array}$ \\
\hline \multirow[t]{2}{*}{$\begin{array}{l}12 \text { dummies for diagnostic cost } \\
\text { groups }\end{array}$} & $\begin{array}{l}12 \text { dummies for diagnostic cost } \\
\text { groups }\end{array}$ & $\begin{array}{l}12 \text { dummies for diagnostic cost } \\
\text { groups }\end{array}$ \\
\hline & 38 hospital dummies & 38 hospital dummies \\
\hline \multirow[t]{2}{*}{4 DTC pair dummies } & 4 DTC pair dummies & 4 DTC pair dummies \\
\hline & & $\begin{array}{l}152 \text { interaction terms between the } \\
\text { hospital- and DTC pair dummies }\end{array}$ \\
\hline
\end{tabular}


Table 6: Results of regression models 3 and 4

\begin{tabular}{|llllll|} 
Diagnosis & Kolom1 & Model 3 & Model 4 & $\begin{array}{l}\text { computed } \\
\text { Chi Square }\end{array}$ & $\begin{array}{l}\text { critical value } \\
\text { Chi Square }(0,001)\end{array}$ \\
\hline combined regression & DF & 38 & 76 & & \\
\cline { 1 - 5 } & $-2 \log \mathrm{L}$ & 72,119 & 70,440 & 1,679 & 59.70
\end{tabular}

Table 7: Results of regression models 4 and 5

\begin{tabular}{|llllll|} 
Diagnosis & Kolom1 & Model 4 & Model 5 & $\begin{array}{l}\text { computed } \\
\text { Chi Square }\end{array}$ & $\begin{array}{l}\text { critical value } \\
\text { Chi Square }(0,001)\end{array}$ \\
\hline combined regression & DF & 76 & 199 & & \\
\cline { 1 - 4 } & $-2 \log \mathrm{L}$ & 70,440 & 66,073 & 4,367 & 149.40
\end{tabular}

In Tables 6 and 7 the results of each model are shown together with two likelihood ratio tests. Table 6 compares Model 4 to Model 3 and table 7 compares Model 5 with Model 4. The outcome of the test indicates that Model 4 (inclusion of hospital dummies) is a significant improvement over Model 3. This implies that, also for the pooled data, including hospital dummies significantly contributes to the explanatory power of the variation in the proportion of the DTC with a higher reimbursement. Model 5 is a further significant improvement of Model 4. From this we conclude that there are both hospital-specific effects on the probability that the DTC with a higher reimbursement is chosen as well as specialty-specific effects within a hospital.

Even though our analysis indicates that hospital-specific effects do exist, what these effects entail is still unknown. We explore whether there is a relation between the type of hospital and the hospital-specific effect. In Figures 6-11 the relative value of the coefficients (we have set the lowest coefficient to zero and computed the differences between the other coefficients and the lowest coefficient) is plotted on the $x$-axis against the type of hospital on the $y$-axis. There are three types of hospitals: $\mathrm{U}=$ university hospital; $\mathrm{TC}=$ top clinical hospital; and $\mathrm{G}=$ general hospital. The larger the bar on the $y$-axis, the larger the hospital-specific effect on upcoding is for that specific hospital. 


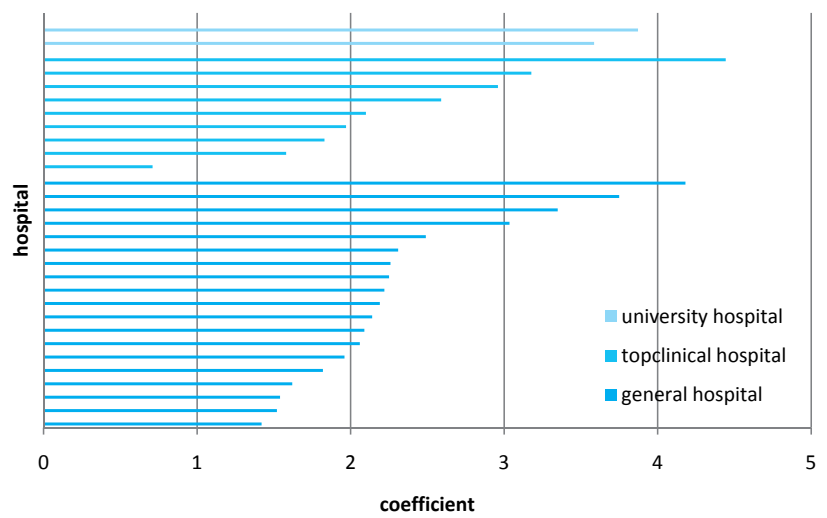

Figure 6: Coefficients hospital dummies related to the type of hospital - inguinal hernia

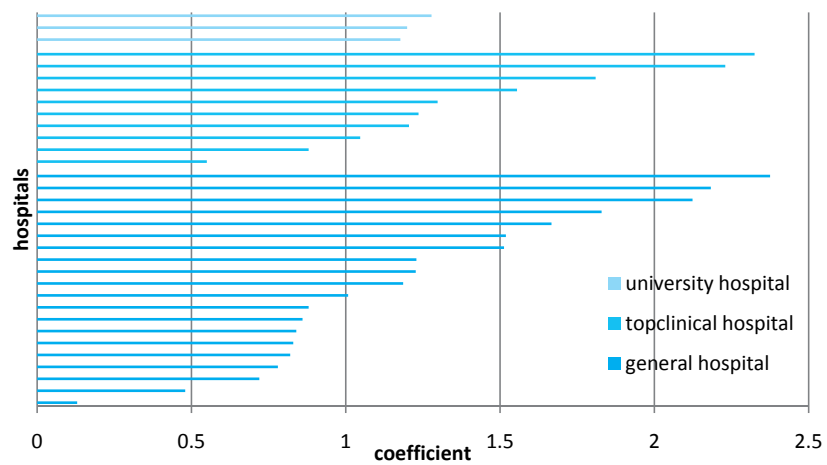

Figure 7: Coefficients hospital dummies related to the type of hospital - diabetes mellitus

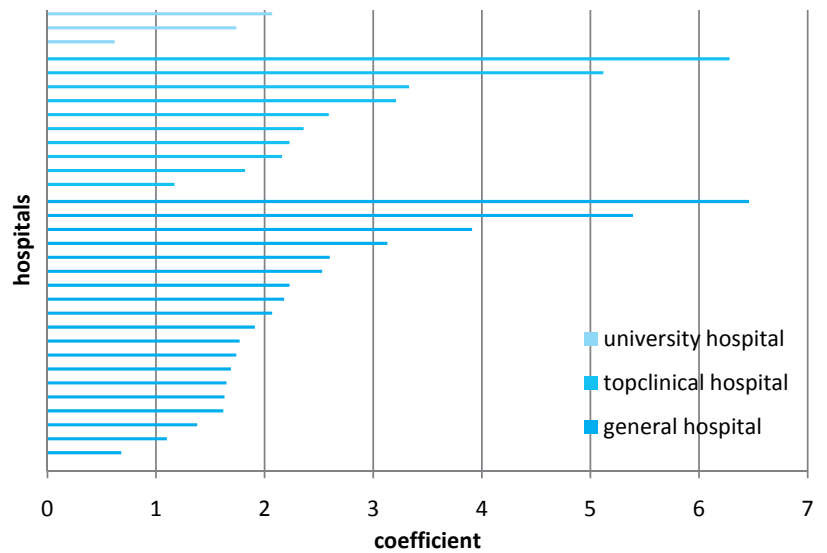

Figure 8: Coefficients hospital dummies related to the type of hospital - varicos veins by dermatologist 


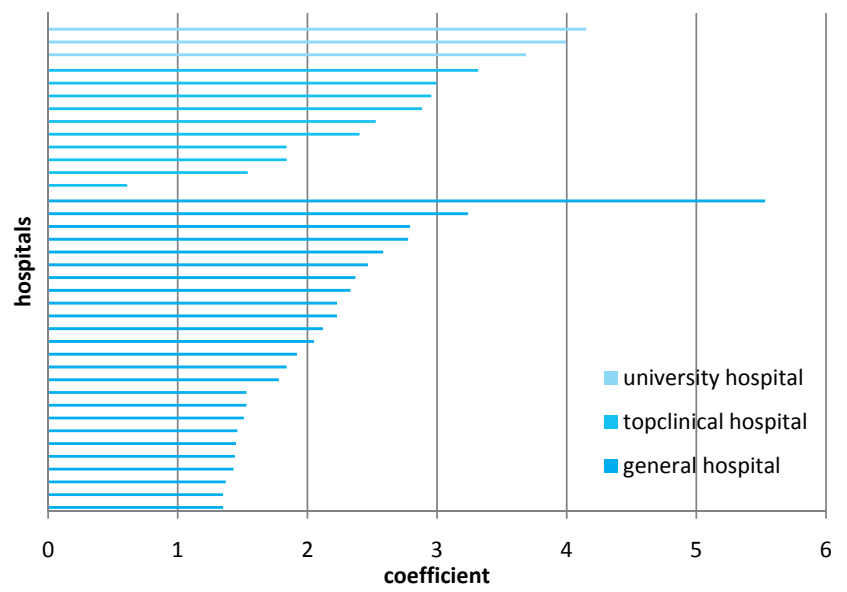

Figure 9: Coefficients hospital dummies related to the type of hospital - varicose veins by surgeon

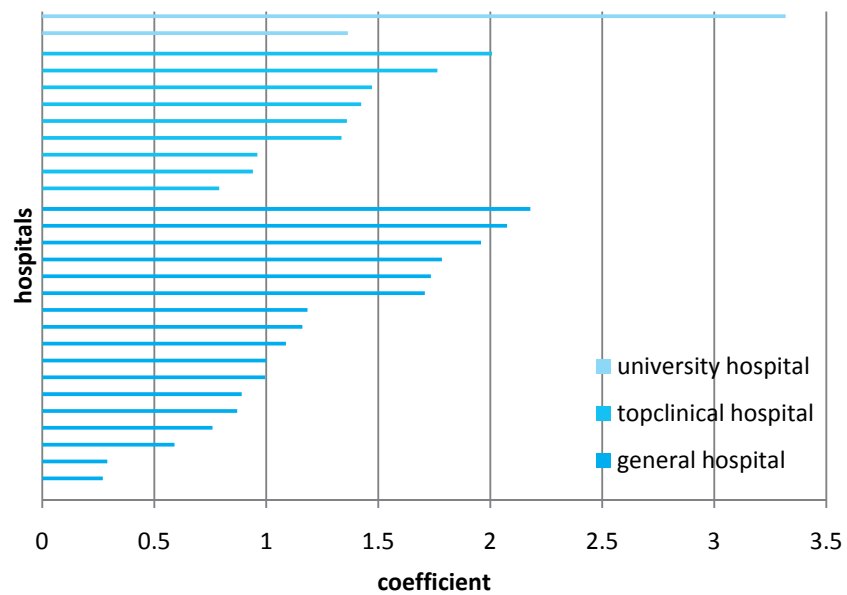

Figure 10: Coefficients hospital dummies related to the type of hospital - pelvic organ prolapse

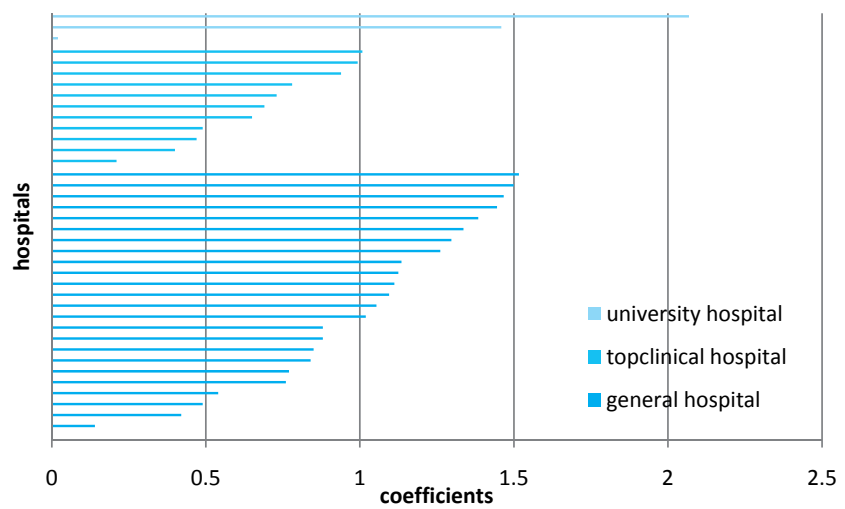

Figure 11: Coefficients hospital dummies related to the type of hospital - pooled regression 
We can see from Figures 6-11 that the coefficients vary both between the types of hospitals, within the types of hospitals and between the diagnoses. A possible explanation for the higher coefficients for university hospitals for the diagnosis pelvic organ prolapse could be a more severe casemix unobserved from our control variables. The higher coefficients for general hospitals compared to the top-clinical hospitals from the pooled regression could indicate upcoding.

\section{Summary}

We can now answer part of the explorative questions:

- Is there variation between hospitals in the proportion of the DTC with the higher reimbursement?

Yes, large differences do exist in the proportion of DTCS with a higher reimbursement between hospitals for the five interchangeable pairs of DTCs we selected.

- Is there variation within hospitals for the different specialties in the proportion of the DTC with the higher reimbursement?

Yes, also within hospitals there is variation as can be seen from comparing models 3,4 and 5 .

- Can this variation be explained by casemix differences between the hospitals? Part of this variation is explained by casemix differences between the hospitals as can be seen from model 1 .

- Are there unobserved hospital-specific effects?

Yes, there are unobserved hospital-specific effects as can be seen from comparing model 2 to model 1.

- Are there unobserved specialty-specific effects within a hospital?

Yes, there are unobserved specialty-specific effects as can be seen from comparing to model 4 and model 3.

- Do specialty effects differ between hospitals?

Yes, these specialty-specific effects differ between hospitals as can be seen from comparing to model 5 and model 4.

In conclusion, these analyses show that the large variation in the proportion of the DTC with a higher reimbursement described in the previous paragraph can be partly explained by hospital-specific, as well as specialty-specific effects within a hospital. These hospital- and specialty-specific effects within a hospital can be seen as an indication of upcoding. 


\section{A closer look at price effects}

In the literature, upcoding is linked to differences in prices between two related diagnostic groups (Silverman and Skinner, 2001; Psaty et al., 1999). Since the prices of DTCs in segment B are negotiable in the Netherlands, we can use the difference in prices from our health insurance data of the five DTC pairs to test for the occurrence of upcoding. The hypothesis to be tested is that in hospitals with a larger difference in price between the two DTCs, the more complex DTC is performed more often. We use the relative price (defined as the price of the DTC with a higher reimbursement divided by the price of the DTC with a lower reimbursement) and not the absolute price difference, since the relative price reflects the difference between the options more equally between hospitals regardless of the absolute price level of a hospital. Figures 12-16 show the relative prices of the pairs of DTCs compared to the proportion of the DTC with the higher reimbursement. Every dot represents a hospital in a given year. If upcoding responds to relative prices, we would expect that a higher relative price leads to a higher proportion of DTCs with a higher reimbursement.

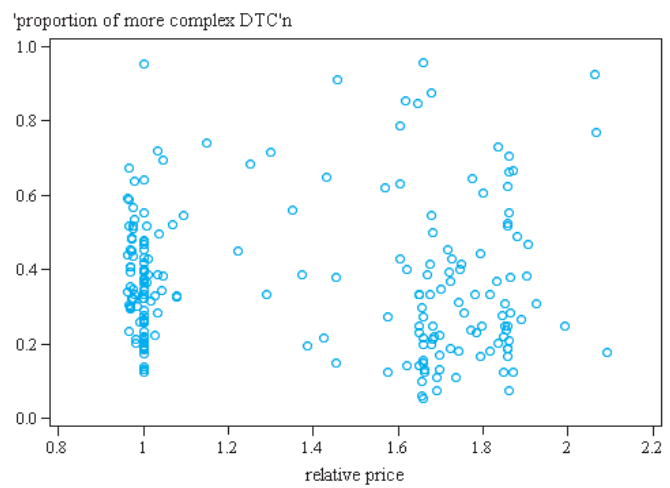

Figure 12: Relative prices for treating varicose veins by a surgeon

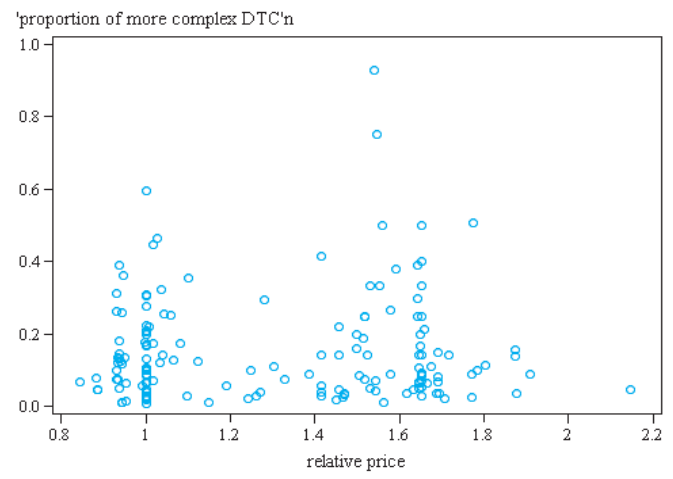

Figure 13: Relative prices for treating inguinal hernia 


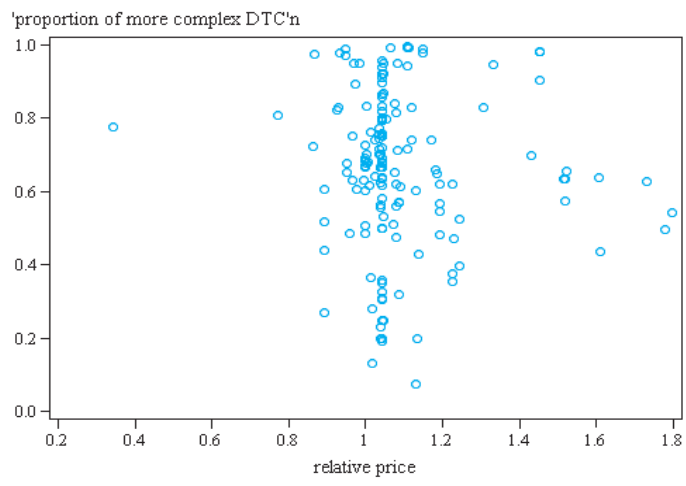

Figure 14: Relative prices for treating varicose veins by a dermatologist ${ }^{18}$

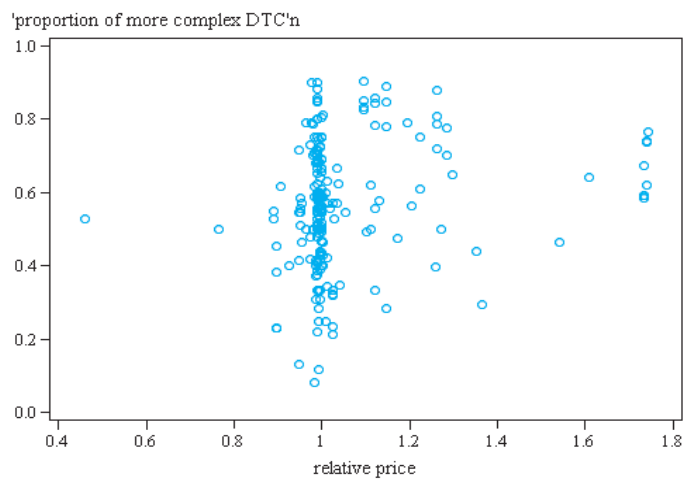

Figure 15: Relative prices for treating diabetes mellitus

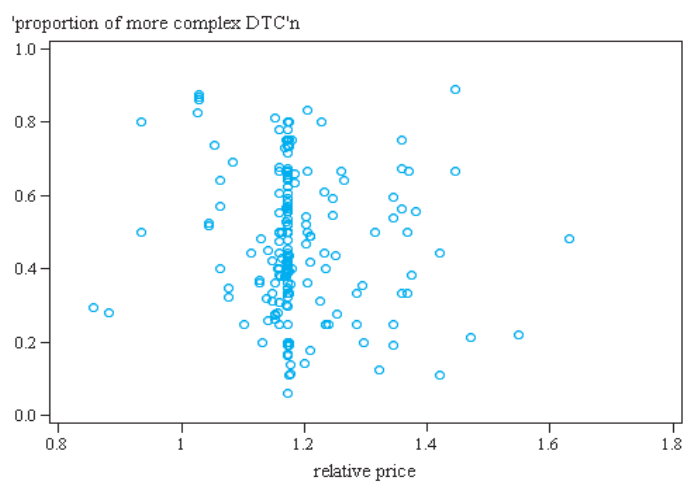

Figure 16: Relative prices for treating pelvic organ prolapse

\footnotetext{
${ }^{18}$ The dot on the far left side of this graph is an outlier from a very low price agreed for treating varicose veins as a complex outpatient treatment. The number of observations from this hospital is very low and is therefore automatically excluded from the regression analysis later in this paragraph.
} 
As can be seen from the graphs, for most diagnoses the relative price is often 1 . This price is preferred by the health insurer to eliminate the incentive for a hospital to upcode. By negotiating an average price based on more than one treatment setting, and thus also more than one DTC the risk of upcoding is already reduced (Hasaart et al., 2006). There are also relative prices less than 1: in these prices the fee of the medical specialist is added to the hospital component when calculating the average price. Overall the plots do not suggest a relation between relative price and upcoding and tend to cluster around a certain relative price; for example 1.18 for pelvic organ prolapse.

Although Figures 12 - 16 do not show a relation between relative price and upcoding, we have also performed a sixth logistic regression to analyze the statistical relation between the relative prices of the two DTCs and the chance that the most expensive DTC was chosen. The independent variable is the negotiated price recoded into a relative price (the price of the DTC with higher reimbursement/the price of the DTC with lower reimbursement) and we have again added our control variables. This model (Model 6) can be seen in Table 8.

Table 8: Overview Regression Model 6

Model 6
Logit indication more or less complex DTC =
Relative price of the DTC pair
2 dummies for hospital types 'top clinical' and 'university' in comparison with 'general'
Age of patient
2 dummies for years 2006 and 2007 compared to 2005
19 dummies for pharmaceutical cost groups
12 dummies for diagnostic cost groups


Table 9: Results Regression Model 6

\begin{tabular}{|c|c|c|}
\hline \multicolumn{2}{|l|}{ Diagnosis } & \multirow{2}{*}{$\begin{array}{l}\text { Model } 6 \\
\text { Not significant } \\
65 \\
p=0.01\end{array}$} \\
\hline Inguinal hernia & $\begin{array}{l}\text { Coefficient relative price } \\
\text { percent concordant }\end{array}$ & \\
\hline Diabetes mellitus & $\begin{array}{l}\text { Coefficient relative price } \\
\text { percent concordant }\end{array}$ & $\begin{array}{l}-0.9625 \\
64.8\end{array}$ \\
\hline Varicose veins treated by surgeon & $\begin{array}{l}\text { Coefficient relative price } \\
\text { percent concordant }\end{array}$ & $\begin{array}{l}\text { Not significant } \\
70.7\end{array}$ \\
\hline Varicose veins treated by dermatologist & $\begin{array}{l}\text { Coefficient relative price } \\
\text { percent concordant }\end{array}$ & $\begin{array}{l}0.9080 \\
62.6 \\
p=0.04\end{array}$ \\
\hline Pelvic organ prolapse & $\begin{array}{l}\text { Coefficient relative price } \\
\text { percent concordant }\end{array}$ & $\begin{array}{l}\text { Not significant } \\
54.5\end{array}$ \\
\hline
\end{tabular}

The results of the regression with relative price as explanatory variable for upcoding are inconclusive, as can be seen in Table 9. The two pairs in which upcoding leads to higher hospital costs (which we have labelled Type 2 upcoding), varicose veins treated by a surgeon and inguinal hernia, do not show a significant effect of relative price, and neither does pelvic organ prolapse. For varicose veins treated by a dermatologist and diabetes mellitus there does exist a significant relationship, but it is positive for varicose veins and negative for diabetes mellitus.

After this analysis we can answer the last explorative question:

- Can differences in the proportion of the DTC with the higher reimbursement between hospitals be explained by differences in relative prices?

Overall we conclude that the relative price does not seem to be related to upcoding.

\section{Discussion and Limitations}

Even though we have attempted to include as many control variables as possible, there may still be other factors explaining the choice of a more or less complex DTC. As we have analyzed only five pairs of DTCs we cannot draw conclusions for the whole segment of hospital care (these five pairs account for only $3 \%$ of total hospital care). A reason that relative price differences do not seem to impact the choice for upcoding in the Netherlands could be that differences in relative prices affect the profitability of the two DTCs only from the point of view of the hospital. The medical specialist is the one who actually makes the choice for a DTC and he or she receives a fixed fee depending on the DTC. Moreover, this fee is the same in all hospitals. Another explanation for a lack of response to relative price differences could be that even though the price difference is large, the absolute level of the 
price is high enough to discourage upcoding. It could also be that the difference in costs is higher than the difference in reimbursement.

Furthermore, we did not analyze the consequences of differences in the choice of a more or less complex DTC for the quality of care. The impact of the new hospital funding upon the quality of care is beyond the scope of our study.

\section{Conclusion}

Upcoding is a risk in every casemix system and hence also in the DTC system, in which a medical specialist might choose a higher DTC than is medically necessary. In this study we have performed an explorative analysis on the occurrence of upcoding in the DTC system. This analysis shows that large differences do exist in the proportion of DTCs with a higher reimbursement between hospitals for the five interchangeable pairs of DTCs studied in this chapter. After correcting for casemix differences, we still identify hospital-specific effects. These effects can be seen as a 'soft' indicator for upcoding. A pooled logit analysis shows that there are both specialtyspecific and hospital-specific effects, implying that the actors behind upcoding can be both hospital management and the medical specialist. Hospital effects cannot be explained based on the type or the size of the hospital. Further analysis shows that economic incentives are not the main drive behind upcoding. Relative price differences do not have a large effect on the decision to upcode. A policy implication of these results is that it is important for health insurers not only to negotiate over prices, but also to benchmark hospital billing behavior. 


\section{Annex}

\section{Regression Equations}

Model 1: Prob $\left(\mathrm{I}_{\mathrm{i}}\right)=\beta_{0}+\beta_{1} \times \mathrm{HT} 1+\beta_{2} \times \mathrm{HT} 2+\beta_{3} \times \mathrm{A}_{\mathrm{i}}+\beta_{4} \times \mathrm{Y} 1+\beta_{5} \times \mathrm{Y} 2+\beta_{6-24} \times \mathrm{FKG}_{\mathrm{i}}+\beta_{25-36} \times \mathrm{DKG}_{\mathrm{i}}$

Model 2: Prob $\left(\mathrm{I}_{\mathrm{i}}\right)=\beta_{0}+\beta_{1} \times \mathrm{HT} 1+\beta_{2} \times \mathrm{HT} 2+\beta_{3} \times \mathrm{A}_{\mathrm{i}}+\beta_{4} \times \mathrm{Y} 1+\beta_{5} \times \mathrm{Y} 2+\beta_{6-24} \times \mathrm{FKG}_{\mathrm{i}}+\beta_{25-36} \times \mathrm{DKG}_{\mathrm{i}}$ $+\beta_{37-74} \times H D$

Model 3: Prob $\left(I_{i j}\right)=\beta_{0}+\beta_{1} \times A_{i}+\beta_{2} Y 1+\beta_{3} \times Y 2+\beta_{4-22} \times F_{K G}+\beta_{23-34} \times D K G_{i}+\beta_{35-38} \times D T C$

Model 4: Prob $\left(I_{i j}\right)=\beta_{0}+\beta_{1} \times A_{i}+\beta_{2} Y 1+\beta_{3} \times Y 2+\beta_{4-22} \times F_{K G}+\beta_{23-34} \times D K G_{i}+\beta_{35-38} \times D T C+\beta_{39-76} \times H D$

Model 5: Prob $\left(I_{i j}\right)=\beta_{0}+\beta_{1} \times A_{i}+\beta_{2} Y 1+\beta_{3} \times Y 2+\beta_{4-22} \times F_{K G}+\beta_{23-34} \times D K G_{i}+\beta_{35-38} \times D T C+\beta_{39-76} \times H D+$ $\beta_{77-228} \times(D T C \times H D)$

Model 6: Prob $\left(\mathrm{I}_{\mathrm{i}}\right)=\beta_{0}+\beta_{1} \times \mathrm{RP}_{\mathrm{i}}+\beta_{2} \times \mathrm{HT} 1+\beta_{3} \times \mathrm{HT} 2+\beta_{4} \times \mathrm{A}+\beta_{5} \times \mathrm{Y} 1+\beta_{6} \times \mathrm{Y} 2+\beta_{7-25} \times \mathrm{FKG}_{\mathrm{i}}+$ $\beta_{26-37} \times D K G_{i}$

$\mathrm{I}_{\mathrm{i}}=$ Indication more or less complex DTC in hospital $\mathrm{i}$

HT = Dummies for type of hospital; HT1= top clinical hospitals and HT2 = university hospital

$A_{i}=$ Age of the patient in hospital $i$

$Y=$ Yeardummies; year $1=2006$ and year $2=2007$

$F K G_{i}=$ Dummies for Pharmaceutical Cost Groups per patient in hospital i

$D K G_{i}=$ Dummies for Diagnostic Cost Groups per patient in hospital i

$\mathrm{HD}=$ Dummies for individual hospitals

$\mathrm{I}_{\mathrm{ij}}=$ Indication more or less complex DTC in hospital i for diagnosis pair $\mathrm{j}$

DTC = Dummies for pair of DTC

$R_{i}=$ Relative price of more complex DTC versus less complex DTC for hospital $i$ 


\section{References}

Busse, R., Schreyögg, J. and Smith P.C. (2006). "Hospital case payment systems in Europe." Health Care Manag Sci 9(3): 211-213.

Carter, G. M., Newhouse, J.P. and Relles, D.A. (1990). "How much change in the Case Mix Index is DRG creep?" J Health Econ 9(4): 411-428.

DBC Onderhoud (2006), Vragen over DBC's, http://www.dbconderhoud.nl/client/1/?websiteid=$1 \&$ contentid=163\&hoofdid=103\&pagetitle=Wat_is_een_DBC?. Accessed 11 January 2008

DBC Onderhoud (2007), Instructies per specialisme: Interne Geneeskunde, Heelkunde, Dermatologie en Gynaecologie.

Douven, R. (2004). "Risk adjustment in the Netherlands: an analysis of insurers' health care expenditures." CPB Discussion Papers.

Dranove, D., Ramanarayanan, S. and Rao, H. (2006), "The Substance of Style: A Study of Small Area Variations in the Practice Styles of Ob/Gyn Specialists in Florida" Working Paper, Stanford University.

Evans, R. G. (2009). "There's No Reason for It, It's Just Our Policy." Healthcare Policy 5(2): 14.

Folmer, K. and E. Mot (2003). "Diagnosis and treatment combinations in Dutch hospitals." CPB Report.

Gupta Strategists (2010), "De donkere kamer van Damocles".

Hasaart, F., Pomp M., et al. (2006). "Financiële prikkels en behandelkeuzes in het nieuwe zorgstelsel." Economisch Statistische Berichten 91(4493): 424-426.

Klompenhouwer, J. and Vos-Deckers, G. (2005). De DBC-methodiek. Haarlemmerolie of een werkzaam geneesmiddel voor de Gezondheidszorg? iBMG. Rotterdam, Erasmus University. Master's thesis.

Maarse, H. and Bartholomée, Y. (2008). "Course and Impact of Market Reform in Dutch Health Care Uncertain." Intereconomics 43(4): 189-194.

Maarse, H. and Normand, C. (2009) "Market competition in European hospital care." Investing in hospitals of the future: 103. European Observatory on Health Systems and Policies.

Maarse, H. (2011). Markthervorming in de zorg. Maastricht, the Netherlands: Maastricht University.

McClellan, M. (1997). "Hospital reimbursement incentives: an empirical analysis." Journal of Economics \& Management Strategy 6(1): 91-128.

McGuire, T. G. (2000). "Physician agency." Handbook of health economics 1: 461-536. Elsevier.

Ministerie van Volksgezondheid, Welzijn en Sport (2006a) "Ruimte voor Betere Zorg", Kamerstuk CZ/IZ2695262

Ministerie van Volksgezondheid, Welzijn en Sport (2006b) "Regeling beleidsregels vereveningsbijdrage zorgverzekering 2006, Artikel 6. Verzekerdenraming 2006

Ministerie van Volksgezondheid, Welzijn en Sport (2007), "Waardering voor Betere Zorg", Kamerstuk CZ/TSZ/2771129

Psaty, B. M., Boineau, R., Kuller, L.H., and Luepker, R.V. (1999). "The potential costs of upcoding for heart failure in the United States." The American journal of cardiology 84(1): 108.

RVZ (2003), Marktwerking in de medisch specialistische zorg: achtergrondstudies, Academische en publieke functies op de markt.

Silverman, E. and Skinner, J.S. (2001). Are for-profit hospitals really different? Medicare upcoding and market structure, National Bureau of Economic Research Cambridge.

Simborg, D. W. (1981). "DRG creep." New England Journal of Medicine 304(26): 1602-1604.

Steinbusch, P. J. M., Oostenbrink, J.B., Zuurbier, J.J. and Schaepkens, J.M. (2007). "The risk of upcoding in casemix systems: A comparative study." Health Policy 81(2-3): 289-299.

Wennberg, J. and Gittelsohn, A. (1973). "Small area variations in health care delivery." Science 182(4117): 1102.

Wennberg, J. E., Barnes, A.B. and Zubkoff, M. (1982). "Professional uncertainty and the problem of supplier-induced demand" Social Science \& Medicine 16(7): 811-824.

Zorgverzekeraars Nederland. (2004). "DBC-inkoopgids 2005." Zeist: Elsevier Gezondheidszorg 


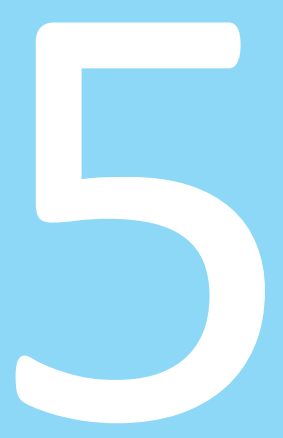

Fee-for-Service Use of the Dutch Casemix System of DTCS 


\section{Introduction}

In 2005 a new system for reimbursing hospital care, based on so-called Diagnosis Treatment Combinations $^{19}$ (DTCs), was introduced in the Netherlands. The new system involved a switch from a fixed hospital budget (Maarse, 1996) to a casemixbased funding model. DTCs were introduced not only to establish a clear link between hospital production and hospital revenues (budget), but also to stimulate competition in hospital care (Ministerie VWS, 2006).

A change in the hospital payment system implies a change in financial incentives for hospital management and medical specialists (McClellan, 1997; McGuire, 2000; Mot, 2002; Pauly, 1980). The purpose of this article is to investigate the impact of the new payment system on the strategic behavior of hospital management and medical specialists. We are particularly interested in a volume effect of the change in the hospital funding system defined here as overdeclaration. A DTC can be conceptualized as a complete package of care with a fixed price independent of the actual costs incurred. The hospital thus bears a financial risk in case a patient needs more care than the DTC covers. However, in some cases, the DTC-system allows the hospital to charge an additional DTC for the treatment of a single patient. There are rules and guidelines for each specialty on when the opening of a second DTC is warranted. The main rule is that a second DTC may be opened only if a patient needs $40 \%$ extra costs and/or effort in comparison with the average costs of the first DTC. This rule leaves room for discretionary decision making, since the costs and/or effort per DTC are not quantified. This leads to the risk that hospitals and medical specialists 'game' the DTC system in order to increase revenues or income (Putters, 2003). We call this behavior overdeclaration.

The funding of hospitals and medical specialists is complex in the Netherlands. With the introduction of the DTC system in 2005 , about $10 \%$ of hospital care was liberalized. In this liberalized part - called segment B - hospitals and insurers negotiate on volume and prices. There is no government-imposed budget ceiling. However, note that insurers and hospitals may agree on a maximum number of treatments. Extra production in segment $B$ will directly lead to extra revenues for the hospital and for the medical specialist involved. ${ }^{20}$ The size of the $B$ segment has been increased gradually from about $10 \%$ in 2005 to about $20 \%$ in 2008 and about $34 \%$ in $2009 .^{21}$

\footnotetext{
${ }^{19}$ DTC or Diagnose Behandelings Combinatie in Dutch.

${ }^{20}$ This observation applies only to self-employed specialists. Their revenues are related to their production. About 70 percent of medical specialists working in a hospital setting are self-employed. The remaining $30 \%$ are paid a salary by the hospital.

${ }^{21}$ According to Gupta (consultancy firm) the real size of the B segment has so far always been smaller: 4.1 $\%$ in $2005,6.0 \%$ in 2006, $5.9 \%$ in 2007, $13.3 \%$ in 2008 and $19.9 \%$ in 2009 (Gupta, 2010).
} 
For the rest of hospital care (segment A), DTCs are used only as an administrative tool and hospitals are still budgeted.

Every DTC consists of a cost component for the hospital and a fee component for the medical specialists based on a nationally set hourly tariff. Until 2008 the funding (payment) scheme for medical specialists was similar to that of hospitals: whereas extra production in segment $B$ generated extra income, extra production in segment A did not because there was a budget ceiling, called lump sum (a total budget per hospital for the payment of self-employed medical specialists). This lump-sum arrangement was abolished in 2008. Since then, medical specialists no longer work within a budget and are paid per DTC. The abolition of the lump sum budget led to huge budget overruns for hospitals in 2008 and 2009 and tariff cuts were introduced in 2010 (Ministerie VWS, 2010). There were two causes of the budget overruns. The first cause was that the abolition of the lump sum arrangement permitted medical specialists to increase their production beyond the budget limits that still applied for hospital care in the A segment. The second cause was that the fixed fee component in the DTC for the medical specialist was based on old time measurements many of which overestimated the time needed, especially for those specialties that had booked huge efficiency gains in time over the years, like medical microbiologists, anesthesiologists and radiologists. Given the institutional setting of hospital care we expect overdeclaration to occur more frequently in segment B over the period 2005-2007, since in that period extra revenues led directly to extra income for both hospitals and medical specialists. From 2008 onwards medical specialists have had an incentive for extra production for both segments. Hospitals are still funded through a budget and the incentives of medical specialists and hospitals are thus non-aligned in segment $A$.

An internal analysis by a health insurer showed that almost $5 \%$ of all DTCs billed could be classified as overdeclarations. In this study we use the results of this analysis to explore which factors influence the amount of overdeclaration. We explore whether the type of specialty, specific DTC characteristics, the ICT system used by the hospital for validation (see below) and hospital management affect the amount of overdeclaration. Such an analysis is of great importance because it may give us more insight into strategic behavior on the part of hospital and medical specialists. Preventing overdeclaration is of great importance for an effective cost control strategy of insurers; it also fits in perfectly with the government's cost control strategy.

\section{Diagnosis Treatment Combinations}

The definition of a DTC is the whole of activities (procedures) and services (consultations) of a hospital and medical specialists stemming from the demand for care for 
which the patient consults the specialist (DBC Onderhoud, 2006a). A DTC encompasses the activities and services of the complete care-process: from the first consultation of the medical specialist until the completion of the treatment in the hospital. Hospitals receive a payment for each DTC, and the payment varies with the type of treatment and casemix. One may speak of a casemix-based funding model. The price of a DTC is the 'total price' that a hospital receives for the whole package of care regardless of co-morbidity and age of the patient. A hospital thus bears a financial risk on a DTC if a patient's treatment costs more than the DTC price or tariff. To offset this risk, hospitals and/or specialists may be tempted to divide the care process into multiple (the same or separate) DTCs to increase revenues and avoid possible losses.

\section{Coding}

Every DTC has a unique performance code that reflects all information concerning that particular DTC. The performance code consists of 14 digits and contains information about the type of care, the demand for care, the diagnosis and type of treatment. Table 1 gives an example of a DTC.

Table 1: Performance code 01110005540031

\begin{tabular}{|c|c|c|}
\hline performance code & explanation & translation \\
\hline $01-\ldots-\ldots \ldots-\ldots$ & specialty & ophthalmology \\
\hline$\ldots-11-\ldots \ldots-\ldots \ldots$ & type of care & regular care \\
\hline$\ldots-.00-\ldots . . \ldots$ & demand for care & no defined demand for care \\
\hline$\ldots-\ldots-.0554-\ldots$. & diagnosis & cataract \\
\hline$\ldots-\ldots . . . .0031$ & treatment & treatment outpatient department \\
\hline
\end{tabular}

On first contact with a patient, the medical specialist decides which DTC should be assigned. The choice for a DTC is made by using a set of guidelines on how to open, close and determine the type of DTC. Every specialty has its own set of instructions, which are updated if necessary. These guidelines are made by the Dutch Healthcare Authority, together with the respective scientific association of the specific specialty. Though some differences between specialties exist, the general rule is as follows.

A new DTC is opened when (a) a patient visits a medical specialist for the first time with a new demand for care, (b) when the patient consults a specialist from a different specialty, (c) when a patient is transferred to another provider organization or (d) when a new demand for care arises that will lead to substantially more costs and effort. When a new demand for care arises, it is only possible to open a second DTC if the extra costs and/or effort of treatment are at least $40 \%$ as much as the initial DTC. If the extra costs and/or effort are less than $40 \%$ of the initial DTC, the 
treatment should be continued within the initial DTC. A DTC is closed when either the treatment has come to and end or after 365 days. After this initial DTC a DTC for chronic periodical check-up care can be opened to monitor the patient after treatment. In principle this follow-up care DTC has a length of 365 days. The rule about $40 \%$ costs and/or effort leaves room for discretionary decision making, since costs and effort have not been quantified per DTC (DBC Onderhoud, 2006b).

The DTC chosen can be adjusted during the process, for example if the treatment setting of a patient changes from outpatient treatment to clinical admission. In this case the initial DTC should be adjusted to the most serious treatment setting used by recoding the DTC. An often performed but not permitted strategy is to close the initial DTC, open a new DTC and bill for both DTCs. This strategy obviously contradicts the purpose of the DTC system and is for that reason forbidden by the instructions. This is an example of overdeclaration, the behavioral effect we aim to examine in this chapter.

The risk of overdeclaration is unique to the DTC system in comparison with other casemix-based systems. In the DRG system only one DRG is attributed to a patient per admission, even when the patient has received extra care due to complications or a new diagnosis. Co-morbidity and possible complications are taken into account when attributing a DRG to a patient; this forms a control system for the severity of the patient and reimbursement can be adjusted to the patient's condition.

Each DTC must be validated by the hospital before it can be sent to the insurer for billing. Hospitals use various types of ICT-validation modules to check the validity of a DTC. Unfortunately, however, overdeclaration is not detected by the (nationally obligated) validation module of the hospital. These modules check only whether a DTC code is correct by matching all the registered activities of a patient with the chosen DTC. An example of a DTC that will not be validated is a clinical DTC without an overnight stay registry. The only way to detect overdeclaration is to check the coherence with other DTCs. However, such a check is not required. The validation module is supplied by a number of different ICT systems and can differ per hospital. The ICT system used by the hospital may affect the amount of overdeclaration, because business rules around the opening and closing of DTCs can be built into the validation module. An example of overdeclaration caused by an ITC system is explained in the data section, when we discuss which DTCs are included in our analysis. 


\section{Overdeclaration}

Multiple DTCs per patient can occur in two different ways: the first option is that multiple DTCs are open at the same time, which is referred to as parallel DTCs. The second option is that DTCs are opened and closed shortly after each other; this is referred to as serial DTCs. According to the instructions it is possible to bill multiple DTCs per patient, for example in the case of chronic care or if continued monitoring is necessary. However, there is reason to assume that billing multiple DTCs per patient is often unwarranted. In this case the casemix-based reimbursement system is in fact used as a type of fee-for-service system, which is not in accordance with the intentions of the new payment system.

In order to detect overdeclaration, an algorithm was built by a Dutch consultancy firm (CHS) which assesses all DTCs billed, and which in the case of multiple DTCs per patient examines whether the declaration of the second (or even third and fourth) DTC is warranted or not. These rules have been further fine-tuned for parallel and serial DTCs and for different types of care with specific exceptions per specialty. Parallel DTCs can occur in three main forms. Both DTCs can run exactly parallel: their beginning dates and end dates are the same. We refer to this type of parallelism as Type 1 . Type 2 is DTCs that have the same beginning date but a different end date and Type 3 is DTCs that have both different beginning and end dates. See Table 2 for a visual overview.

Table 2: The four types of overdeclaration

Parallel Type 1 Parallel Type 2 Serial

This algorithm determines the parallel DTCs based on the two most important rules in the DTC system: 1 ) the second DTC is based on a new demand for care, i.e. the second DTC differs substantially from the first DTC, and 2) the second DTC leads to at least $40 \%$ more costs for the hospital and/or $40 \%$ more effort on the part of the medical specialist (CHS, 2007).

Serial DTCs are DTCs which are opened after each other (see also Table 2). The main two rules for determining unwarranted DTCs in this case are: 1) a second serial DTC is unwarranted if it concerns regular care, has the same main diagnosis ${ }^{22}$ and is opened one day after closing the first DTC, and 2) a second serial DTC is unwar-

\footnotetext{
${ }^{22}$ The main diagnosis is deduced from a further clustering of the four digit diagnosis, which differs per specialty.
} 
ranted if it concerns follow-up care, has the same main diagnosis and is opened within one year after opening the first DTC. The use of this algorithm is criticized by many hospitals. The '40\% extra costs and/or effort' rule in particular has led to a lot of discussion. The algorithm uses tariffs and prices as the determinant of the $40 \%$ extra costs and/or effort, since there is no information on either costs or effort. Even though there is a lot of criticism of this algorithm, the majority of hospitals have come to accept the results and have refunded payments received for unwarranted DTCs to the insurer involved. Table 3 gives some examples of both correct use of multiple DTCs per patient and overdeclaration in the DTC system.

\section{Literature}

A casemix system for reimbursing hospitals has its own set of financial incentives. A distinction can be made between five different types of incentives. The first incentive is to increase production to raise revenues/income. This incentive is present when there is no budget restraint or volume contract between insurers and hospitals (McGuire, 2000). The second incentive is to choose the most lucrative code even though this is not medically necessary. This phenomenon is called upcoding (Simborg, 1981; Silverman and Skinner, 2001; Psaty et al, 1999). The third incentive is to cream-skim for profitable patients. In this case the provider organization engages in patient selection to avoid high-risk patients (Ellis, 1998; Lakerveld, 2001). The fourth incentive is to lower the quality of care within a certain code in order to save costs (quality skimping) (Glaser, 1987; Siciliani and Hafsteinsdóttir, 2008; Busse, 2006). In this chapter we analyze a fifth type: overdeclaration. As described before, overdeclaration occurs when the DTC system is used as a kind of fee-forservice system (FFS). By opening unjustified parallel or serial DTCs, hospitals seek to increase their production and revenues (Custers, 2008; McClellan, 1997; Hellinger, 1996). 


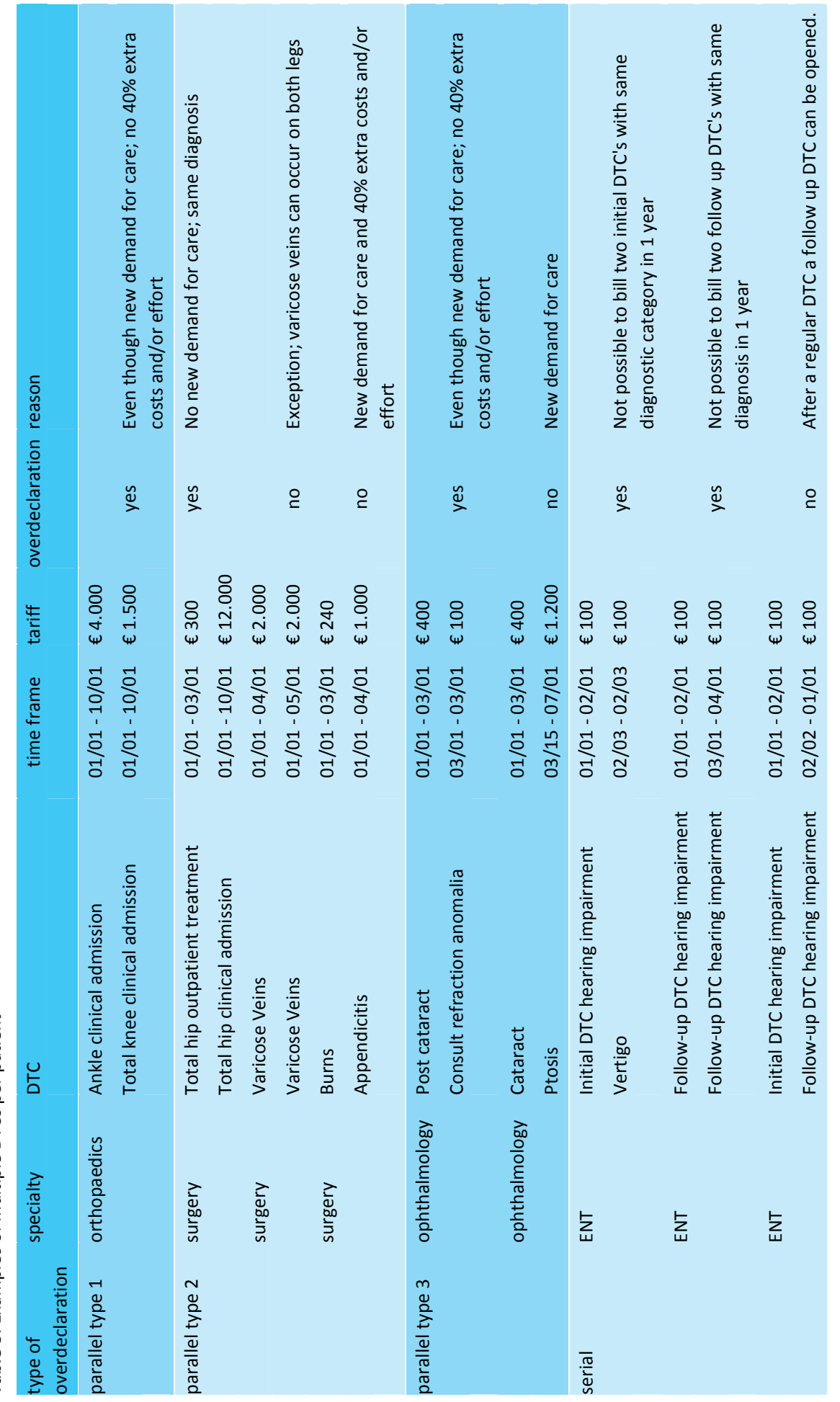


The purpose of using the DTC system as a FFS system is to avoid a financial loss per patient or to gain extra income from high cost patients. In a prospective per-case payment such as the DTC system, hospitals have an economic incentive to treat a more profitable case-mix (Aas, 1995). Treating high cost patients can be compensated for by billing for multiple DTCs. In theory, this type of behavior could offset the risk of cream skimming. It is plausible to assume that unclear or multiinterpretable coding guidelines offering hospitals and specialists some discretionary room increase the risk of overdeclaration. Because of this room for discretion, hospitals may even believe that their coding behavior is justified.

Earlier research on overdeclaration in the DTC system has concluded that differences exist in 'declaration culture' between hospitals. This research also mentioned the guidelines' lack of clarity as the main cause for overdeclaration. When hospitals were confronted with possible cases of fraud, they argued that they had not clearly understood the rules and guidelines on what is and is not warranted in the DTC system (Bruins Slot et al., 2008).

The degree to which hospitals and specialists react to incentives is influenced by various factors. One factor can be the profit status of a hospital. Research has shown that for-profit hospitals engage more in strategic behavior such as upcoding (Silverman and Skinner, 2001). The salary structure of the physician also influences behavior: medical specialists who are paid on a fee-for-service basis (about 70 percent of the specialists in Dutch hospitals) are expected to produce more medical services relative to their salaried colleagues (Pomp and Hasaart, 2009). Variations in treatment intensity have been studied extensively by Wennberg, who attributes these differences to differences in practice style between physicians or hospitals, after having corrected for demand factors influencing the difference. An example is the difference in incidence of tonsillectomy in the US, which appeared to be three times higher in a specific region in comparison with its neighboring regions. These differences were attributed to differences in beliefs among physicians concerning the indications for, and efficacy of the procedure (Wennberg and Gittelsohn, 1973; Wennberg et al., 1982). Research by Dranove describes regional variations that are caused by differences in treatment style, which depend on where the physician was educated (Dranove et al., 2006).

Financial incentives embedded in funding schemes influence treatment. However, the clustering of behavior or practice style within a region that has the same reimbursement system also indicates 'strongly that physicians' preferences are formed within, and respond to, a local culture.' (Evans, 2009). 


\section{Data}

We used the data of a large health insurance company that operates mainly in the south of the Netherlands and has a market share of approximately $15 \%$ of the Dutch population. The insurer makes use of a module created by a consultancy firm (DubDec3, CHS) as a tool for health insurers to detect unwarranted DTCs, with the aim of reclaiming the costs involved from hospitals. The algorithm to determine the amount of overdeclaration was used on all declarations from 2005, 2006, 2007 and 2008, billed until July 2009, from 100 Dutch hospitals. We used the outcomes of the algorithm to analyze the concept of overdeclaration. To avoid overestimating the amount of overdeclaration due to start-up problems of the DTC system, we excluded the year 2005 from our analysis. We computed for each hospital, for each specialty and for each year the percentage of unwarranted DTCs (see Box 1).

Box 1: Percentage of overdeclaration:

Percentage of overdeclaration $=$ number of unwarranted DTCS for specialty $X$ in hospital $Y$ in year $Z$ number of billed DTCS for specialty $X$ in hospital $Y$ in year $Z$

Many unwarranted DTCs are administrative errors, like an overlap of one day between an initial DTC and a follow-up DTC. This is an example of the ICT system causing overdeclaration, which we mentioned earlier. Even though these DTCs were technically wrong and could be considered as overdeclarations, we have excluded them from our dataset in order to get a more appropriate view of overdeclaration.

Table 4 shows the amount of overdeclaration for the years 2006, 2007 and 2008. This amount is the sum of both the hospital component and the fee component of the medical specialist; i.e. the total amount billed to the health insurer.

Table 4: Overdeclaration in 2006, 2007 and 2008:

\begin{tabular}{|lrrr|} 
& total & Overdeclaration & percentage unwarranted DTCS \\
\hline Number of DTCs & $5,821,623$ & 285,117 & $4.8 \%$ \\
\hline Costs of DTCs & $5,798,175,323$ & $196,820,512$ & $3.4 \%$ \\
\hline
\end{tabular}

The percentage of overdeclaration increases between 2006 and 2007, and decreases in 2008, as can be seen in Graph 1. It is remarkable that the amount of overdeclaration decreased in 2008, since the abolishment of the lump sum arrangement reinforced the medical specialists' incentive for strategic behavior. An explanation for this finding may be that the amount of overdeclaration for 2008 is underestimated here, since our data was collected only until July 2009, at which 
point not all DTCs from 2008 had been billed. A second and more fundamental explanation may be that overdeclaration should be understood as a transitional problem due to the introduction of the DTC system, and it might be expected to decrease or even disappear once all players know the exact rules of the game.

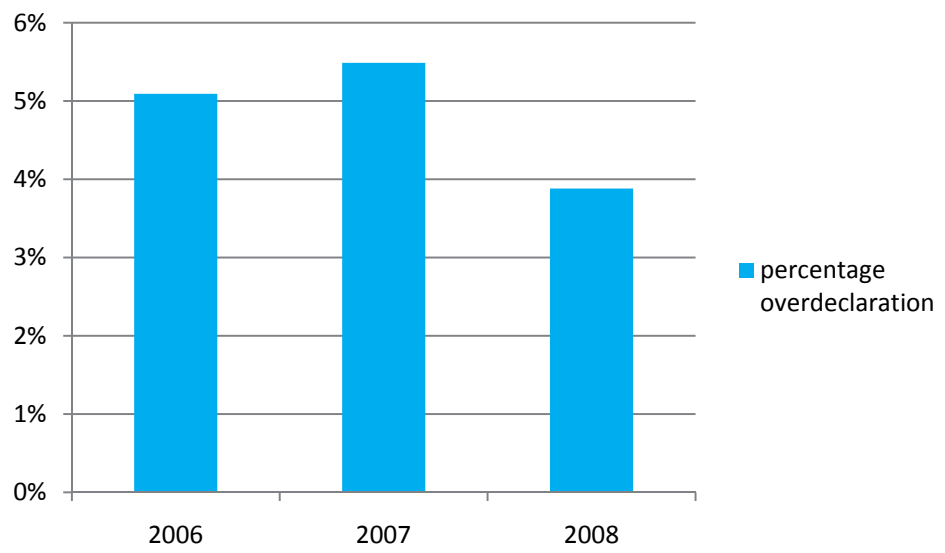

Graph 1: Percentage of overdeclaration per year

The amount of overdeclaration varies between specialties, between hospitals and even between specialties within hospitals, as can be seen from Graphs 2 and 3. All percentages shown in the graphs are summarized percentages for all three analyzed years. Graph 2 shows that the percentage of overdeclaration (defined above as the number of unwarranted DTCs for specialty $X$ in hospital $Y$ in year $Z$, divided by the number of DTCs billed for specialty $X$ in hospital $Y$ in year $Z$ ) varies from $0.10 \%$ for clinical genetics to $9 \%$ for cardiology. This variation can be caused partly by differences in the discretionary room in the instructions. For example, the instructions for cardiology contain specific rules on serial DTCs concerning angina pectoris. Unfortunately, we cannot attribute the observed variations in Graph 2 to differences in type of specialty, like surgical or non-surgical. 


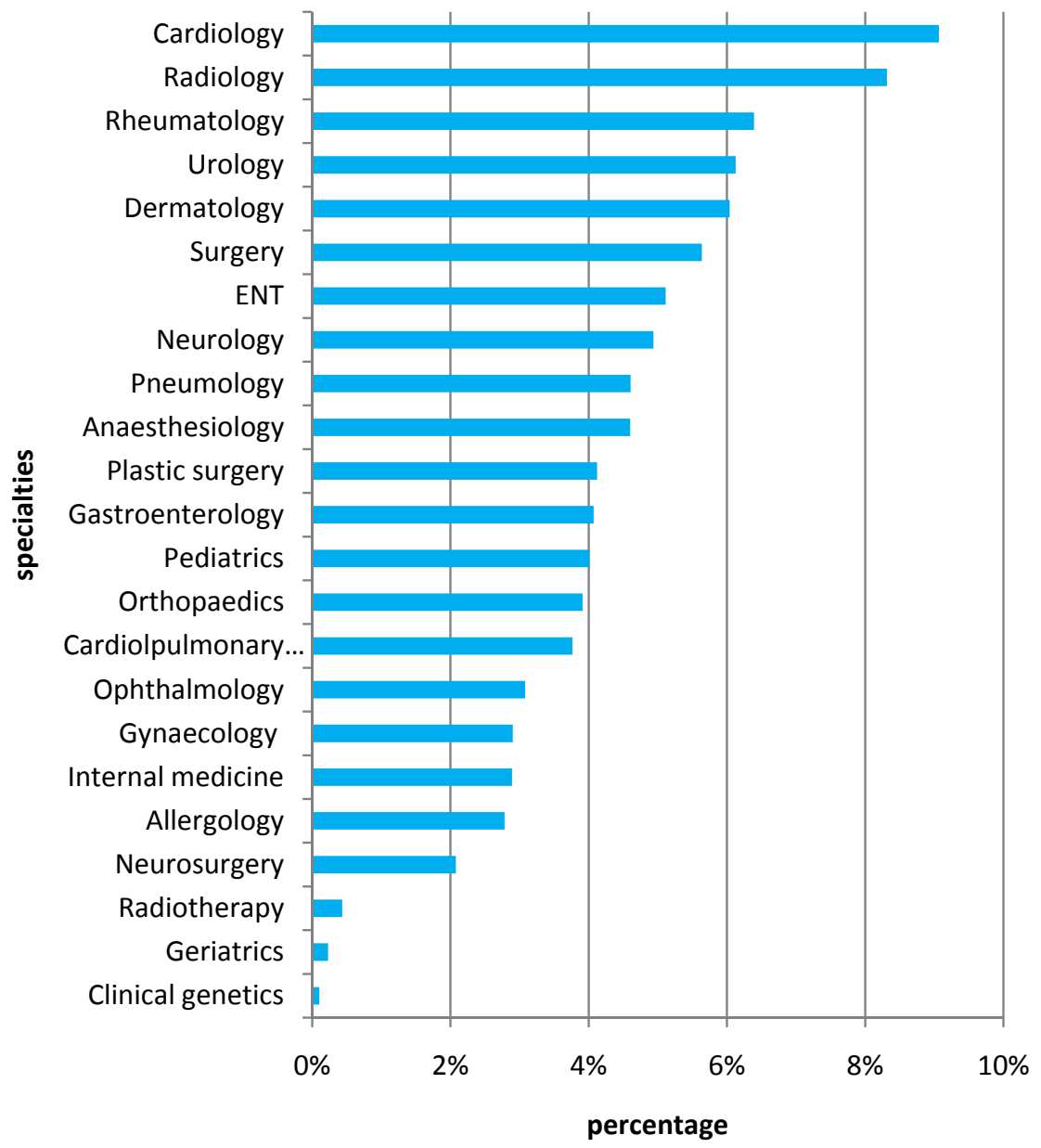

Graph 2: Variation between specialties

Graph 3 demonstrates a very large variation between hospitals. The percentage of unwarranted DTCs ranges from almost 0 percent to 20 percent. Even though we have not yet corrected these percentages for casemix differences between the hospitals, the variation is so large that we expect that this variation will still exist after correcting for these differences; this is an indication of hospital-specific effects. 


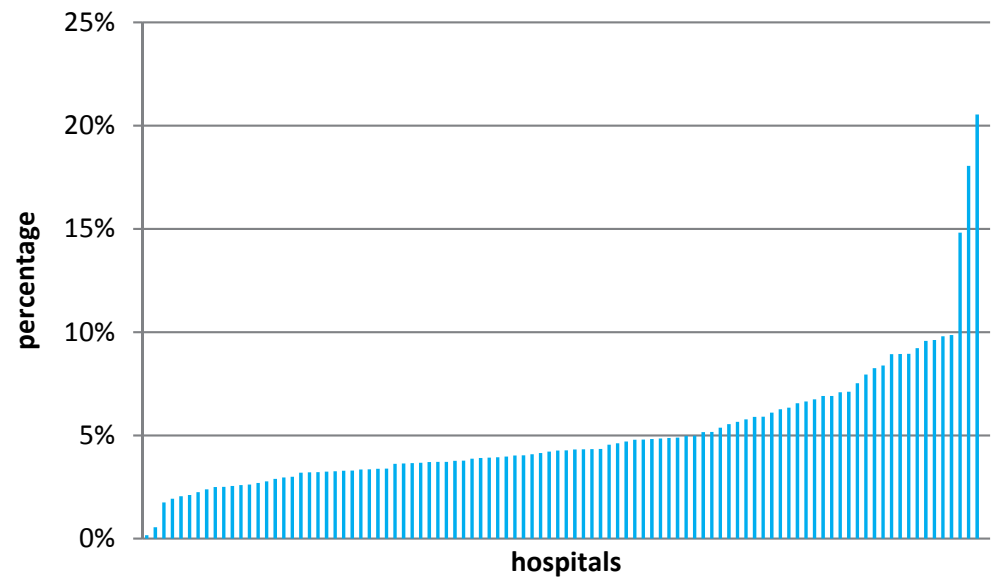

Graph 3: Variation between hospitals

We also see large variation between specialties within a hospital that does not always correspond to the variations between specialties for all hospitals combined. Therefore we analyzed if there is also large variation from the average percentages of overdeclaration per specialty within a specific hospital. For this purpose we scored the percentages of overdeclaration per specialty per hospital as either higher or lower than the average percentage of that specialty. Graph 4 shows how often a specialty in a hospital scores above average on the percentage of overdeclaration. We see that that $40 \%$ of the hospitals have scores below the average for all their specialties regarding unwarranted declarations. This suggests that hospital-specific effects at least partly determine the percentage of overdeclaration.

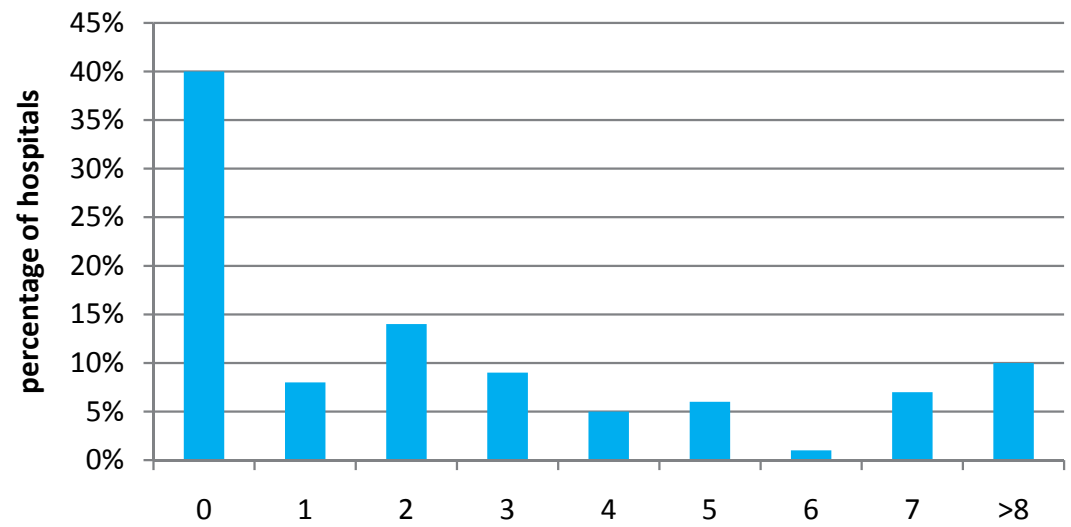

Graph 4: Scoring of hospitals based on number of incidences in the category 'above average percentage of overdeclaration':

In the next paragraph we will analyze whether there are significant hospital- and/or specialty specifc effects that explain the varation in the amount of overdeclaration. 


\section{Further analysis}

The descriptive statistics show large variation between both hospitals and specialties in the amount of overdeclaration. Apart from hospital-specific or specialtyspecific effects, it could also be the case that other factors play a role. The type of ITC system a hospital uses for validation could affect the amount of overdeclaration. Moreover, the amount of overdeclaration in segment B can be expected to occur because of the direct link between production, revenue and income in this segment. The type of care of the DTC (initial or follow-up care) may also influence the likelihood of overdeclaration.

To analyze which of all these factors explain the variation in overdeclaration, we performed a set of multiple regressions to control for differences in patient characteristics between hospitals. Furthermore, we added, one by one, the factors that we expected might influence the amount of overdeclaration. Our dependent variable, the amount of overdeclaration, is defined in box 1 as the number of unwarranted DTCs for specialty $X$ in hospital $Y$ in year $Z$ divided by the number of DTCs billed for specialty $X$ in hospital $Y$ in year $Z$.

As control variables we include: age and sex of the patient and a proxy for comorbidity. To estimate co-morbidity we included the percentage of patients who were in either one of the 20 pharmaceutical or one of the 13 diagnostic cost-groups in the year previous to the DTC. These cost groups are also used as cost estimators in the calculations of risk adjustment schemes (Douven, 2004; Ministerie VWS, 2007). Apart from the control variables, we further include two time dummies (dummy year $1=2007$ and dummy year $2=2008$, in comparison with 2006).

We start with a basic model with only control variables:

Model 1: Amount of overdeclaration $=\beta_{0}+\beta_{1} \times$ dummy year $1+\beta 2 \times$ dummy year $2+\beta_{3} \times$ age of patient $+\beta_{4} \times$ sex of patient $+\beta_{5} \times$ percentage of patients with FKG + $\beta_{6} \times$ percentage of patients with a DKG

In Table 4, six additional regression models are shown; Models 2-5 are extensions of Model 1 and Models 6 and 7 combine variables used in Models 2-5. The full equations of these models can be found in the annex.

In Model 2 we add two DTC characteristics: the segment ( $1=B$ segment, $0=A$ segment). We expect that overdeclaration will happen more often in segment $B$ because of the direct link with extra income in segment B. Furthermore, we add type of care ( $1=$ follow-up care, $0=$ initial care) to see if overdeclaration differs significantly per type of care. 
In Model 3 we add specialty dummies. We already inferred from the descriptive statistics that the amount of overdeclaration differs per specialty.

In Model 4 we add dummies for the six main ICT systems used in hospitals. The ICT system may have an influence on the amount of overdeclaration, since the opening and closing of DTCs can also be computerized.

In Model 5 we add dummies for all 98 hospitals $^{23}$ to test for hospital-specific effects.

Model 6 is a combination of Models 3 and 5, in which we add both the specialty and the hospital dummies.

Model 7 is a combination of Models 4 and 6 in which we also add the ICT system dummies.

Table 5 gives an overview of the seven regression models. Unfortunately the number of observations in our dataset does not allow us to regress the full model (with interaction terms between hospitals and specialties) which makes it impossible to detect hospital-specific versus specialty-specific effects within a hospital.

To test whether there are indeed hospital-specific, specialty-specific, ICT-specific and DTC characteristic-specific effects we perform F tests between the nested models, to see whether the added variables contribute significantly to the explanatory power of the model. If, for example, Model 3 shows a significant improvement over Model 1 , we can conclude that there are specialty-specific effects that determine the percentage of overdeclaration.

Table 5: Overview of regression models

\begin{tabular}{ll}
\hline Model & Variables \\
\hline Model 2 & Controls + DTC characteristics \\
\hline Model 3 & Controls + specialty dummies \\
\hline Model 4 & Controls + ICT system dummies \\
\hline Model 5 & Controls + hospital dummies \\
\hline Model 6 & Controls + hospital dummies + specialty dummies \\
\hline Model 7 & Controls + hospital dummies + specialty dummies +DTC characteristics \\
\hline
\end{tabular}

\footnotetext{
${ }^{23}$ Only hospitals with more than 1000 declarations have been included in our analysis.
} 


\section{Results}

Table 6 shows the results from the seven regressions. It can be seen that we have 3,969 observations for each model, with at least 6 control variables in every model and up to 124 added variables in Model 7.

All $\mathrm{F}$ tests (see Table 7) indicate a significant extra effect of the added variables. The last model, number 7 , has the highest R square (43\%) and is (based on the F test) our preferred model. This implies that there are statistically significant hospital effects in the amount of overdeclaration. This result can be interpreted as empirical evidence of the fact that, as a strategic response to the DTC-system, overdeclaration differs between hospitals.

The specialty dummies also add significantly to the explanatory power of the model, and also in combination with the hospital dummies. These findings are an indicator of specialty-specific effects. An explanation of this result could be that overdeclaration is easier to perform in some specialties. Unfortunately, our data do not allow us to explore this further.

The ICT systems do have some explanatory power, but the $2 \%$ increase in $\mathrm{R}^{2}$ is much less than the effects of specialty or hospital, which add $13 \%$ and $22 \%$ respectively to the $R^{2}$. However, there is an ICT system-specific effect, also in combination with the specialty and hospital dummies.

The DTC characteristics do not add a lot of explanatory power to the model, even though the effect is statistically significant. It increases the $R^{2}$ by less than $1 \%$. Model 7 indicates that overdeclaration occurs more frequently in follow-up DTCs than in initial DTCs. The dummy for segments A and B did show a positive and significant coefficient in Model 2, indicating that overdeclaration occurs more often in segment $B$, but after adding the hospital dummies this effect is no longer significant. 


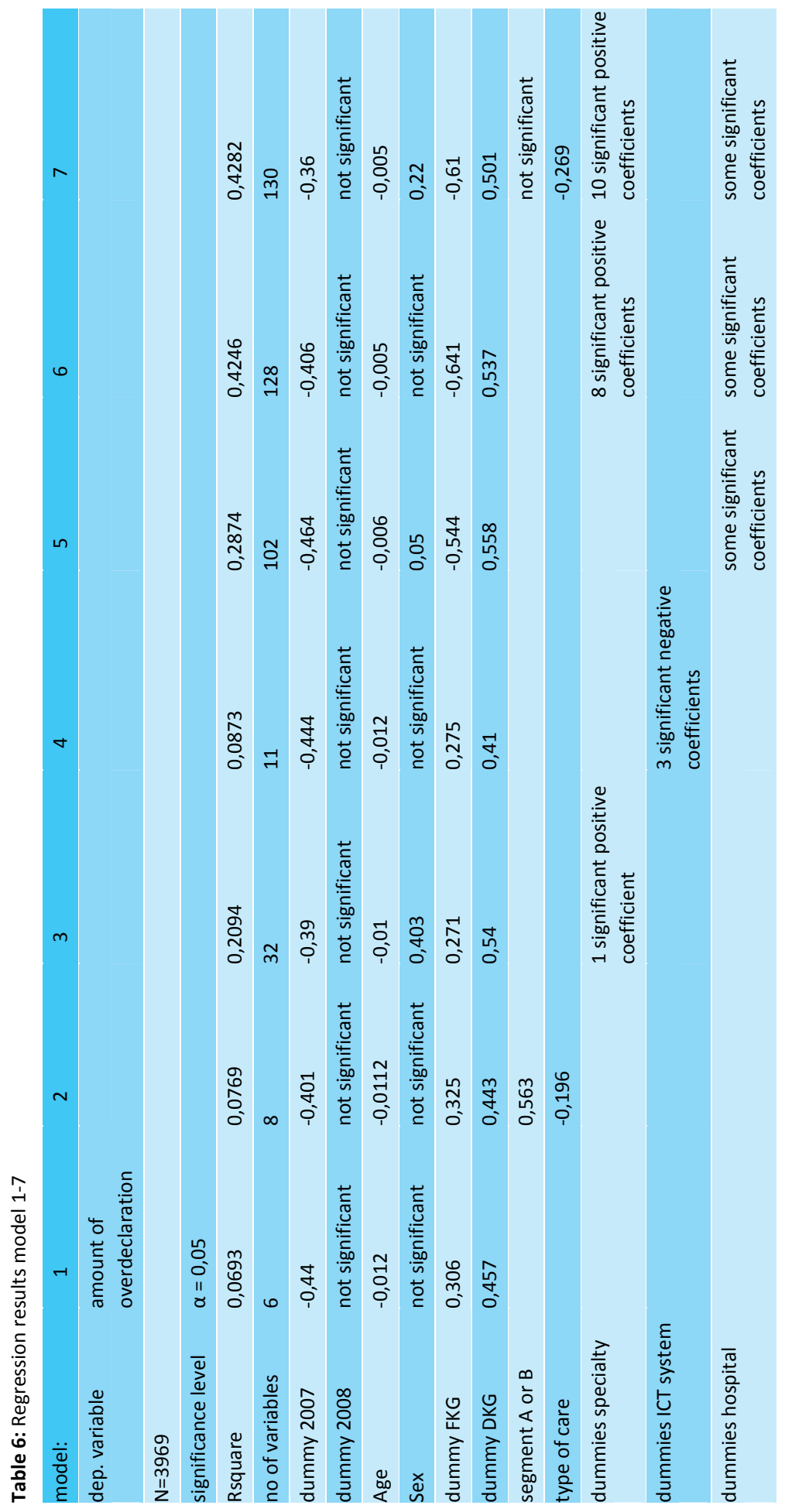


Table 7: $\mathrm{F}$ tests between models:

\begin{tabular}{|llll|}
\hline F test & F values & & critical value \\
\hline Models 1 to 2 & 16.30 & $>$ & 3.00 \\
\hline Models 1 to 3 & 26.83 & $>$ & 1.17 \\
\hline Models 1 to 4 & 15.61 & $>$ & 2.10 \\
\hline Models 1 to 5 & 12.33 & $>$ & 1.25 \\
\hline Models 1 to 6 & 19.44 & $>$ & 1.25 \\
\hline Models 1 to 7 & 19.43 & $>$ & 1.25 \\
\hline Models 4 to 6 & 14.96 & $>$ & 1.25 \\
\hline Models 5 to 6 & 35.22 & $>$ & 1.50 \\
\hline Models 5 to 7 & 33.75 & 12.08 & $>48$ \\
\hline Models 6 to 7 & 12.05 & 2.61 \\
\hline
\end{tabular}

In conclusion, we find that the amount of overdeclaration is caused by unobserved hospital-specific and specialty-specific effects. To a lesser degree, overdeclaration can also be explained by the type of ICT system used and the type of care. Contrary to what we expected, overdeclaration does not happen more in segment B of hospital care, in which there is a direct link between production and income, than in segment A. An interesting finding is that there are wide differences in overdeclaration between hospitals, suggesting differences in declaration 'culture' between hospitals. Unfortunately, our analysis does not allow us to draw conclusions on what these differences specifically entail. A second interesting finding is that the variation in overdeclaration between specialties is also large. Whether this variation also exists within hospitals and is related to a specific department within each hospital or whether it is the same for all hospitals and, as a consequence, inherent in either the DTC system or the professional community, cannot be concluded from our analysis.

\section{Limitations}

There are some possible limitations to this study. First, we have used data only from the years 2006-2008. As a consequence, we cannot determine whether overdeclaration is only a transitional problem of the DTC system or a structural problem. A second limitation is that our data stem only form the southern part of the Netherlands. However, we have no reason to assume that the amount of overdeclaration is different in other regions of the Netherlands. A final limitation is that, although we have controlled for differences in patient populations between hospitals as much as possible, the control can never be perfect. Therefore there may be an omitted variable bias in our estimations. 
We have used an algorithm (DubDec3, CHS) used by health insurers, with which many hospitals disagree. The ' $40 \%$ extra costs and/or effort' rule has led to a lot of discussion between the parties. The algorithm uses tariffs and prices as a proxy of the $40 \%$ extra costs and/or effort, since there is no information on either costs or effort. The algorithm is controversial among hospitals.

The policy implications of this chapter are potentially substantial, since the total amount of overdeclaration could come to over 1 billion Euros (extrapolating from 196 million in our data, representing $15 \%$ of the market). Since part of hospital care is still budgeted (segment $A$ ), all cost overruns will be offset by expenditure cuts in hospital care imposed by the government. However, as segment B increases in size it becomes ever more important for health insurers (and the government) to monitor costs in general and strategic behavior by means of overdeclaration in particular. The introduction of the renewed DTC system (DOT consisting of 3,000 newly defined care products) will reduce the risk of overdeclaration described in this chapter, because medical specialists no longer choose the DTCs themselves. Instead, the new care products will be deduced from registered activities. However, the registration of activities will bring back the risk of the traditional fee-for-service system. This risk is slightly tempered, because it is not so much more services that will lead to more expensive care products, but specifically more complex services which will make the 'grouper' assign a more expensive care product. The risk of upcoding thus also exists within the DOT system.

\section{Conclusion}

In this chapter we found empirical evidence of declaration defined as overdeclaration. Overdeclaration can be understood as a form of strategic behavior by medical specialists and hospitals to increase revenues and offset the financial risk of highcost patients. The amount of overdeclaration varies greatly per hospital and per specialty. Regression analyses suggest that unobserved hospital-specific effects explain the variation in the amount of overdeclaration. There are also specialtyspecific effects that cause variation in overdeclaration. 


\section{Annex}

\section{Regression Equations}

Model 1: $A_{i j k}=\beta_{0}+\beta_{1} \times Y 1+\beta 2 \times Y 2+\beta_{3} \times A g_{i j k}+\beta_{4} \times S_{i j k}+\beta_{5} \times F K G_{i j k}+\beta_{6} \times D K G_{i j k}$

Model 2: $A_{i j k}=\beta_{0}+\beta_{1} \times Y 1+\beta 2 \times Y 2+\beta_{3} \times A g_{i j k}+\beta_{4} \times S_{i j k}+\beta_{5} \times F K G_{i j k}+\beta_{6} \times D K G_{i j k}+\beta_{7} \times E_{i j k}+\beta_{8} \times T_{0} C_{i j k}$

Model 3: $A_{i j k}=\beta_{0}+\beta_{1} \times Y 1+\beta 2 \times Y 2+\beta_{3} \times A g_{i j k}+\beta_{4} \times S_{i j k}+\beta_{5} \times F G_{i j k}+\beta_{6} \times D K G_{i j k}+\beta_{7-30} \times S p$

Model 4: $A_{i j k}=\beta_{0}+\beta_{1} \times Y 1+\beta 2 \times Y 2+\beta_{3} \times A g_{i j k}+\beta_{4} \times S_{i j k}+\beta_{5} \times F G_{i j k}+\beta_{6} \times D K G_{i j k}+\beta_{7-9} \times I C T$

Model 5: $A_{i j k}=\beta_{0}+\beta_{1} \times Y 1+\beta 2 \times Y 2+\beta_{3} \times A g_{i j k}+\beta_{4} \times S_{i j k}+\beta_{5} \times F G_{i j k}+\beta_{6} \times D K G_{i j k}+\beta_{7-104} \times H D$

Model 6: $A_{i j k}=\beta_{0}+\beta_{1} \times Y 1+\beta 2 \times Y 2+\beta_{3} \times A g_{i j k}+\beta_{4} \times S_{i j k}+\beta_{5} \times F G_{i j k}+\beta_{6} \times D K G_{i j k}+\beta_{7-104} \times H D+$ $\beta_{105-128} \times \mathrm{Sp}$

Model 6: $A_{i j k}=\beta_{0}+\beta_{1} \times Y 1+\beta 2 \times Y 2+\beta_{3} \times A g_{i j k}+\beta_{4} \times S_{i j k}+\beta_{5} \times F K G_{i j k}+\beta_{6} \times D K G_{i j k}+\beta_{7-104} \times H D+\beta_{105-128} \times$ $\mathrm{Sp}+\beta_{129} \times \mathrm{SE}_{\mathrm{ijk}}+\beta_{130} \times \mathrm{ToC}_{\mathrm{ijk}}$

$\mathrm{A}_{\mathrm{ijk}}=$ Amount of overdeclaration in hospital $\mathrm{i}$ for specialty $\mathrm{j}$ and year $\mathrm{k}$

$Y=$ Year; $Y 1=2007$ and $Y 2=2008$

$\mathrm{Ag}_{\mathrm{ijk}}=$ Average age of the patients in hospital $\mathrm{i}$ for specialty $\mathrm{j}$ and year $\mathrm{k}$

$\mathrm{S}_{\mathrm{ijk}}=$ Percentage of men in hospital $\mathrm{i}$ for specialty $\mathrm{j}$ and year $\mathrm{k}$

$\mathrm{FKG}_{\mathrm{ijk}}=$ Percentage of patients with FKG group in hospital $\mathrm{i}$ for specialty $\mathrm{j}$ and year $\mathrm{k}$

$D K G_{i j k}=$ Percentage of patients with DKG group in hospital $i$ for specialty $j$ and year $k$

$\mathrm{S}_{\mathrm{ijk}}=$ Percentage of unjustly billed DTCs that are from Segment B in hospital $\mathrm{i}$ for specialty $\mathrm{j}$ and year $\mathrm{k}$

$\mathrm{ToC}_{\mathrm{ijk}}=$ Percentage of regular care in hospital $\mathrm{i}$ for specialty $\mathrm{j}$ and year $\mathrm{k}$

$\mathrm{Sp}=$ Specialty

ICT $=$ ICT system in hospital $\mathrm{i}$

$\mathrm{HD}=98$ dummies for the different hospitals 


\section{References}

Aas, I. (1995). "Incentives and financing methods." Health policy 34(3): 205.

Bruins Slot, H. a. M., P. and Geerdes. B. (2008). "Veel switchen ondergraaft het DBC-systeem." Medisch Contact(03): 114-117.

Busse, R., Schreyögg, J. and Smith P.C. (2006). "Hospital case payment systems in Europe." Health Care Manag Sci 9(3): 211-213.

CHS Solutions for Control Information (2009), Cope Health Care Solutions - DubDeC algoritme

Custers, T., J. Hurley, et al. (2008). "Selecting effective incentive structures in health care: A decision framework to support health care purchasers in finding the right incentives to drive performance." BMC health services research 8(1): 66.

DBC Onderhoud (2006a), Vragen over DBC's, http://www.dbconderhoud.nl/client/1/?websiteid=$1 \&$ contentid=163\&hoofdid=103\&pagetitle=Wat_is_een_DBC?. Accessed 11 January 2008

DBC Onderhoud (2006b). Instructies per specialisme. http://www.dbconderhoud.nl/Rechts/Documenten/DBCs-ziekenhuizen-en-zelfstandige-klinieken/Meest-recente-documenten/Instructiesper-specialisme accessed October 102006.

Douven, R. (2004). "Risk adjustment in the Netherlands: an analysis of insurers' health care expenditures." CPB Discussion Papers.

Dranove, D., Ramanarayanan, S. and Rao, H. (2006), "The Substance of Style: A Study of Small Area Variations in the Practice Styles of Ob/Gyn Specialists in Florida" Working Paper, Stanford University.

Ellis, R. P. (1998). "Creaming, skimping and dumping: provider competition on the intensive and extensive margins." J Health Econ 17(5): 537-555.

Evans, R. G. (2009). "There's No Reason for It, It's Just Our Policy." Healthcare Policy 5(2): 14.

Glaser, W. A. (1987). Paying the hospital: the organization, dynamics, and effects of differing financial arrangements, San Francisco: Jossey-Bass.

Gupta Strategists (2010), "De donkere kamer van Damocles".

Hellinger, F. J. (1996). "The impact of financial incentives on physician behavior in managed care plans: a review of the evidence." Medical Care Research and Review 53(3): 294.

Lakerveld, A. (2001). Financiële Prikkels in het DBC-systeem: upcoding en afwenteling. Maastricht, University of Maastricht. Master's thesis

Maarse, H. (1996). "Fixed budgets in the inpatient sector: the case of the Netherlands." Fixing Health Budgets: Experience from Europe and North America. Chichester: John Wiley.

McClellan, M. (1997). "Hospital reimbursement incentives: an empirical analysis." Journal of Economics \& Management Strategy 6(1): 91-128.

McGuire, T. G. (2000). "Physician agency." Handbook of health economics 1: 461-536. Elsevier.

Ministerie van Volksgezondheid, Welzijn en Sport (2006). "Regeling beleidsregels vereveningsbijdrage zorgverzekering 2006, Artikel 6. Verzekerdenraming 2006

Ministerie van Volksgezondheid, Welzijn en Sport (2007), "Waardering voor Betere Zorg", Kamerstuk CZ/TSZ/2771129

Ministerie van Volksgezondheid, Welzijn en Sport (2010), "Waardering voor Betere Zorg IV", Kamerstuk CZ/TSZ 2973145

Mot, E. (2002). Paying the medical specialist: the eternal puzzle: experiments in the Netherlands. Amsterdam: University of Amsterdam. Dissertation

Pauly, M. (1980). Physician information and the consumer's demand for care, University of Chicago Press.

Pomp, M. and Hasaart, F. (2009). Aanbodgeïnduceerde vraag in de ziekenhuismarkt, Economisch Statistische Berichten 94(4562):372-374

Psaty, B. M., Boineau, R., Kuller, L.H., and Luepker, R.V. (1999). "The potential costs of upcoding for heart failure in the United States." The American journal of cardiology 84(1): 108.

Putters, K. (2003). "Anticiperen op marktwerking, achtergrondstudie 03/03." Raad voor de Volksgezondheid en Zorg (RBZ): Zoetermeer.

Siciliani, L. and Hafsteinsdóttir, E.J.G. (2008). "DRG prospective payment system: refine or not refine?" Discussion Papers. 08/29 Department of Economics. York: University of York. 
Silverman, E. and Skinner, J.S. (2001). Are for-profit hospitals really different? Medicare upcoding and market structure, National Bureau of Economic Research Cambridge.

Simborg, D. W. (1981). "DRG creep." New England Journal of Medicine 304(26): 1602-1604.

Wennberg, J. and Gittelsohn, A. (1973). "Small area variations in health care delivery." Science 182(4117): 1102.

Wennberg, J. E., Barnes, A.B. and Zubkoff, M. (1982). "Professional uncertainty and the problem of supplier-induced demand" Social Science \& Medicine 16(7): 811-824. 


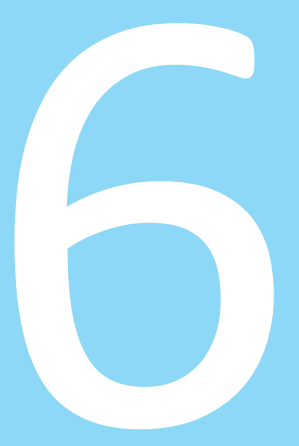

\section{Supplier-induced Demand in Dutch Hospital Care: Evidence from a natural experiment}

"There was once a cholera epidemic in Russia. The government, in an effort to stem the disease, sent doctors to the worst-affected areas. The peasants in the province of $S$ discussed the situation and observed a very high correlation between the number of doctors in a given area and the incidence of cholera in that area. Relying on this hard fact, they rose and murdered their doctors." (Auster and Oaxaca, 1981, $p$. 328). 


\section{Introduction}

Are doctors able to influence the demand for their services? This question has occupied health economists for decades, but convincing answers are still lacking. This unfortunate state of affairs is due to the difficulty of separating cause and effect. The quotation above this article gives a graphic illustration of the problem: observed regional correlations between the number of doctors and the number of treatments may be caused by regional differences in population characteristics (in particular health status) rather than by supply inducement. Failure to control adequately for health status may then lead to unwarranted causal inference.

In this chapter we exploit two unique features of the Dutch hospital sector in order to solve this problem of separating cause and effect:

1. The coexistence of salaried and self-employed doctors in the Netherlands. Only self-employed doctors have an incentive to induce demand, so regional variation in the number of salaried doctors can be used to control for exogenous regional variation in demand, i.e. variation in demand that is not due to supply inducement. If we then find that the number of self-employed doctors has a positive effect on the number of treatments over and above the effect of the doctors in general (salaried and self-employed), we conclude that the evidence points to supply inducement.

2. The co-existence of a regulated segment of hospital care and a liberalized segment. In the regulated segment, self-employed doctors were until very recently being paid on the basis of a fixed annual lump sum, independent of volume of care. Hence, in this segment there was no incentive for supply inducement. In contrast, in the liberalized segment self-employed doctors received a (regulated) fee per treatment. Provided this fee was high enough, doctors in this segment of hospital care may have felt an incentive to induce demand for their services.

The paper is structured as follows. The next section summarizes the literature on supplier-induced demand. Section 3 outlines our empirical strategy. A description of our data follows in Section 4. Section 5 presents the estimation results. Section 6 concludes.

\section{Literature review: supplier-induced demand in hospital care}

For the literature review we took as starting point the systematic review by KCE (2008). In addition we performed a literature search in JSTOR and Google scholar with keywords 'demand inducement' and 'induced demand'. The empirical literature on supplier-induced demand (SID) contains two types of studies: 
1. Studies based on regional differences in the number of doctors per capita. In this type of study, SID is measured by the correlation between doctors per capita and treatments per capita, after controlling for exogenous variation in demand, e.g. due to demographic differences.

2. Studies based on the effect of prices on treatment intensity. If lowering prices leads to a higher probability of being treated, then this is interpreted as evidence in favor of SID.

We identified seven studies of the first type, listed in Table 1. All seven studies report a positive and significant relationship between the number of doctors per capita and the number of treatments per capita. Five of these seven papers report results in the form of elasticities. The absolute value of this elasticity ranges from 0.1 to 0.3 , implying that a 1 percent increase in the number of doctors per capita results in a 1 to 3 percent increase in the number of treatments per capita.

Table 1: Type 1 studies: regional differences in doctors per capita

\begin{tabular}{|c|c|c|}
\hline \multicolumn{2}{|c|}{ NoType of doctor } & Author(s) + title \\
\hline 1 & $\begin{array}{l}\text { General practitioners } \\
\text { and specialists }\end{array}$ & $\begin{array}{l}\text { Jürges H. (2007). Health insurance status and physician-induced demand for } \\
\text { medical services in Germany: new evidence from combined district and indi- } \\
\text { vidual level data, Discussion paper of the Mannheim Research Institute for } \\
\text { Economics of Aging. }\end{array}$ \\
\hline 2 & $\begin{array}{l}\text { General practitioners } \\
\text { and specialists }\end{array}$ & $\begin{array}{l}\text { Delattre, E. and B. Dormont (2003). "Fixed fees and physician induced demand: } \\
\text { A panel data study on French physicians." Health Economics 12(9): 741-754. }\end{array}$ \\
\hline 3 & Surgeons & $\begin{array}{l}\text { Fuchs, V. R. (1978). The supply of surgeons and the demand for operations, } \\
\text { National Bureau of Economic Research Cambridge. }\end{array}$ \\
\hline 4 & Gynecologists & $\begin{array}{l}\text { Gruber, J. and M. Owings (1994). Physician financial incentives and cesarean } \\
\text { section delivery, National Bureau of Economic Research Cambridge, Mass., } \\
\text { USA. }\end{array}$ \\
\hline 5 & Surgeons & $\begin{array}{l}\text { Escarce, J. J. (1992). "Explaining the association between surgeon supply and } \\
\text { utilization." Inquiry: a journal of medical care organization, provision and } \\
\text { financing 29(4): } 403 \text {. }\end{array}$ \\
\hline 6 & Surgeons & $\begin{array}{l}\text { Cromwell, J. and J. B. Mitchell (1986). "Physician-induced demand for surgery* } \\
\text { 1." J Health Econ 5(4): 293-313. }\end{array}$ \\
\hline & Various specialties & $\begin{array}{l}\text { KCE Belgisch Federaal Kenniscentrum voor de Gezondheidszorg (2008), Het } \\
\text { aanbod van artsen in België: Huidige toestand en toekomstige uitdagingen, KCE } \\
\text { reports } 72\end{array}$ \\
\hline
\end{tabular}

In these studies, differences in regional demand due to unobserved exogenous differences in demand are taken into account by various instrumental variable techniques. However, as Dranove and Wehner (1994) have shown, the instruments typically used in these studies are often correlated with unobserved differences in demand. As a consequence, the estimated coefficients for the number of doctors per capita may be biased. 
We found six studies of the second type, listed in Table 2. Again, each of these studies reports results that point to SID. However, in most of these studies the price decline was largest in urban areas, where demand may have grown faster than in rural areas due to urban-rural differences in (changes in) population health. This offers an alternative explanation for the observed negative correlation between price and volume of care. Only one of the studies in Table 2 seems to be immune to this criticism. This is the study by Kantarevic et al. (2008). This Canadian study finds that an exogenous fall in income raises the supply of services per doctor. The elasticity ranges from -0.05 to -0.1 , implying that an exogenous fall in income of 1 percent results in an increase of treatment volume per doctor of 0.05 to 0.1 percent.

Table 2: Type 2 studies: effect of price changes on treatments per doctor

\begin{tabular}{|c|c|c|}
\hline No & Specialism & Author(s) + title \\
\hline 8 & $\begin{array}{l}\text { Surgeons, internists, } \\
\text { primary care doctors }\end{array}$ & $\begin{array}{l}\text { Rice, T. H. (1983). "The impact of changing Medicare reimbursement rates } \\
\text { on physician-induced demand." Medical Care: } 803-815 \text {. }\end{array}$ \\
\hline 9 & Various specialties & $\begin{array}{l}\text { Nguyen, N. X. and F. W. Derrick (1997). "Physician behavioral response to a } \\
\text { Medicare price reduction." Health Services Research 32(3): } 283 .\end{array}$ \\
\hline 10 & Various specialties & $\begin{array}{l}\text { Tai Seale, M., T. H. Rice, et al. (1998). "Volume responses to medicare } \\
\text { payment reductions with multiple payers: a test of the McGuire-Pauly } \\
\text { model." Health Economics 7(3): 199-219. }\end{array}$ \\
\hline 11 & Cardiosurgeons & $\begin{array}{l}\text { Yip, W. C. (1998). "Physician response to Medicare fee reductions: changes } \\
\text { in the volume of coronary artery bypass graft (CABG) surgeries in the } \\
\text { Medicare and private sectors." J Health Econ } 17(6): 675-699 \text {. }\end{array}$ \\
\hline 12 & Various specialties & $\begin{array}{l}\text { Rizzo, J. A. and R. J. Zeckhauser (2003). "Reference incomes, loss aversion, } \\
\text { and physician behavior." Review of Economics and Statistics 85(4): 909- } \\
922 .\end{array}$ \\
\hline 13 & Various specialties & $\begin{array}{l}\text { Kantarevic, J., B. Kralj, et al. (2008). "Income effects and physician labour } \\
\text { supply: evidence from the threshold system in Ontario." Canadian Journal } \\
\text { of Economics/Revue canadienne d'économique 41(4): 1262-1284. }\end{array}$ \\
\hline
\end{tabular}

\section{Empirical Strategy}

As pointed out in the introduction, our empirical strategy is to exploit two unique institutional features of the Dutch hospital sector:

1. The fact that in some hospitals doctors work for a fixed salary while in other hospitals doctors are self-employed. Within a hospital, employment status often differs between specialties: in some specialties doctors may be salaried while in others they may be self-employed.

2. The fact that for treatments in the liberalized segment of hospital care, selfemployed doctors were paid on a per case basis while in the regulated segment payment is based on a fixed budget, irrespective of volume. 
Each of these two institutional features constitutes a natural experiment, allowing us to adjust for regional differences in demand that are caused by (unobserved) patient characteristics.

Thus our identifying assumption is that only self-employed doctors have an incentive to manipulate supply in order to raise income, and that this incentive exists only in the liberalized segment of hospital care. We implement this strategy by estimating the following equation:

$\mathrm{T}_{\mathrm{ij}}=\mathrm{c}+\alpha_{\mathrm{ii}} \cdot \mathrm{Dsa}_{\mathrm{kj}}+\alpha_{2 \mathrm{i}} \cdot \operatorname{Dse}_{\mathrm{kj}}+\alpha_{3 \mathrm{i}} \cdot \operatorname{Dac}_{\mathrm{kj}}+\beta \mathrm{Z}_{\mathrm{j}}+\varepsilon_{\mathrm{ij}(1)}$

Where:

$\mathrm{T}_{\mathrm{ij}}=$ Treatment i per capita in region $\mathrm{j}$

$D_{s a_{\mathrm{kj}}}=$ Salaried doctors in speciality $\mathrm{k}$ in region $\mathrm{j}$, in full time equivalents

Dse $_{\mathrm{kj}}=$ Self-employed doctors in speciality $\mathrm{k}$ in region $\mathrm{j}$, in full time equivalents

$\operatorname{Dac}_{\mathrm{kj}}=$ Doctors in academic hospitals in speciality $\mathrm{k}$ in region $\mathrm{j}$, in full time equivalents

$Z_{j}=A$ vector of control variables in region $j$

Note that Equation 1 includes a separate category for doctors working in academic hospitals. All doctors working in academic hospitals are salaried. Since they are also involved in research and graduate education, the number of treatments per doctor is lower for these doctors than for doctors working in non-academic hospitals. To allow for this we included the separate category of academic doctors.

\section{Data}

We estimated Equation 1 on data for geographical regions, defined on the basis of 3-digit postal codes. There are 802 of these regions. To avoid outliers due to random variation, postal codes with population less than 10000 were omitted. This reduced the number of observations to 502 .

\section{Number of medical specialists per hospital (2005)}

Until 2006, hospitals were under a legal obligation to report the number of specialists, including full time equivalents, type of speciality, salaried versus self-employed, to the Dutch Ministry of Health. The Ministry provided us with access to these data for 87 Dutch hospitals. In order to obtain the number of doctors in each of our geographical regions as defined by postal code, we linked the number of doctors on the basis of the share of region $\mathrm{j}$ in total turnover in hospital $\mathrm{i}$. For example, if region $\mathrm{X}$ accounts for $30 \%$ of hospital i's total turnover, then $30 \%$ of all doctors working in hospital $\mathrm{i}$ are imputed to region $\mathrm{X}$. Repeating this procedure for all 87 hospitals included in the analysis, we obtain the total number of doctors in region X. Table 3 presents descriptive statistics for the number of doctors per region for a number of treatments/specialties. 
Table 3: Doctors per capita per region: means and standard deviations, 2006

\begin{tabular}{|c|c|c|c|c|c|c|}
\hline \multirow[b]{2}{*}{ Treatment / specialty } & \multicolumn{3}{|c|}{$\begin{array}{l}\text { Mean doctors } \\
\text { per capita } \\
\text { x } 1000000\end{array}$} & \multicolumn{3}{|c|}{$\begin{array}{l}\text { Standard deviation doctors } \\
\text { per capita } \\
\text { x } 1000000\end{array}$} \\
\hline & Academic & Salaried & $\begin{array}{c}\text { Self- } \\
\text { employed }\end{array}$ & Academic & Salaried & $\begin{array}{c}\text { Self- } \\
\text { employed }\end{array}$ \\
\hline Tonsillectomy, ENT & 4.2 & 1.7 & 16.3 & 3.9 & 4.3 & 5.1 \\
\hline Inguinal hernia, surgery & 14.2 & 4.4 & 36.8 & 13.9 & 9.8 & 11.0 \\
\hline Varicose veins, surgery & 14.2 & 4.4 & 36.8 & 13.9 & 9.8 & 11.0 \\
\hline Varicose veins, dermatology & 3.3 & 2.0 & 12.0 & 3.4 & 4.5 & 4.5 \\
\hline Cataract, ophtalmology & 4.1 & 2.3 & 18.8 & 4.6 & 5.4 & 7.1 \\
\hline Spinal hernia, neurology & 7.3 & 6.4 & 19.2 & 6.7 & 10.1 & 9.4 \\
\hline Spinal hernia, neurosurgery & 3.1 & 0.9 & 2.4 & 3.1 & 2.7 & 3.5 \\
\hline Spinal hernia, orthopedic surgery & 3.8 & 1.8 & 21.4 & 3.7 & 4.9 & 7.1 \\
\hline Hip replacement, orthopedic surgery & 3.8 & 1.8 & 21.4 & 3.7 & 4.9 & 7.1 \\
\hline Knee replacement, orthopedic surgery & 3.8 & 1.8 & 21.4 & 3.7 & 4.9 & 7.1 \\
\hline Mamma reduction, pl. surgery & 2.1 & 0.4 & 6.4 & 1.9 & 1.2 & 4.3 \\
\hline Kidney stones, urology & 3.3 & 1.2 & 13.1 & 3.3 & 3.2 & 4.1 \\
\hline Urethra stones, urology & 3.3 & 1.2 & 13.1 & 3.3 & 3.2 & 4.1 \\
\hline Urninary incontinence, gynecology & 8.8 & 18.6 & 28.7 & 8.0 & 13.7 & 11.1 \\
\hline Appendectomy, surgery & 14.2 & 4.4 & 36.8 & 13.9 & 9.8 & 11.0 \\
\hline Colon cancer, surgery & 14.2 & 4.4 & 36.8 & 13.9 & 9.8 & 11.0 \\
\hline Prostate cancer, urology & 3.3 & 1.2 & 13.1 & 3.3 & 3.2 & 4.1 \\
\hline Bladder cancer, urology & 3.3 & 1.2 & 13.1 & 3.3 & 3.2 & 4.1 \\
\hline Kidney cancer, urology & 3.3 & 1.2 & 13.1 & 3.3 & 3.2 & 4.1 \\
\hline
\end{tabular}

\section{Treatments per capita (2006 and 2007)}

We use data on the individual use of health services from a database that covers all Dutch health insurers. This database is maintained by Vektis, a consultancy, for the purpose of the risk equalization fund in which all Dutch health insurers are required (by law) to participate.

\section{Individual control variable (2006 and 2007)}

The database also contains information on characteristics of the insured, such as age, gender and chronic disease. Furthermore, the database contains individual data on so-called diagnostic cost groups and pharmaceutical cost groups. These concepts are used to classify the insured into groups according to expected healthcare costs, on the basis of diagnosis and use of medicine. These various types of data have been used to construct the individual control variables included in the 
vector $Z$. These individual controls will capture some of the regional variation in health status.

\section{Additional control variables per postal code (2004 -2007)}

In addition to the individual control variables, we also included regional control variables on household composition, income, house prices (to capture socioeconomic differences) and urbanization. These data are available from Statistics Netherlands (CBS). Table 4 presents descriptive statistics for these control variables.

Table 4: Summary statistics for control variables

\begin{tabular}{|c|c|c|}
\hline Variable & Mean & Standard deviation \\
\hline$\%$ One person households & 24.3 & 8.1 \\
\hline Monthly income x 1000 Euros & 2.0 & 0.3 \\
\hline Value of house $x 1000$ Euros & 150.9 & 43.4 \\
\hline$\%$ male & 49.8 & 3.0 \\
\hline$\%$ diagnostic test order by family doctor & 3.7 & 4.0 \\
\hline$\%$ diagnostic cost group & 2.4 & 0.5 \\
\hline$\%$ severe pharmaceutical cost group & 1.3 & 0.2 \\
\hline$\%$ moderate pharmaceutical cost group & 10.6 & 1.6 \\
\hline$\%$ 0-4 years old & 5.6 & 1.4 \\
\hline$\% 5-9$ years old & 6.2 & 1.4 \\
\hline$\% 10-14$ years old & 6.1 & 1.4 \\
\hline$\% 15-19$ years old & 6.2 & 1.4 \\
\hline$\% 20-24$ years old & 5.6 & 3.8 \\
\hline$\% 25-29$ years old & 5.2 & 2.0 \\
\hline$\% 30-34$ yeas old & 5.8 & 1.6 \\
\hline$\% 40-44$ years old & 7.9 & 1.9 \\
\hline$\% 45-49$ years old & 7.6 & 1.2 \\
\hline$\% 50-54$ years old & 7.1 & 1.2 \\
\hline$\% 55-59$ years old & 7.2 & 2.1 \\
\hline$\% 60-64$ years old & 6.1 & 1.5 \\
\hline$\%$ 65-69 years old & 4.7 & 1.1 \\
\hline$\% 70-74$ years old & 3.8 & 1.0 \\
\hline$\% 75-79$ years old & 3.1 & 0.9 \\
\hline$\% 80-84$ years old & 2.2 & 0.8 \\
\hline$\% 85-89$ years old & 1.3 & 0.7 \\
\hline$\% 90+$ & 0.6 & 0.4 \\
\hline Urbanisation (index 1-5) & 3.9 & 1.1 \\
\hline
\end{tabular}




\section{Linking doctors to regions}

In order to calculate the number of doctors per capita in each of the 502 regions included in the analysis, we must allocate the doctors to regions. This was done in the following manner: if region $X$ accounts for $10 \%$ of total revenue of hospital $Z$, then $10 \%$ of all doctors working in hospital $Z$ are allocated to region $X$. Summing over all hospitals gives the number of doctors per capita in each region.

\section{Treatments included}

Treatments included in the econometric analysis were selected on the basis of expert opinion. We asked specialists in the relevant areas for which treatments supply inducement would be a possibility. We also consulted physicians employed by health insurers. There was wide agreement on which treatments were 'at risk' for supply inducement. The candidate treatments thus selected are also in line with the treatments that have been studied in the literature on supply inducement.

In addition to these treatments in the liberalized segment of hospital care, we also included a number of treatments in the regulated segment of hospital care for which supply inducement would not be expected on a priori grounds. For these treatments, medical specialists were paid on the basis of a lump sum, set annually. The inclusion of these treatment serves the purpose of a check on our model, identifying assumptions and definition of regions. If we would find statistically effects of the number of doctors per capita on treatment intensity for these treatments, then this would point to an error in our model, identifying assumptions and/or definition of regions. Table 5 presents summary statistics for treatments included in our analysis. Between them, these treatments generated almost 900 million Euros in hospital revenue in 2007 , or roughly $5 \%$ of total hospital revenue.

\section{Estimation results}

Equation 1 was estimated separately for each of the treatment/specialty combinations listed in Table 5. Each equation was estimated with and without control variables, using ordinary least squares (OLS) as the estimation method. Table 6 presents the estimation results. For brevity we present only the coefficients for the variables of interest, the number of self-employed and salaried doctors per capita. Thus, for each of the estimated equations we report three coefficient estimates. 
Table 5: Number of treatments per capita, means and standard deviations, 2006

\begin{tabular}{|c|c|c|}
\hline Treatment + specialty & $\begin{array}{l}\text { Treatments per } \\
\text { capita } \\
\text { x } 1000\end{array}$ & $\begin{array}{l}\text { Standard deviation treatments } \\
\text { per capita } \\
\text { x } 1000\end{array}$ \\
\hline \multicolumn{3}{|c|}{ Treatments considered 'at risk' for inducement } \\
\hline Tonsillectomy, ENT & 3.6 & 1.4 \\
\hline Inguinal hernia, surgery & 1.8 & 0.9 \\
\hline Varicose veins, surgery & 1.6 & 0.9 \\
\hline Varicose veins, dermatology & 2.2 & 1.8 \\
\hline Cataract, ophthalmology & 8.0 & 2.6 \\
\hline Spinal hernia, neurology & 3.2 & 1.2 \\
\hline Spinal hernia, neurosurgery & 0.6 & 0.4 \\
\hline Spinal hernia, orthopaedic surgery & 0.2 & 0.2 \\
\hline Hip replacement, orthopaedic surgery & 1.5 & 0.7 \\
\hline Knee replacement, orthopaedic surgery & 1.9 & 0.9 \\
\hline Mamma reduction, plastic surgery & 0.3 & 0.2 \\
\hline Kidney stones, urology & 0.2 & 0.2 \\
\hline Urethra stones, urology & 0.2 & 0.2 \\
\hline Pelvic organ prolapse, gynaecology & 0.9 & 0.5 \\
\hline \multicolumn{3}{|l|}{ Control treatments } \\
\hline Appendectomy, surgery & 0.8 & 0.4 \\
\hline Colon cancer, surgery & 0.3 & 0.2 \\
\hline Prostate cancer, urology & 0.3 & 0.3 \\
\hline Bladder cancer, urology & 0.4 & 0.3 \\
\hline Kidney cancer, urology & 1.4 & 0.6 \\
\hline
\end{tabular}

In general, we find positive and significant coefficients for the number of doctors. In most cases the estimated coefficient is larger for self-employed doctors than for salaried doctors, as would be required in case of supply inducement. This remains true after including control variables. In a few cases (mamma reduction and pelvic organ prolapse) we find negative coefficients for salaried doctors. This implies that for some reason in regions with relatively many salaried doctors, the demand for these treatments is low. This points to an omitted variables problem (even after the inclusion of all the control variables listed in Table 4), and underscores the need to take these unobserved variables into account. As already pointed out, to account for the effects of unobserved variables we employ the difference between salaried and self-employed doctors. 
Table 6: Estimation results Equation 1

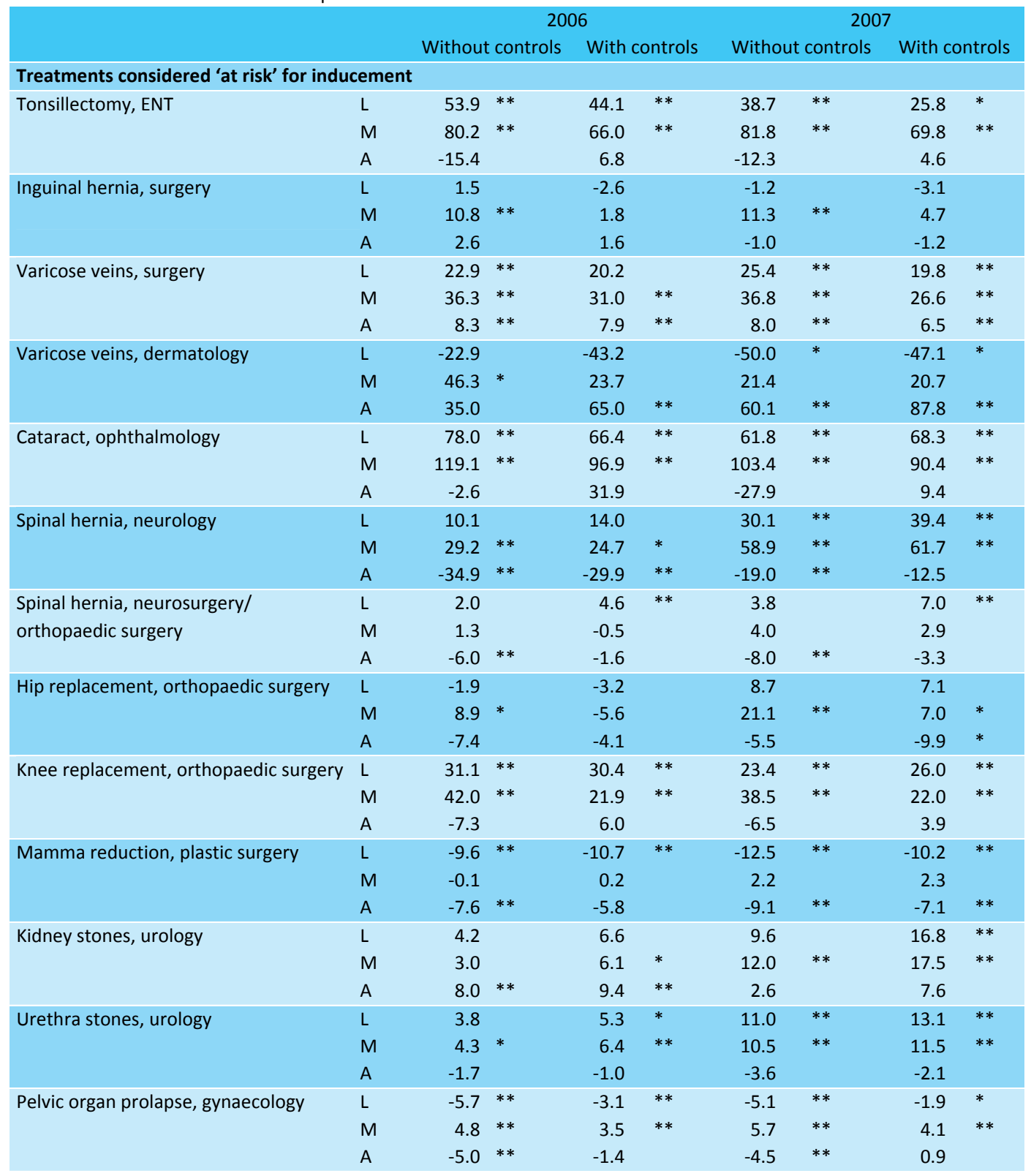




\begin{tabular}{|c|c|c|c|c|c|c|c|c|c|c|c|}
\hline & & & & & 20 & & & & 200 & & \\
\hline & & & & Without & controls & With & ontrols & Withol & controls & With c & trols \\
\hline Control tre & tm & & & & & & & & & & \\
\hline Appendect & & rgery & $\mathrm{L}$ & 1.3 & & 2.0 & & 1.4 & & 1.5 & \\
\hline & & & $M$ & 2.0 & & 2.1 & & 2.5 & & 2.1 & \\
\hline & & & $A$ & -1.6 & & 0.4 & & -1.2 & & 0.0 & \\
\hline Colon canc & & & $\mathrm{L}$ & 2.6 & $* *$ & 1.9 & & 1.7 & & 1.0 & \\
\hline & & & $M$ & 4.1 & $* *$ & 1.9 & & 3.8 & $* *$ & 2.5 & $* *$ \\
\hline & & & $A$ & 1.0 & & 1.0 & & 0.9 & & 0.8 & \\
\hline Prostate ca & icer & ology & $\mathrm{L}$ & -8.1 & * & -6.1 & & 6.7 & & 12.2 & $* *$ \\
\hline & & & $M$ & -1.2 & & -2.4 & & 13.5 & $* *$ & 14.4 & $* *$ \\
\hline & & & $A$ & -5.4 & & -7.1 & * & -4.8 & & -2.8 & \\
\hline Bladder ca & cer, & ology & $\mathrm{L}$ & -8.5 & $* *$ & -6.7 & & -2.2 & & 0.8 & \\
\hline & & & $M$ & -3.7 & & -4.0 & & 6.7 & & 4.2 & \\
\hline & & & $A$ & 1.7 & & 2.3 & & 0.3 & & 5.2 & \\
\hline Kidney can & er, & logy & $\mathrm{L}$ & 6.3 & & 5.4 & & 6.6 & & 8.8 & $*$ \\
\hline & & & $M$ & 15.4 & $* *$ & 12.3 & $* *$ & 10.9 & $* *$ & 10.6 & $* *$ \\
\hline & & & $A$ & 7.4 & $*$ & 10.3 & $* *$ & 1.8 & & 3.6 & \\
\hline L & & Sala & & & & & & & & & \\
\hline$M$ & $=$ & Self & & & & & & & & & \\
\hline$A$ & $=$ & Wor & $\mathrm{c} \mathrm{h}$ & & & & & & & & \\
\hline$*$ & sta & tically & & & & & & & & & \\
\hline$* *$ & sta & tically & & & & & & & & & \\
\hline
\end{tabular}

We used an F-test to assess the statistical significance of the positive difference between the estimated coefficients for self-employed and salaried doctors. The outcome of this test is reported in Table 7. In most cases, the difference is significant at the $5 \%$ level. Two of the five control treatments (where supply inducement was not expected) showed a positive difference between the estimated coefficients for self-employed and salaried doctors. However, the statistical significance of the difference drops substantially (in most cases to below 5\%) after including control variables. We conclude that these tests point to supply inducements for tonsillectomy, inguinal hernia, varicose veins, cataract, spinal hernia, mamma reduction and pelvic organ prolapse. 
Table 7: Significance test for difference between self-employed doctors and salaried doctors per capita ${ }^{a}$

\begin{tabular}{lllll}
\hline & \multicolumn{2}{c}{2006} & & \\
Treatment & Without controls & With controls & Without controls & With controls \\
\hline Treatments considered 'at risk' for inducement & & & 0.000 & 0.000 \\
\hline Tonsillectomy, ENT & 0.010 & 0.018 & 0.000 & 0.000 \\
\hline Inguinal hernia, surgery & 0.000 & 0.009 & 0.015 \\
\hline Varicose veins, surgery & 0.000 & 0.000 & 0.000 & 0.000 \\
\hline Varicose veins, dermatology & 0.000 & 0.000 & 0.000 & 0.000 \\
\hline Cataract, ophthalmology & 0.012 & 0.020 & 0.018 & 0.124 \\
\hline Spinal hernia, neurology & 0.001 & 0.070 & 0.000 & 0.000 \\
\hline Mamma reduction, plastic surgery & 0.032 & 0.032 & 0.000 & 0.003 \\
\hline Pelvic organ prolapse, gynecology & 0.000 & 0.000 & 0.000 & 0.000 \\
\hline Control treatments & & & & 0.612 \\
\hline Prostate cancer, urology & - & - & 0.062 & 0.578
\end{tabular}

${ }^{\mathrm{a}}$ The table contains $\mathrm{p}$-values from an F-test for equal coefficients.

In order to assess the size of the inducement effects implied by our estimation results, we used the estimated coefficients to compute elasticities (see Table 8). These elasticities measure the percentage increase in the number of treatments per capita as a consequence of raising the number of doctors per capita by $1 \%$. In line with our identifying assumption that salaried doctors will not engage in demand inducement, the calculated elasticities are based on the difference between the estimated coefficients for self-employed doctors and salaried doctors. These elasticities range from 0.1 to 0.25 , with an outlier of 0.36 for varicose veins treated by a dermatologist, implying that a 10 percent increase in the number of doctors per capita would raise the volume of care by $1-2.5$ percent.

Table 8: Elasticities

\begin{tabular}{lc|}
\hline Treatment & Elasticity \\
\hline Tonsillectomy & 0.10 \\
\hline Inguinal hernia & 0.09 \\
\hline Varicose veins, surgery & 0.24 \\
\hline Varicose veins, dermatology & 0.36 \\
\hline Cataract & 0.07 \\
\hline Spinal hernia neurologist & 0.06 \\
\hline Mamma reduction & 0.24 \\
\hline Pelvic organ prolapse & 0.22 \\
\hline
\end{tabular}




\section{Conclusions}

Our empirical analysis offers strong support for supplier-induced demand for the following treatments: tonsillectomy, inguinal hernia, varicose veins, cataract, spinal hernia, mamma reduction and pelvic organ prolapse. The estimation results imply an elasticity of between 0.1 and 0.25 , which is broadly in line with other estimates reported in the literature. This means that a 10 percent increase in the number of doctors per capita would raise the volume of care by $1-2.5$ percent. However, it does not follow that health expenditures would rise by the same percentage. It is even conceivable that raising the number of doctors could result in lower health expenditures. An increase in the supply of doctors may shift the bargaining position from doctors to health insurers, resulting in lower fees. Moreover, such a shift in bargaining positions may make it easier for health insurers to introduce measures aimed at containing spending, such as selective contracting, utilization review and partial capitation. 


\section{References}

Auster, R. D. and R. L. Oaxaca (1981). "Identification of supplier induced demand in the health care sector." Journal of Human Resources: 327-342.

Cromwell, J. and J. B. Mitchell (1986). "Physician-induced demand for surgery* 1." J Health Econ 5(4): 293-313.

Delattre, E. and B. Dormont (2003). "Fixed fees and physician induced demand: A panel data study on French physicians." Health Economics 12(9): 741-754.

Dranove, D. and P. Wehner (1994). "Physician-induced demand for childbirths." J Health Econ 13(1): 6173.

Escarce, J. J. (1992). "Explaining the association between surgeon supply and utilization." Inquiry: a journal of medical care organization, provision and financing 29(4): 403.

Fuchs, V. R. (1978). The supply of surgeons and the demand for operations, National Bureau of Economic Research Cambridge.

Gruber, J. and M. Owings (1994). Physician financial incentives and cesarean section delivery, National Bureau of Economic Research Cambridge, Mass., USA.

Jürges H. (2007). Health insurance status and physician-induced demand for medical services in Germany: new evidence from combined district and individual level data, Discussion paper of the Mannheim Research Institute for Economics of Aging.

Kantarevic, J., B. Kralj, et al. (2008). "Income effects and physician labour supply: evidence from the threshold system in Ontario." Canadian Journal of Economics/Revue canadienne d'économique 41(4): 1262-1284.

KCE Belgisch Federaal Kenniscentrum voor de Gezondheidszorg (2008), Het aanbod van artsen in België: Huidige toestand en toekomstige uitdagingen, KCE reports 72

Nguyen, N. X. and F. W. Derrick (1997). "Physician behavioral response to a Medicare price reduction." Health Services Research 32(3): 283.

Rice, T. H. (1983). "The impact of changing Medicare reimbursement rates on physician-induced demand." Medical Care: 803-815.

Rizzo, J. A. and R. J. Zeckhauser (2003). "Reference incomes, loss aversion, and physician behavior." Review of Economics and Statistics 85(4): 909-922.

Tai Seale, M., T. H. Rice, et al. (1998). "Volume responses to medicare payment reductions with multiple payers: a test of the McGuire-Pauly model." Health Economics 7(3): 199-219.

Yip, W. C. (1998). "Physician response to Medicare fee reductions: changes in the volume of coronary artery bypass graft (CABG) surgeries in the Medicare and private sectors." J Health Econ 17(6): 675699. 


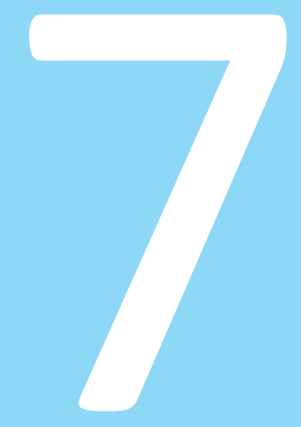

Summary and discussion 


\section{Main conclusions}

The aim of this dissertation is to analyze the impact of a new funding system for hospitals and medical specialists in the Netherlands. We are particularly interested in the effects of the financial incentives of the new funding scheme and have focused mainly on its effects on the volume of care. Using the framework of physicianinduced demand and variations in practice style we explored various responses to the new financial incentives. We feel that, even though the literature has so far been indecisive, overall we find some evidence for responses to a change in the funding mechanism. Before stating our main conclusions we will first briefly recap the introduction of the DTC system and the way it works. Then we will discuss our main conclusions. Section 2 provides a brief summary of each chapter. The main limitations of this study are discussed in Section 3. In Section 4 we will discuss the policy developments that occurred during the time of the research. Section 5 illustrates the policy relevance of this study. The final Section, 6 , is devoted to suggestions for further research.

In the Netherlands, the funding of hospitals and medical specialists is complex. A new model for hospital funding, based on Diagnosis Treatment Combinations or DTCS (DBC in Dutch: Diagnose Behandel Combinatie), was introduced in 2005. The new funding or reimbursement model meant a switch from a fixed budget model to one in which hospitals are paid a casemix-based tariff for the entire treatment of a patient in the hospital. The DTC model was introduced as a tool to support market competition (Maarse and Bartholomée, 2007; van de Ven \& Schut, 2008). With the introduction of the DTC system in 2005 , about $10 \%$ of hospital care was liberalized. In this liberalized part - called segment B - hospitals and insurers are expected to negotiate on volume and prices. There is no government-imposed budget ceiling. However, insurers and hospitals may agree on a maximum number of treatments and on an arrangement for dealing with extra volume. Extra production in segment $B$ leads directly to extra revenues for the hospital and for the medical specialist involved. The size of segment B was increased gradually from about $10 \%$ in 2005 to about $20 \%$ in 2008 and about $34 \%$ in 2009 . For the rest of hospital care (segment A), DTCs are used only as an administrative tool and hospitals must still operate within a fixed budget.

Every DTC consists of a cost component for the hospital and a fee component for the medical specialist, based on a nationally set hourly tariff. Until 2008 the funding scheme for medical specialists was similar to that of hospitals: whereas extra production in segment B generated extra revenues, extra production in segment A did not because of the budget ceiling, called lump sum (a total budget per hospital for the payment of self-employed medical specialists). This lump-sum arrangement was 
abolished in 2008. Since then, medical specialists no longer work within a budget and are paid per DTC.

A change in the hospital funding model can be conceptualized as a change in the financial incentives for medical specialists and hospital management (McClellan, 1997). In Chapter 2 we identified a number of possible financial incentives which came into play following the introduction of the DTC system. In Chapter 3 we investigated the volume increase in segment $B$ before and after the introduction of the DTC system. In Chapter 4 we looked into the occurrence of upcoding, which can be defined as 'a deliberate and systematic shift in a hospital's reported casemix in order to improve reimbursement'. We analyzed upcoding within segment B as a theory-based predicted incentive of a casemix system (Simborg, 1981). In Chapter 5 we investigated overdeclaration - defined as unwarranted declarations - in both segments as a risk unique to the Dutch DTC system, defining overdeclaration as gaming the DTC system by increasing the volume of DTCs to make use of the discretionary room for decision-making. In addition we investigated the relation between the number of medical specialists per GDP and the number of procedures per GDP in chapter 6 . Table 1 gives an overview of the different analyses presented in this dissertation.

Table 1: Overview of analyses

\begin{tabular}{|c|c|}
\hline Chapter & Conclusions \\
\hline 2. Comparison of DTC to DRG & $\begin{array}{l}\text { Upcoding and overdeclaration are more likely to happen in the DTC } \\
\text { system in comparison with the DRG system. The impact of special } \\
\text { institutional settings, such as segment B, needs to be considered. }\end{array}$ \\
\hline 3. Increasing production & $\begin{array}{l}\text { Growth in segment B exceeded growth in segment A in the first year } \\
\text { after the introduction of the DTC system. }\end{array}$ \\
\hline 4. Upcoding & $\begin{array}{l}\text { From a theoretical perspective, upcoding is most likely to occur in } \\
\text { segment B; our analysis shows that individual hospitals respond differ- } \\
\text { ently to the possibility of upcoding in segment B. This difference cannot } \\
\text { be linked to differences in relative prices. }\end{array}$ \\
\hline 5. Overdeclaration & $\begin{array}{l}\text { Between } 2006 \text { and 2008, around } 5 \% \text { of total DTCs billed were unwar- } \\
\text { ranted. There are large differences among hospitals and specialties in } \\
\text { the percentage of overdeclaration. }\end{array}$ \\
\hline 6. Physician-induced demand & $\begin{array}{l}\text { There is some support for a hypothesis of physician-induced demand in } \\
\text { segment B, where there are differences in the number of treatments } \\
\text { provided by salaried and self-employed medical specialists. }\end{array}$ \\
\hline
\end{tabular}

Although responses found following the introduction of the DTC system are small, they may be significant. All responses need to be added to get an overview, at the macro-level, of the aggregated response to the introduction of the DTC system. Overall we conclude that there is some evidence of a response to the introduction of the case-based system in the Netherlands. The size of this effect is not quantified 
here. Our findings cannot be extrapolated to the whole sector of hospital care, because we have analyzed only a number of DTCs specifically selected as possible risks for overdeclaration, except for Chapter 5, where we have analyzed the amount of overdeclaration for all billed DTCs.

The volume of responses found cannot be interpreted directly as evidence of overproduction. In fact there can be many explanations for these responses, like preexisting waiting lists, pre-existing conditions under treatment or differences in practice style. An example of a response that could or could not be labeled as overproduction is the growth of segment B diagnoses as described in Chapter 3. We have not investigated whether this growth is or is not medically relevant production; however, we found a significant response in production linked to the introduction of the DTC system. In our analyses we have not dealt with quality of care implications. For example, our analyses on upcoding in Chapter 4 see differences in treatment intensity as upcoding. However, it may also be the case that clinical admission for varicose veins increases quality for some patients. The differences found between hospitals in Chapters 4 and 5 and between regions in Chapter 6 can be placed within the literature on practice style variations as noted by Wennberg (Wennberg, 1973). Recent research by Plexus in the Netherlands also shows great variations between regions for a number of treatments in Segment B (Van Beek et al., 2010). Variations in practice style are most probably not new to hospital care in the Netherlands, but the introduction of DTCs has made it easier for interested parties to detect them; before the DTC system was introduced, health insurers, for example, had no information about the diagnoses given to patients. Risks like upcoding and overdeclaration, on the other hand, are newly identified risks inherent in the DTC system.

\section{Main findings per chapter}

\section{Chapter 2 - Hospital funding in the Netherlands: The DTC system unveiled}

Chapter 2 begins with a descriptive overview of the history of hospital funding in the Netherlands, covering the historic budgeting model and the functional budgeting model. These models had several problems, such as a lack of transparency and no stimulus for efficiency or innovation. These problems led to the introduction of the DTC system. The main elements of the DTC system are laid out, such as segment A and $B$, and the build-up of the coding system. The second purpose of Chapter 2 is to compare the DTC model to the model of hospital funding by means of diagnosisrelated groups (DRGs) which is currently used in the United States, Germany and Australia. Finally, as a third aspect, we systematically compare the incentives and problems of the DTC model with the DRG model. The DTC and the DRG system are two very different systems. These differences can be divided into three main cate- 
gories: differences in starting point and intentions, differences in structure and procedures and differences in financial incentives. An important distinction between the two systems concerns the wider scope of the DTC system, which includes the treatment axis and outpatient clinical care. The wider scope, however, increases the potential for upcoding. Other differences between the DRG- and DTC system are that the DTC system includes the fee of the medical specialist involved; each DTC is coded prospectively by the medical specialist him or herself, instead of retrospectively, by a hospital administrator, as in the DRG-system. Another disparity is that DTCs were not introduced mainly to control costs, but also as a tool to support market competition in Dutch hospital care, with partly liberalized prices. In the DTC system, there is the possibility to use more than one DTC per patient and a corresponding incentive to maximize the number of DTCs per patient.

\section{Chapter 3 - The volume effect of a new casemix-based funding system of hospital care on the behavior of medical specialists in the Netherlands}

Chapter 3 is a country-specific case study which tests the occurrence of a volume increase due to the changing financial incentives in the delivery of hospital care. Our hypothesis is that the new funding model elicits an increase in the volume of hospital care, because under the new funding system a higher volume means more revenue for both hospitals and doctors, whereas under the old system revenues were only partially dependent on the volume of care, as the so-called production or volume contracts between hospitals and insurers, which put a cap on payment for care, prospectively, were an important element in determining a hospital's budget. The co-existence of the old model for one part of hospital budgets (segment A) together with the new funding system (segment B of hospital production) since 2005 has created a natural experiment in the Netherlands whereby we can test our hypothesis. The possibilities for strategic behavior on the part of medical specialists also depend on the type of diagnosis. Procedures that can be regarded as relatively 'elective procedures' are presumed to provide physicians with greater flexibility in this respect. The possibility for induced demand varies across treatments, because the underlying production functions and relative demand for various treatments vary. Therefore, we expected to find that the volume growth of DTCs in segment B occurs only with elective treatments. From interviews with professionals we selected 10 diagnoses from segment $B$ that are open to demand inducement. For the analysis we have used a dataset of over 2 million inpatient hospital discharge diagnoses. To compare the change in volume in segment $B$ with that in segment $A$ of hospital care, we used a difference-in-difference analysis, where we assume that without the changes in the reimbursement model, the differences in volume growth between the two segments in 2004 would have continued in 2005. A difference-indifference analysis is commonly used to evaluate the impacts of a policy, using the assumption that the growth of the group subject to policy change versus the growth 
of the control group would otherwise have remained unchanged. This analysis showed that in the first year after the introduction of DTCS and segment B (2005) the relative volume growth of elective treatments in segment $B$ was $8 \%$ higher compared to similar procedures in segment $A$. This finding suggested that there was extra growth on top of the overall growth, and that the additional growth could be related to the financial incentives in segment $B$, which is in accordance with our hypothesis. This outcome is an important empirical contribution to academic debates on the incentives of provider funding models and is relevant at policy level, as countries experiment with price competition in health care provision as a tool for reducing costs.

\section{Chapter 4 - Does upcoding occur in the DTC system? An explorative analysis}

In Chapter 4 we explored the occurrence of upcoding in the DTC system. Upcoding, which is defined as 'a deliberate and systematic shift in a hospital's reported casemix in order to improve reimbursement', is a theoretical risk of a casemix-based payment system. We explored the occurrence of upcoding in Dutch hospitals for 5 different pairs of DTCs (a less expensive DTC and a more expensive DTC) for each of the following conditions: pelvic organ prolapse, inguinal hernia, diabetes mellitus, varicose veins as treated by a dermatologist, and varicose veins treated by a surgeon. Within all these diagnoses the DTC system provides two interchangeable options - a less expensive and a more expensive option - and with that an opportunity for upcoding to the DTC with the higher reimbursement. There is large variation between hospitals in the proportion of DTCs with higher reimbursement, which can be seen as an indication of upcoding, as these large differences remain after correcting for casemix differences. The analyses are performed with data from a large health insurance company. Analysis was done by logistic regression, with patient and hospital characteristics as control variables and dummies per hospital to estimate the hospital-specific effect on the chance that upcoding might be occurring. The inclusion of hospital dummies led to a significantly better explanation of the variation in the chance that upcoding will occur, implying a hospital-specific effect. From a pooled regression for all five pairs of DTCs, we concluded that both hospitalspecific and specialty-specific effects influence the occurrence of upcoding. The nature of the hospital- and specialty specific effects cannot be analysed further due to data restrictions. We also tested whether the chance that upcoding will occur depends on the relative price of the two interchangeable DTCs, but this could not be concluded from our results. We therefore attributed upcoding to differences in hospital culture rather than to pure economic incentives. A hospital with a more revenue-oriented culture is more likely to engage in upcoding. These results suggest that it is important for health insurers not only to negotiate favorable prices, but also to benchmark hospital declarations in combination with patient characteristics. Note that in this study, we did not analyze the consequences of differences in the 
choice of a more or less complex DTC for the quality of care. The impact of the new hospital funding on the quality of care is beyond the scope of our study.

\section{Chapter 5 - Fee-for-Service use in the Dutch casemix system of DTCs}

In Chapter 5 we analysed a volume-effect typical of the Dutch DTC system, i.e. the fee-for-service use of the case-based DTC system defined as overdeclaration. A DTC can be conceptualized as a complete package of care with a fixed price which is independent of the actual costs incurred. The hospital thus bears a financial risk if a patient needs more care than the DTC covers. However, in some cases, the DTC system allows the hospital to charge an additional DTC for the treatment of a single patient. There are rules and guidelines for each specialty on when the opening of a second DTC is warranted. The main rule is that a second DTC may be opened only if a patient needs $40 \%$ extra costs and/or effort in comparison with the average cost of the first DTC. This rule leaves room for discretionary decision making, since the costs and/or effort per DTC are not quantified. This leads to the risk that hospitals and medical specialists 'game' the DTC system in order to increase revenues or income. An internal analysis by a health insurer showed that almost $5 \%$ of all DTCs billed could be classified as overdeclaration. In this study we used the results of this analysis to explore which factors influence the amount of overdeclaration. We expected that the type of specialty, specific DTC characteristics, the ICT system used by the hospital for validation and hospital management might affect the amount of overdeclaration. Such an analysis is of great importance because it may give us more insight into strategic behavior on the part of hospitals and medical specialists. Preventing overdeclaration is of great importance for an effective cost control strategy for insurers; it also fits in perfectly with the government's cost control strategy. In order to analyze the factors underlying overdeclaration, we used the results of an algorithm built by a Dutch consultancy firm (CHS) which assessed all DTCs billed, and in the cases of multiple DTCs per patient examined whether the declaration of the second (or even third and fourth) DTC was warranted or not. From these results we computed for each hospital and for each specialty the percentage of unwarranted DTCs for the years 2006, 2007 and 2008. The descriptive statistics of these percentages showed large variation between both hospitals and specialties in the amount of overdeclaration, suggesting hospital- and specialty specific effects. Regression analyses confirmed this hypothesis and we have found that the amount of overdeclaration is caused by unobserved hospital-specific and specialty-specific effects. To a lesser degree, overdeclaration can also be explained by the type of ICT system used and the type of care. Contrary to what we expected, overdeclaration does not happen more in segment B of hospital care, in which there is a direct link between production and income, than in segment $A$. An interesting finding is that there are wide differences in overdeclaration between hospitals, suggesting differences in declaration 'culture' between hospitals. Unfortunately, our analysis did not 
allow us to draw conclusions on what these differences specifically entail. A second interesting finding was that there is also a large variation in overdeclaration between specialties. Whether this variation also exists within hospitals and is related to a specific department within each hospital or whether it is the same for all hospitals and, as a consequence, inherent either in the DTC system or the professional community, could not be concluded from our analysis. One of the limitations of this study was that we do not know whether the overdeclaration analysis in this study is a structural or a transitional problem. It is a potentially substantial problem, since the total amount of overdeclaration in the years 2006-2008 could add up to over 1 billion Euros (extrapolating from the 196 million in our data, representing 15\% of the market).

\section{Chapter 6 - Supplier-induced demand in Dutch hospital care: evidence from a natural experiment}

In Chapter 6 we analyzed supplier-induced demand in the Netherlands by relating the number of specific surgical procedures per capita to the number of medical specialists per capita for both salaried and self-employed medical specialists. In order to solve the problem of separating cause and effect, we exploited two unique features of the Dutch hospital sector: 1 . The coexistence of salaried and selfemployed doctors in the Netherlands. Only self-employed doctors have an incentive to induce demand, so regional variations in the number of salaried doctors can be used to control for exogenous regional variations in demand, i.e. variation in demand that is not due to supply inducement. If we then find that the number of selfemployed doctors has a positive effect on the number of treatments over and above the effect of the doctors in general (salaried and self-employed), we conclude that the evidence points to supply inducement. 2 . The co-existence of a regulated segment of hospital care and a liberalized segment. In the regulated segment, selfemployed doctors were until very recently being paid on the basis of a fixed annual lump sum, independent of volume of care. Hence, in this segment there was no incentive for supply inducement. In contrast, in the liberalized segment, selfemployed doctors received a (regulated) fee per treatment. Provided this fee was high enough, doctors in this segment of hospital care may have felt an incentive to induce demand for their services. Each of these two institutional features constitutes a natural experiment, allowing us to adjust for regional differences in demand that are derived from (unobserved) patient characteristics. Thus our identifying assumptions were that only self-employed doctors have an incentive to manipulate supply in order to raise income, and that this incentive exists only in the liberalized segment of hospital care. For this analysis we used data on the number of medical specialists per hospital from the Dutch Ministry of Health, and data on the individual use of health services from a national database that covers all Dutch health insurers. Our empirical analysis offered support for the existence of supplier-induced demand 
for the following treatments: tonsillectomy, inguinal hernia, varicose veins, cataract, spinal hernia, mamma reduction and pelvic organ prolapse. In most cases the estimated coefficient was larger for self-employed doctors than for salaried doctors, as would be required in case of supply inducement. This remained true after including control variables. In order to assess the size of the inducement effects implied by our estimation results, we used the estimated coefficients to compute elasticities. These elasticities measured the percentage increase in the number of treatments per capita as a consequence of increasing the number of doctors per capita by $1 \%$. In line with our identifying assumption that salaried doctors do not engage in demand inducement, the calculated elasticities are based on the difference between the estimated coefficients for self-employed doctors and salaried doctors. These elasticities ranged from 0.1 to 0.25 , with an outlier of 0.36 for varicose veins treated by a dermatologist, implying that a 10 percent increase in the number of doctors per capita would increase the volume of care by $1-2.5$ percent. However, it does not necessarily follow that health expenditure rises by the same percentage. It is even conceivable that increasing the number of doctors may result in lower health expenditures. An increase in the supply of doctors may shift the bargaining position from doctors to health insurers, resulting in lower fees. Moreover, such a shift in bargaining positions may make it easier for health insurers to introduce measures aimed at containing spending such as selective contracting, utilization review and partial capitation.

\section{Limitations}

There are four main limitations to this study. The first is that we have not incorporated information about costs in our analyses; the second is that our analyses cover only the first years of the DTC system and therefore our findings may be the result of transitional problems rather than structural responses to financial incentives; a third limitation is another possible effect of the DTC system that we have not investigated, namely the transfer of DTCs from segment A to segment B; and the last is that our results cannot easily be extrapolated to the whole of hospital care in the Netherlands.

\section{No information on costs}

All the analyses done in this dissertation are based on billed DTCs. Chapters 3 and 6 use national datasets in which neither the tariff or price of the DTC nor the costs of the DTCs were included. In Chapters 4 and 5 we have used data from a health insurance company; for the DTCs used in these analyses we have used tariff and price information, but again we do not know anything about the costs per DTC. The Netherlands Health Care organization has used cost data indications to calculate the 
tariffs of DTCs in segment A and the indicative prices in segment B. However, these data no longer reflect current costs since they are based on calculations from the 1990s. Individual hospitals (may) attempt to calculate costs of DTCs and their different components, but this information is private to the hospital. The fee component of the medical specialist is based on a nationally set hourly tariff combined with a norm time per DTC. However, these times, set by the Dutch Healthcare Authority, are also based on old time registrations and no longer reflect reality. An important assumption made in this study is the profitability of extra production. We assume that both the fees of the medical specialists and the prices of the hospitals are on average higher than the costs involved. There is no reason to assume this is not the case, but our hypothesis of an incentive to increase production does not hold without this assumption.

\section{Transition problem}

Our analyses use data from the first few years after the DTC system was introduced. Consequently, the responses we have found could be transitional. Literature from the United States and Germany, for example, shows that upcoding decreases after an initial increase shortly after the casemix system is introduced (Lauterbach and Lungen, 2001; Harrington et al., 2007). Eventually, upcoding decreases due to a well-functioning control mechanism from the government or health insurers, but a learning effect could also play a role. A learning effect can either increase upcoding, because the ways to game the system become clearer for medical specialists and hospital management, or it can decrease upcoding once all players understand the rules of the game. Note that there may also be a learning effect for health insurers; they can learn to better detect upcoding. Chapter 5, on overdeclaration, also addresses the possibility that the risk is only temporary. If the problems are not transitional, more effort needs to made by health insurers and/or the government to monitor the hospitals closely; we will come back to this point in the next section.

\section{Recoding of DTCs from segment A to segment B}

Another possible effect of the introduction of the segments $A$ and $B$ is that medical specialists or hospital management will try to recode DTCs from the A- to segment $B$. There is an incentive for hospitals to bill DTCs within segment $B$, since these DTCs are reimbursed per case, whereas once the budget ceiling in segment $A$ is met, extra DTCs will not be reimbursed. In theory, hospitals could escape the budget limitations set in segment A by billing DTC in segment B. Medical specialists had this same incentive until 2008, when the removal of the lump sum arrangement removed the budget limitations for both segments. We have not investigated this effect in this research, since the original segment $B$ (in place from 2005 until 2007) did not offer many possibilities for transfers from segment $A$ to segment $B$, apart from transfers 
from conservative to operative treatment, which we covered in Chapter 3 by analyzing the growth of elective surgeries in segment $B$. New diagnoses were added to segment $B$ after it was expanded in 2008; these have created new possibilities for transfers from $A$ to $B$.

\section{Focus on specific parts of segment B}

Apart from Chapter 5, we focus our analyses on specific diagnoses from the (initial) $B$ segment. We have done this because the incentive structure for segment $B$ has changed with the introduction of the DTC system. Conclusions from analyses on segment B cannot simply be extrapolated to the remaining DTCs of segment B and the rest of segment A. The DTCs were carefully chosen for either their elective character or the existence of two interchangeable DTC codes. Further analyses will also require careful choosing of DTCs; consequently our analyses cannot be applied oneon-one to the rest of the system.

\section{Recent policy developments}

During the time of this research a number of policy developments occurred that either changed the institutional settings or have had an impact on the DTC system itself. We will discuss the three main developments that were also mentioned in previous chapters: first, the expansion of segment $B$, second, the change in funding for medical specialists and finally the development of a renewed DTC system.

\section{Expansion of segment B}

Between the introduction of the DTC system in 2005 and 2010, segment B gradually increased in size, officially, from $10 \%$ to $20 \%$ and later $34 \%$. In reality the size of the $B$ segment was much smaller. The reasons for expansion were mainly the moderate price development of the DTCs in segment B and a policy decision to increase the scope for market competition. Hospitals called for a substantially bigger segment $B$. The latest policy plans, presented by the Minster of Health in the beginning of 2011, consist of a maximum expansion of segment $B$ and total abolishment of functional budgeting. The part of hospital care that cannot or is undesirable to be liberalized will be regulated by setting maximum tariffs and will remain segment $A$. The rest of hospital care $-70 \%$ - will be transferred to or remain in segment $B$.

Increasing the size of segment B has always been a politically sensitive affair. It is the task and responsibility of the Minister of Health to decide how much and how fast the segment should grow. However, since market competition in health care has remained controversial, the Minister has to maneuver carefully and demon- 
strate that free pricing works as intended (lower prices, no unwarranted volume effect). For this reason, the Dutch Healthcare Authority regularly publishes a monitoring report on the effects of free pricing. The latest report of 2010 shows that adjusted prices of segment B increased only slightly between 2008 and 2009, and actually decreased between 2009 and 2010 (NZa, 2011). Developments in the volume of care are more difficult to monitor, due both to the expansion of segment $\mathrm{B}$ and the time lag in registration, which is why there is no comparison of volume developments in segment $A$ versus segment $B$ in the above-mentioned report. In Chapter 3, however, we show that in the first year after the introduction of the DTC system, segment B grew $8 \%$ faster than segment $A$.

In reality, total costs have substantially overrun the macro budget instated for hospital care in both 2008 and $2009^{24}$. These overruns were to be paid back by the hospitals through a budget cut for subsequent years; this has been fought in court because the calculations of the overrun were over both the segment $A$ and $B$, contradicting the open-ended structure of hospital funding in segment B. Late in 2010, following an appeal by the Minister, the Minister's line of action was approved; the hospitals are now appealing for cassation of this verdict.

\section{Abolishment and reinstatement of a budget for medical specialists}

In 2008 the funding mechanism of medical specialists was drastically changed. Until 2008 the funding mechanisms of medical specialists was similar to that of hospitals: whereas extra production in segment $B$ generated extra income, extra production in segment A did not because of a ceiling, called lump sum. This lump sum arrangement was abolished in 2008. Since then, medical specialists have no longer been budgeted and are paid per DTC. The abolition of the lump sum was followed by macro budget overruns in 2008 and 2009, and tariff cuts were introduced in 2010 (Ministerie VWS, 2010). The exact size of the budget overruns is unclear and the Minister of Health and the Association of Medical Specialists disagree on this. There are two explanations for the budget overruns. One explanation is that the fixed fee component for the medical specialist is based on old time measurements which overstate the time actually needed to perform certain treatments now, especially for those specialties that have booked huge efficiency gains in time over the years, like medical microbiology. Another potential explanation is that with the abolition of the lump sum arrangement, medical specialists increased their production beyond the budget limits that still applied for hospital care; this is a typical form of non-alignment of incentives. Note that with the abolishment of the lump sum arrangement there were no longer differences in direct financial incentives for medical specialists between segment $A$ and segment $B$.

\footnotetext{
${ }^{24}$ For 2010 the cost overruns are not yet determined.
} 
The budget overruns by medical specialists were offset by generic and specific fee cuts. The hourly fee is currently 139.50 Euros with a range of plus and minus 6.50 Euros, but due to the overruns a generic fee cut of $12.7 \%$ was instated for 2010 , with additional cuts varying per specialty during this year (NZa, 2010). Even though these cuts will reduce expenditure per DTC, total costs are still not controlled by a fee cut - as volume is still open-ended. Therefore, from 2012 onwards medical specialists will once again be budgeted. There will be a lump sum payment per hospital that the medical specialists will have to divide among themselves. This is the result of negotiations between the National Association of Medical Specialists and the Minister of Health. Initially, it was the intention of the Minister that the hospital board had to decide on how to pay medical specialists from the available lump sum, but this plan was fiercely rejected by the medical specialists because they feared that this would abolish their status as self-employed professionals, which gives them certain fiscal advantages, and endanger their professional autonomy. The new budget system will also have a variable component of $15-25 \%$ to ensure a production and qualityincentive.

\section{Renewal of the DTC system: DOT}

Shortly after the DTC system was introduced there were already calls for a less complex system, even by those actively involved in the design of the DTC system, such as the medical communities. In 2006 and 2007 the types of care 'emergency care' and 'exacerbation' were removed from the coding lists. Besides removing some DTC codes, the DTC maintenance organization (SDO) also added new codes to solve practical problems, such as the treatment type 'clinical admission without clinical days' when a patient is clinically treated by more than one specialty. Even though these changes have improved the DTC system, all parties involved considered a more substantial revision into a whole new system to be necessary. The new system is called DOT: DTCS On their way to Transparency. The aim was to introduce DOT in 2010, but introduction has been postponed to 2011 and now to 2012. The goals of DOT are to achieve the original goals of the DTC system, such as increased transparency, medical recognizability, stability and openness to innovation, but also to reduce the complexity of the current DTC system. The renewal is based on three important pillars. The first pillar is that the care products will be inferred from registered activities by a web-based grouper $^{25}$ instead of being opened by the medical specialist. This change is intended to solve the problems of the first-generation validation modules and to reduce the administrative burden of medical specialists and hospitals. The second pillar is the reduction of the number of

\footnotetext{
${ }^{25}$ A grouper is an algorithm that combines all activities and information on a patient into a billable care product. (DBC Onderhoud, 2010)
} 
DTCs, now 110,000, to approximately 3,000 DTC care products. These new care products will contain medically recognizable products that can support negotiations between care providers and health insurers. The instructions will be uniform for all specialties. There will be a measure for casemix of the patient, as is common in the DRG system, to ensure fair compensation for every patient. The last pillar is that the classification of the DTC care products will be based on the uniform ICD10 coding system, making the international exchange of data possible. Apart from exchangeability, the new coding system will also reduce complexity because all 24 different specialties will now use the same coding system. Multiple specialties that can treat the same diagnosis will be combined into the same DTC care products and multidisciplinary diseases can be captured in a single DTC care product as well. Even though there will be a lot of change, the second generation DTC system will retain combining diagnosis and treatment as its unique feature (DBC Onderhoud, 2010).

\section{Policy Relevance}

There are a number of policy recommendations that follow from this research. In this section we will discuss our recommendations in view of recent developments on the DTC system itself and on the institutional settings in the Netherlands.

\section{Expanding segment B?}

As noted before, expanding segment $B$ has always been controversial. For this reason, the Minister of Health had to maneuver cautiously. From the evidence presented in this study we cannot derive (strong) arguments against a further liberalization of prices and volume by further expanding the size of segment B. In Chapter 3 we found that the volume of elective surgeries indeed increased in the first year after the DTC system was introduced. However, this finding is too weak to provide a basis for predicting a strong volume effect following a further extension of segment B. In this connection, it is important to point out that health insurers have had few opportunities to limit unwarranted volume growth, e.g. by using degressive prices for medical specialists. Recall that presently medical specialists are paid on the basis of a fixed rate per DTC. It seems advisable to combine a further extension of segment B with an expansion of the scope for innovative contracts, e.g. by including the specialist's fee in the price of the DTC. Health insurers would then be better able to include incentives to limit volume in their contracts with hospitals. The hospital management could then translate these incentives internally in the remuneration terms for medical specialists. In addition, we do not know the welfare implications of a volume growth (does it point to overproduction or to a shortening of waiting times and a reduction of waiting lists?). In 2005 - the year of introduction of partial price liberalization - there were several waiting lists for the medical services in- 
cluded in segment B. The risk of upcoding described in Chapter 4 turns out to be unrelated to negotiated prices. Therefore, this risk cannot be used as an argument to abstain from further price liberalization. Chapter 5, on overdeclaration, analyzed a real problem in hospital funding. Extending segment B may aggravate this problem, but stricter controls and simplifying the funding model by introducing DOTs may help to solve it.

On the other hand, the results of our study do not suggest arguments for a further liberalization of hospital funding either. It is unclear whether our results can be extrapolated to the future, as our data were taken during a period when the DTC system was still new. Furthermore, more aspects of hospital funding have to be taken into account, such as administrative costs and the consequences of the funding model for total hospital care expenditures and quality of care. Extending segment $B$ in hospitals may also bring about a substantial reduction in the administrative complexity of the current dual funding model, which consists of two distinct compartments (functional budgeting versus free pricing) According to the Minister of Health, hospital funding is 'stuck in the middle' (Ministerie VWS, 2011). It takes several years to calculate the exact size of total health care expenditures and to detect cost overruns. Even worse, knowing that generic expenditure cuts will be used to offset the cost overruns may induce hospitals to spend more than their budget allows them to do. Even hospitals who economize to avoid spending beyond their budget ceiling will be hit by generic expenditure cut programs. Good behavior is not rewarded.

As we have also shown in Chapter 1, it is important to have at least some alignment in the incentives of hospitals and medical specialists. Furthermore, it is also important to keep in mind that any hospital funding model may be sensitive to gaming. This is true not only for models that relate funding to production and performance, but also for models without incentives to stimulate hospital production. The history and effects of fixed hospital budgets in the Netherlands are a clear demonstration of this (Maarse, 1996).

Expanding segment B and no longer imposing budget cuts over segment B will also increase the efficiency of the negotiations. Right now the stakes of the negotiations are not high enough, which does not lead to optimal results. The main reasons for this are the fact that the financial stakes are not high enough, given the size of the current segment $B$ and the fact that cross-subsidizing with segment $A$ is still possible. Apart from the lack of financial interests there is also a learning effect for both health insurers and hospitals in these negotiations. It is impossible to be able to negotiate immediately on the volume, price and quality of thousands of DTCs. Until now, negotiations have usually been on the prices and quality of a handful of diag- 
noses from segment B; for the other DTCs in segment B, price negotiations are on the generic price increase compared to the previous year.

\section{DOT}

The transition of the DTC system towards DOT does seem to be a good solution for a number of the current problems with the DTC system. The complexity of the system is greatly reduced, registration is more meaningful medically and more easily comparable internationally, and it makes it possible to bill for multidisciplinary treatments. It also offers a solution to the problems of overdeclaration described in Chapter 5. If the medical specialists can no longer open and close DTCs, the number of parallel and serial DTCs will be reduced greatly or completely. However, most of the problems could have been solved in the existing DTC system, and it remains to be seen whether transparency is indeed increased in the DOT system. By clustering the DTCs, negotiations and billing might become more transparent - given the limited number of DOTs - but transparency of care will not necessarily improve. Furthermore, it is important to keep in mind that every funding system can and will be gamed. Therefore policy makers and health insurers should also look at the possible new responses this system might create. Within the DOT system the incentive to increase production in segment B as described and analyzed in Chapter 3 continues to exist. The risk of upcoding changes with the DOT system, because upcoding on the treatment axis is no longer possible for a lot of diagnoses, since treatment and setting options are clustered. However, upcoding can still occur through registering more complicated activities and services that will lead to the grouper choosing a more expensive DOT. The possibility of overdeclaration is largely reduced in the DOT system, because many of the parallel and serial combinations of DTCs are not clustered into one DOT. However, this can turn the risk of overdeclaration into a risk of upcoding, because clustering multiple care products can lead to a more expensive DOT.

\section{Number of medical specialists}

A policy implication related to the institutional settings is that the number of medical specialists no longer needs to be restricted. From the information provided in Chapter 6 we can conclude that increasing the number of medical specialists per capita by 10 percent would raise the volume of care by $1-2.5$ percent. However, it does not follow that health expenditure would rise by the same percentage. It is even conceivable that increasing the number of doctors results in lower health expenditure. An increase in the supply of doctors may shift the bargaining position from doctors to health insurers, resulting in lower fees. Moreover, such a shift in bargaining positions may make it easier for health insurers to introduce measures aimed at containing spending, such as selective contracting, utilization review and 
partial capitation. This does also require that the fees of medical specialists be liberalized. These fees are currently regulated to prevent specialists from abusing their market power to negotiate higher fees, but this is no longer necessary when the number of medical specialists increases to market equilibrium. The government statement of 2010 notes that the number of university spots for medical students will be liberalized, which is in line with our findings (Regeerakkoord, 2010).

\section{Rules of the game must be clear}

It is very important that the rules of the game be set clearly and backed by the government to ensure maximum legal certainty. As argued in Chapter 5, there has been and still is a lack of clarity and discussion about the rules concerning parallel and serial DTCs. Within a framework of regulated market competition, it is essential that the regulations set by the government leave no room for debate, since this disturbs the level playing field between the parties. The government must ensure that regulations are both clear and timely. If, for example, segment B will be expanded further, the indicative prices of the DTCs in the expansion need to be set in time for the hospitals and health insurers to enter negotiations on both segments with full information.

\section{Volume of care}

The introduction of segment B has created a ceilingless playing field for hospitals and medical specialists. Our results on growth in segment B, presented in Chapter 3 , suggest possible undesirable side-effects of the new reimbursement system for hospital expenditures. Whereas the Dutch Healthcare Authority found that price competition has not led to an explosion of prices in segment $B$, our analysis indicates an upward volume effect. If the volume effect outweighs the price effect, the new funding model will boost the growth of hospital expenditures, undermining the government's policy of cost control. It is therefore important to take both effects into account when assessing the effects of market competition and the DTC system. A solution for controlling growth in segment B is to press health insurers to set limits on volumes in segment $B$. If health insurers are partially responsible for budget overruns on hospital care, they will have an incentive to negotiate limited volume contracts. However, this should be done based on calculations on the incidence of certain procedures in combination with agreements on need assessment. Another solution could be to stimulate hospitals to control volume growth by only partially reimbursing DTCS above a certain volume, for example by reimbursing only the marginal costs. This can be achieved by negotiating staggered prices between the health insurer and hospital; this system was recently introduced in Germany as a way to ensure control on volume growth (Federal Ministry of Health, 2007). 


\section{Monitoring}

Since many of the responses found in our analyses, like upcoding and induced demand, are not easily detectible, it is necessary to monitor hospital behavior. A hospital's deviations from trend growth or from treatment intensity can only be signaled through benchmarking. If segment $B$, and with that financial interests, increase, it is even more important to keep track of risks like upcoding and overdeclaration and also to look into practice style variations. With the introduction of the DTC system, the transparency of hospital care for health insurers and policy makers has increased, since these parties now have insight into the actual diagnoses made and respective treatments provided by hospitals. With this extra information, monitoring also becomes possible. Although this can be done by the government, preferably it is done by the health insurers, who will have to up their game as a countervailing power to the providers of health care.

\section{Suggestions for Further Research}

To our knowledge our study presents one of the first academic and empirical studies on the behavioral effect of the introduction of DTCs in Dutch health care. The study also addresses some issues - in particular upcoding and overdeclaration which so far have not been studied in the monitoring reports of the Dutch Healthcare Authority. It is evident, however, that our analyses in this study are far from complete and leave many questions unanswered. For instance, it would be interesting to include the employment status of medical specialists in the analysis (we only did so in chapter 6). Another suggestion is to extend the list of DTCs (in future DOTs) in the analysis of upcoding to see whether our findings hold for other DTCS (DOTs). Other important topics are the behavioral effects of the transition from DTCs to DOTs. Do DOTs really solve the many problems inherent to funding hospitals by DTCs, for instance by lowering the risk of upcoding and reducing the possibility of overdeclaration? The analysis of the impact of the new funding model on the structure of hospital care including market shares would also be a promising topic of research. We are certain that the effects of the new model of hospital funding upon the behavior of specialists and hospitals will remain an important topic of research in the future. Such research is essential to escape a mainly ideology-driven political debate on the effects of hospital funding system. 


\section{References}

DBC Onderhoud (2010), DOT in Grote Lijnen, www.DBConderhoud.nl/Ontwikkelen-van-de-DBCsystematiek/Cure/DOT-implementatie/DOT-in-grote-lijnen/Grouper

Federal Ministry of Health, (2007a). Auswertungen des BMG-Fragenkatalogs zu den Erfahrungen mit der DRG-Einführung.

Harrington, K. A. A. L. R. (2011). Restraining Medicare abuse: the case of upcoding. Highbeam Research.

Lauterbach, K. W. and Lungen, M. (2001). "Q Was hat die Vergütung mit der Qualität zu tun?" Krankenhaus-Report 2000.: Schwerpunkt: Vergütungsreform mit DRGs.: 115.

Maarse, H. (1996). "Fixed budgets in the inpatient sector: the case of the Netherlands." Fixing Health Budgets: Experience from Europe and North America. Chichester: John Wiley.

Maarse, H. and Bartholomée, Y. (2007). "A public-private analysis of the new Dutch health insurance system." The European Journal of Health Economics 8(1): 77-82.

McClellan, M. (1997). "Hospital reimbursement incentives: an empirical analysis." Journal of Economics \& Management Strategy 6(1): 91-128.

Ministerie van Volksgezondheid, Welzijn en Sport (2010), "Waardering voor Betere Zorg IV", Kamerstuk CZ/TSZ 2973145

Ministerie van Volksgezondheid, Welzijn en Sport (2011), Betreft Zorg die werkt: de beleidsdoelstellingen van de minister van Volksgezondheid, Welzijn en Sport, Kamerstuk MC-U-3048431

Nederlandse Zorgautoriteit (Nza) (2010), Marktscan Medisch specialistische zorg tussenrapportage deel 2

Nederlandse Zorgautoriteit (Nza) (2011), Marktscan Medisch specialistische zorg Weergave van de markt 2006-2010

Regeerakkoord (2010). Vrijheid en verantwoordelijkheid Regeerakkoord VVD-CDA.

Simborg, D. W. (1981). "DRG creep." New England Journal of Medicine 304(26): 1602-1604.

Van Beek, E., Lemmens, K., van Schooten, G. and Vlieger, E. (2010). "Reduceren van praktijkvariatie: budgettaire effecten van scherpere indicatiestelling." Plexus for Ministerie van Volksgezondheid, Welzijn en Sport.

Van de Ven, W. P. M. M. and Schut, F.T. (2008). "Universal mandatory health insurance in the Netherlands: a model for the United States?" Health Affairs 27(3): 771.

Wennberg, J. and Gittelsohn, A. (1973). "Small area variations in health care delivery." Science 182(4117): 1102. 



\section{Samenvatting}

Het doel van dit proefschrift is het in kaart brengen van de invloed van het nieuwe bekostigingssysteem door middel van Diagnose Behandeling Combinaties (DBC's) voor ziekenhuizen en medisch specialisten. We zijn geïnteresseerd in een aantal effecten van de financiële prikkels in het nieuwe bekostigingssysteem. We hebben deze effecten geanalyseerd met behulp van de theorie van aanbodgestuurde vraag en het optreden van regionale variaties.

Een verandering in het bekostigingssysteem kan worden geconceptualiseerd als een verandering in de financiële prikkels voor medisch specialisten en ziekenhuismanagement. In hoofdstuk twee hebben we een aantal mogelijke financiële prikkels binnen het DBC systeem geïdentificeerd die we vervolgens in de hoofdstukken drie tot en met zes hebben onderzocht.

De betaling aan ziekenhuizen en medisch specialisten in Nederland zit complex in elkaar. In hoofdstuk twee wordt een beschrijving gegeven van de geschiedenis van ziekenhuisbekostiging in Nederland, waarin zowel het historisch budget als het functioneel budget worden besproken. Deze modellen hadden een aantal beperkingen zoals het gebrek aan transparantie en het ontbreken van krachtige prikkels voor efficiëntie en innovatie. Deze problemen hebben geleid tot de ontwikkeling van een nieuw systeem: het DBC systeem. Dit nieuwe systeem, geïntroduceerd in 2005, betekende een ommekeer in het bekostigingsmodel waar ziekenhuizen en medisch specialisten vóór 2005 onder vielen. Het DBC systeem is een casemix systeem: voor de gehele behandeling van een patiënt wordt één tarief of prijs betaald. Het is geïntroduceerd als een instrument om marktwerking binnen de medisch specialistische zorg tot stand te brengen. Samen met de introductie van het DBC-systeem werd in 2005 ook 10\% van de ziekenhuiszorg overgeheveld naar een geliberaliseerd segment met vrije prijzen en afspraken over volume en kwaliteit. Dit segment wordt het B-segment genoemd. Volume en prijzen in dit segment zijn geheel gebaseerd op lokale afspraken tussen zorgverzekeraar en ziekenhuis, waarbij extra omzet in het Bsegment zich direct vertaalt in extra inkomsten. De rest van de ziekenhuiszorg zit in het A-segment, dat nog steeds valt onder het functioneel budget. In dit segment vervullen DBC's slechts een administratieve functie. Het B-segment is uitgebreid naar 20\% in 2008 en 34\% in 2009. Vanaf 2012 zal het B-segment uitgebreid worden naar $70 \%$. Naast een beschrijving van het DBC systeem wordt ook het Diagnosis 
Related Group (DRG) systeem zoals dat momenteel bestaat in de Verenigde Staten, Australië en Duitsland beschreven. Hoofdstuk 2 wordt afgesloten met een vergelijking tussen het DBC systeem en het DRG systeem. De verschillen kunnen in drie categorieën worden verdeeld: verschillen in uitgangspunten, verschillen in structuur en verschillen in financiële prikkels. Een belangrijk verschil tussen de twee systemen betreft de bredere scope van het DBC systeem dat bijvoorbeeld ook de polikliniek includeert. Hierdoor neemt de kans op het upcoding toe. Een ander verschil is dat het honorarium van de medisch specialist ook deel uitmaakt van het DBC systeem. In dit systeem kiest de medisch specialist vooraf de DBC, terwijl deze in het DRG systeem achteraf door een administratief medewerker wordt bepaald. Een vierde verschil is dat het doel van het DBC systeem was marktwerking te stimuleren en niet primair kosten te beheersen zoals bij DRG systemen het geval is. Tenslotte bestaat in het DBC systeem de mogelijkheid om meerdere DBC's per patiënt te openen, wat leidt tot het risico op overdeclaratie.

Hoofdstuk drie is een casestudie waarin de hypothese wordt getoetst of de invoering van DBC's een volume-effect heeft gehad. Onze hypothese is dat het nieuwe bekostigingssysteem een toename in de groei in ziekenhuisproductie binnen het Bsegment uitlokt, omdat hogere productie in het B-segment leidt tot hogere inkomsten in tegenstelling tot in het oude systeem waar deze prikkel slechts gedeeltelijk aanwezig was. Doordat A- en B-segment naast elkaar bestaan, kan een natuurlijk experiment uitgevoerd worden waarbij de groei in het B-segment wordt vergeleken met de groei in het A-segment. De mogelijkheden voor strategisch gedrag door medisch specialisten hangen ook af van het type diagnose. Bij electieve behandelingen zijn er meer mogelijkheden om productie door vraaginductie te verhogen. De mogelijkheid voor vraaginductie varieert dan ook tussen behandelingen, omdat de onderliggende productiefuncties en vraagcurven verschillen. Wij verwachten dat de groei in het B-segment alleen zal voorkomen bij electieve aandoeningen. Uit interviews met medisch specialisten hebben we 10 aandoeningen uit het B-segment geselecteerd (te weten: cataract, liesbreuk, spataderen behandeld door een dermatoloog, spataderen behandeld door een chirurg, rughernia behandeld door een neurochirurg, rughernia behandeld door een orthopeed, keel en neusamandelverwijdering, prolapse uterus, heupprothese en knieprothese), waarbij enige vorm van inductie mocht worden verwacht. Voor de analyse hebben we een dataset gebruikt met meer dan 2 miljoen observaties. Deze data komt uit de Landelijke Medische Registratie en was verplicht tot en met 2005. Een belangrijke restrictie van deze dataset is dat het niet mogelijk was om individuele ziekenhuizen te identificeren. Om de verandering in volumegroei in het B-segment te vergelijken met die in het Asegment hebben we een DID (difference-in-difference) analyse uitgevoerd. De veronderstelling bij deze analyse is dat zonder de overgang naar het geliberaliseerde Bsegment de groei tussen het A- en het B-segment gelijk zou zijn gebleven. 
Uit de analyse blijkt dat in het eerste jaar na de introductie van het DBC-systeem en het B-segment (2005) de groei van de geselecteerde behandelingen in het Bsegment $8 \%$ hoger was dan de groei van behandelingen binnen dezelfde setting (dagbehandeling of klinische opname) in het A-segment. Deze bevinding suggereert dat er extra groei is geweest naast de trendmatige groei. Deze bevinding komt overeen met onze hypothese. Het is ook mogelijk dat de toename in groei geen pure vraaginductie is geweest, maar een gevolg van eerder bestaande wachtlijsten. De uitkomst is een empirische bijdrage aan het academisch debat over prikkels binnen bekostigingssystemen, maar heeft ook beleidsrelevantie aangezien landen experimenteren met liberalisering als een experiment om kosten te beheersen.

In hoofdstuk vier hebben we het optreden van upcoding binnen het DBC-systeem geëxploreerd. Upcoding wordt gedefinieerd als een opzettelijke en systematische verschuiving van de casemix van een ziekenhuis met als doel de vergoeding te verhogen. We hebben het optreden hiervan in Nederlandse ziekenhuizen geanalyseerd voor vijf specifieke aandoeningen. Bij ieder van deze aandoeningen zijn steeds twee inwisselbare DBC's geanalyseerd waarvan één DBC duurder was dan de andere. We hebben dit gedetecteerd voor de volgende aandoeningen: prolapse uterus binnen het specialisme gynaecologie, liesbreuk en spataderen binnen het specialisme heelkunde, diabetes mellitus binnen het specialisme interne geneeskunde en nogmaals spataderen maar dan binnen het specialisme dermatologie. Voor elk van deze aandoeningen is er de optie om 'up-te-coden' naar een duurdere DBC. Er bestaat een grote variatie tussen ziekenhuizen in de verhouding van de goedkopere versus de duurdere DBC voor alle vijf aandoeningen. Deze grote spreiding is een eerste indicator voor het voorkomen van upcoding. Deze spreiding kan echter ook te maken hebben met verschillen in patiëntkenmerken tussen de ziekenhuizen. Om dit uit te sluiten is een logistische regressie uitgevoerd waarin wordt gecorrigeerd voor een aantal patiëntkenmerken. Daarnaast zijn alle ziekenhuizen als dummy's opgenomen om mogelijke ziekenhuisspecifieke effecten te identificeren. Het opnemen van deze dummyvariabelen leidt tot een significant betere voorspellende waarde van het model, hetgeen betekent dat ziekenhuisspecifieke kenmerken invloed hebben op de mate waarin upcoding voorkomt. We hebben ook een gepoolde regressie uitgevoerd waarin we de vijf aandoeningen hebben samengevoegd. Deze analyse leverde op dat er zowel ziekenhuis- als specialisme-specifieke kenmerken een rol spelen bij het optreden van upcoding. De aard van deze ziekenhuis- en specialisme-specifieke effecten kon als gevolg van datarestricties niet verder worden onderzocht. We hebben ook onderzocht of de kans dat upcoding voorkomt samenhangt met de afgesproken relatieve prijs van de twee inwisselbare DBC's (de 'gouden test'). Dit kan echter niet uit de resultaten worden geconcludeerd. Daarom wijzen we het optreden van upcoding toe aan verschillen in 'declaratiecultuur' in plaats van aan pure economische prikkels. Een ziekenhuis dat meer omzetgedreven werkt zal sneller overgaan tot upcoding. Deze resultaten suggereren dat het belangrijk is voor zorg- 
verzekeraars om niet alleen gunstige prijzen af te spreken, maar om ook de verhouding tussen bepaalde DBC's te benchmarken tussen ziekenhuizen.

In hoofdstuk vijf hebben we een typisch effect van het DBC-systeem geanalyseerd, namelijk het gebruik van het DBC-systeem als verrichtingensysteem. We hebben dit gedrag overdeclaratie genoemd. Een DBC bestaat uit een pakket van zorg dat voor één prijs wordt geleverd onafhankelijk van de kosten die binnen dit pakket zijn gemakkt. Het ziekenhuis loopt dus een financieel risico als een patiënt meer kosten veroorzaakt dan de DBC opbrengt. In bepaalde gevallen is het geoorloofd een nieuwe DBC te openen voor de behandeling van een patiënt. Er zijn per specialisme instructies over wanneer een DBC te openen en sluiten. De stelregel is dat het (binnen eenzelfde specialisme) is toegestaan een tweede DBC te openen, indien de patiënt $40 \%$ meer kosten en/of inzet behoeft van medisch specialist en ziekenhuis in vergelijking met de kosten van de eerste DBC. Deze regel geeft ruimte voor eigen interpretatie, omdat kosten en inzet niet zijn gekwantificeerd. Dit leidt tot het risico dat ziekenhuizen en medisch specialisten het systeem gebruiken als een verrichtingensysteem om omzet en inkomsten te verhogen. Een interne analyse van een zorgverzekeraar laat zien dat bijna $5 \%$ van alle gedeclareerde DBC's kunnen worden geclassificeerd als overdeclaratie. In hoofdstuk 5 hebben we de resultaten van deze analyse gebruikt om te exploreren welke factoren overdeclaratie beïnvloeden. We verwachtten dat het soort specialisme, specifieke DBC-kenmerken en mogelijk het ICT systeem dat wordt gebruikt voor openen en sluiten van de DBC's invloed kunnen hebben op overdeclaratie. Uit de analyses blijkt dat er tussen de ziekenhuizen wederom sprake is van grote variatie in het percentage overdeclaratie. Ook tussen specialismen treedt grote variatie op. Dit lijkt te wijzen op zowel ziekenhuis- als specialisme-specifieke kenmerken. Regressieanalyses hebben dit beeld bevestigd. We kunnen concluderen dat het percentage overdeclaratie wordt veroorzaakt door niet-geobserveerde ziekenhuis- en specialisme-specifieke kenmerken. Het gebruikte ICT systeem en het zorgtype van de DBC hebben een kleinere invloed op het percentage overdeclaratie. In tegenstelling tot onze verwachting werd niet gevonden dat overdeclaratie vaker voorkomt in het B-segment. Eén van de beperkingen van deze studie is, dat onbekend is of de gevonden overdeclaratie een structureel probleem betreft of dat het aan de transitie van de functionele bekostiging naar het DBC-systeem toe te schrijven valt. Het gaat echter wel om een substantieel probleem, want bij extrapolatie naar de gehele markt zou de totale omvang van overdeclaratie in de periode 2006-2008 meer dan 1 miljard hebben bedragen. Inzicht in de oorzaken van overdeclaratie is van groot belang voor een effectieve kostenbeheersingstrategie van zorgverzekeraars en past ook binnen de wens van de overheid om kosten te beheersen.

Binnen de discussie rondom marktwerking in de zorg wordt vaak als tegenargument aanbodgeïnduceerde vraag genoemd. In hoofdstuk zes hebben we dit fenomeen in 
Nederland geanalyseerd door een aantal specifieke chirurgische procedures per inwoner te relateren aan het aantal medisch specialisten per inwoner voor zowel medisch specialisten in loondienst als vrijgevestigde medisch specialisten. Om het probleem van het niet kunnen onderscheiden van oorzaak en gevolg op te lossen hebben we gebruik gemaakt van twee unieke kenmerken in Nederland; namelijk het naast elkaar bestaan van medisch specialisten in loondienst en vrijgevestigde medisch specialisten en het naast elkaar bestaan van een A- en een B-segment. Deze twee unieke kenmerken laten het toe een natuurlijk experiment uit te voeren, waarbij kan worden gecorrigeerd voor regionale verschillen die bestaan door nietgeobserveerde verschillen in patiëntenkenmerken. Onze identificerende hypotheses waren dat alleen vrijgevestigde medisch specialisten een prikkel tot meer productie hebben en dat deze prikkel alleen in het B-segment bestaat. Onze empirische analyse ondersteunt het bestaan van aanbodgeïnduceerde vraag voor de volgende aandoeningen: keel- en neusamandelverwijdering, liesbreuk, spataderen, staar, hernia, borstverkleining en prolapse uterus. In de meeste gevallen was de coëfficiënt hiervoor groter voor vrijgevestigde medisch specialisten dan voor medisch specialisten in loondienst. Ook na het toevoegen van de controlevariabelen blijven deze uitkomsten staan. Om de omvang van aanbodgeïnduceerde vraag in te schatten hebben we de coëfficiënten uit de regressie gebruikt om elasticiteiten te construeren. Deze elasticiteiten meten het percentage stijging in het aantal behandelingen per hoofd van de bevolking als het aantal medisch specialisten per hoofd van de bevolking met $1 \%$ zou toenemen. Deze elasticiteiten zijn berekend op basis van het verschil tussen de coëfficiënt voor vrijgevestigde medisch specialisten en medisch specialisten in loondienst. De elasticiteiten variëren van 0.1 tot 0.25 met een uitschieter van 0.36 voor spataderen behandeld door een dermatoloog.

We kunnen concluderen we dat de invoering van het DBC-systeem een effect heeft op het gedrag van medisch specialisten en ziekenhuizen. Hoe groot dit effect precies is kunnen we niet kwantificeren, omdat het niet mogelijk is voor alle hoofdstukken de analyses te extrapoleren naar de gehele sector van medisch specialistische zorg. De volume-effecten die we hebben gevonden kunnen we niet direct interpreteren als overproductie. Er kunnen ook andere redenen zijn voor de toename in volume zoals eerder bestaande wachtlijsten, onderbehandeling of verschillen in behandelstijl. Een voorbeeld van een reactie die niet kan worden gelabeld als overproductie is de groei van de B-segment diagnoses in hoofdstuk drie. We hebben niet onderzocht of deze groei medisch relevant is of niet; we hebben wel een significante relatie gevonden tussen de toename in productie door de invoering van het DBCsysteem. In onze analyses hebben we ons niet bezig gehouden met kwaliteit van zorg. Bijvoorbeeld in de analyse in hoofdstuk vier over upcoding beschrijven we verschillen in behandelintensiteit. Een intensievere behandeling kan voor sommige patiënten leiden tot een kwalitatief betere behandeling. De verschillen tussen zie- 
kenhuizen zoals beschreven in hoofdstuk vier en vijf kunnen worden geplaatst binnen de literatuur van Wennberg over regionale verschillen.

Tijdens het schrijven van dit proefschrift hebben er een aantal beleidsveranderingen plaatsgevonden. Ten eerste zal er vanaf 2012 overgegaan worden op een nieuw DBC systeem genaamd DOT (DBC's Op weg naar Transparantie). Dit nieuwe systeem is een sterk gecomprimeerde versie van het $\mathrm{DBC}$ systeem en verschilt op een aantal belangrijke punten: het zorgpoduct wordt niet langer vooraf gekozen door medisch specialist, maar achteraf afgeleid uit de geregistreerde verrichtingen; er komen multidisciplinaire zorgproducten en de codering volgt de - medisch zinvollere - ICD10 codering in plaats van per specialisme een eigen codering. DOT zal naar verwachting een aantal van de huidige problemen met het DBC systeem, zoals de complexiteit en overdeclaratie oplossen. Het is echter nog maar de vraag of de medisch specialistische zorg inderdaad transparanter wordt door DOT, aangezien er ook veel informatie verloren gaat door de aggregatie van DBC's. Daarnaast blijft upcoding een risico maar dan op een andere manier: namelijk niet meer door vooraf een duurdere DBC te kiezen, maar door de verrichtingen zo te kiezen of te registreren dat ze tot een duurder declarabel product leiden. Naast de overgang naar DOT zal ook het B-segment in 2012 worden uitgebreid naar 70\%, als onderdeel van de prestatiebekostiging. De analyses uit dit proefschrift wijzen niet direct op het niet doorzetten van de prijsliberalisering. Er is namelijk voor de onderzochte aandoeningen geen relatie gevonden tussen upcoding en afgesproken prijzen. Daarnaast leidt het bestaan van twee systemen naast elkaar (het FB systeem en het DBC systeem) tot inefficiënties in de onderhandelingen over het B-segment. Het belangrijkste probleem echter van het uitbreiden van het B-segment is dat het volume kan toenemen (voorzichtig bewijs hiervoor wordt in hoofdstuk 3 geleverd). Om ongewenst volumegroei tegen te gaan kunnen verzekeraars hierop scherper gaan inkopen door het afspreken van staffelprijzen of volumelimieten. Het monitoren en benchmarken van instellingen op zowel casemix als volume door verzekeraars zal de grootste uitdaging voor 2012 zijn. 


\section{Dankwoord}

Lang heb ik uitgekeken naar het moment dat ik dit dankwoord kon gaan schrijven. Maar zoals met iedere pagina in dit proefschrift begon ik toch later dan gepland.

In de eerste plaats heel veel dank aan Zorgverzekeraar CZ die dit onderzoek zowel gedeeltelijk financieel als data-wise heeft mogelijk gemaakt. Na een leuke en interessante stageperiode bij $\mathrm{OZ}$ wilde ik mijn scriptieonderzoek uitbreiden naar een promotieonderzoek en gelukkig zag de toenmalige Raad van Bestuur van OZ hier ook wat in. Ik wil daarom Han Tanis, Joël Gijzen en Eggo Boer hartelijk danken voor de kans die ze me gegeven hebben. Han, jij hebt me bij BI geplaatst en tot op de dag van vandaag ben ik daar heel blij om. Joël, toen ik na vier jaar ICT weer bij Zorg ging werken was het precies de goede tijd om het laatste hoofdstuk samen te bespreken en je ideeën te verwerken. Ik zie er naar uit om de resultaten van dit proefschrift verder te implementeren binnen het nieuwe expertisecentrum.

Op de tweede eerste plaats wil ik hier ook graag mijn promotor Hans Maarse bedanken voor al zijn hulp en steun de afgelopen jaren. Onze, vaak niet erg gestructureerde, gesprekken waren altijd inspirerend. Ik ben na vijf jaar samenwerken met je zelfs bijna van mijn geloof gevallen over de reikwijdte van economische prikkels.

Ook veel dank aan mijn copromotor Marc Pomp bedanken voor zijn inspanningen, vooral op statistisch gebied. Het was erg leerzaam om mee te werken aan het onderzoek naar aanbodgeïnduceerde vraag. Jouw altijd positieve blik heeft me vaak weer vooruit geholpen.

Uiteraard wil ik ook graag alle artsen bedanken die mee hebben gedaan aan de interviews voor hoofdstuk 3. Oorspronkelijk was het afnemen van deze interviews geen deel van mijn onderzoeksplan, maar het was erg interessant om te doen en heeft me veel nieuwe inzichten gegeven voor de rest van de hoofdstukken.

Professor Frits van Merode gaf ons bijna privécolleges over 'complex adaptive systems', waarvoor veel dank.

I would also like to thank Barbara Greenberg for editing my work so thoroughly. 
Een woord van dank ook voor alle CZ collega's die al mijn vragen over inkoop of DBC's de afgelopen jaren hebben beantwoord, zoals Nicolette Huiskes, Nico Martens, Rien Pijnenburg en Sanne van Roessel.

Mijn neef Jules wil ik graag bedanken voor het mooie ontwerp voor de kaft. Je hoeft het nog steeds niet te lezen, hoor.

Graag wil ik ook al mijn collega's van BEOZ bedanken voor de leuke omgang de afgelopen jaren. Ook al was ik er slechts twee dagen per week, ik heb me altijd erg welkom gevoeld. Speciale dank aan de volgende dames: Hanneke, Janneke, Aggie, Saskia, Suus, Brigit, Ellen, Irma, Marla, en Marike.

Hierboven nog niet genoemd, maar wel een speciale plek van dank voor Adrienne en Irene. Ik ben heel blij dat jullie mijn paranimfen willen zijn. Adrienne, bedankt voor de leuke vriendschap die tussen ons is ontstaan en ik hoop dat we elkaar blijven zien. Irene: grazie mille per tutti i emails! I wish you the best of luck finishing your PhD and hope we continue our e-friendship.

Dan mijn CZ collega's. In de eerste plaats Erwin van Dongen: jij werd mijn dagelijks begeleider bij CZ en samen konden we naast data-minen ons verwonderen over de wetenschappelijke wereld. Ook toen je wegging bij CZ ben je betrokken gebleven bij mijn onderzoek; dankjewel daarvoor. Dan Paul, het was vast bijzonder toen je op 2 mei 2006 te horen kreeg dat je er per 1 mei iemand bij had gekregen in je team en dan ook nog een vrouw. Heel erg bedankt dat ik al die jaren bij BI heb mogen zitten en er nu nog steeds welkom ben. Ik ben voor altijd (ook) een beetje nerd geworden. Ook bedankt aan al mijn BI collega's voor de hulp met programmeren of 'bij elkaar klikken'. Speciale dank voor al jullie geduld aan: Ruud, Henk, Michiel en Marius. Dankzij jullie input (of was het nou put?) kon ik steeds weer verder als ik vast zat. Karen en Jacqueline: bedankt voor de gezellig koffiebreaks die we gelukkig nu nog steeds in ere houden en jullie interesse tot het einde. Tenslotte nog dank aan mijn 'nieuwe' CZ-collega's van het Projectbureau, Monique, Hans, Suzanne en Suad, die ook erg hebben meegeleefd tijdens de laatste maanden.

Naast alle collega's van twee werkplekken wil ik ook kort mijn vrienden en familie bedanken voor hun interesse in mijn boekje de afgelopen jaren. In het bijzonder dank aan mijn lieve vriendinnen Anne, Dilek, Heske, Karlijn, Madelon, Mascha, Sabina en Virginia voor het kunnen luchten van mijn hart. Ook oma en Epie en mijn twee tantes Ellyke en Susan wil ik graag bedanken voor het altijd maar weer vragen naar de voortgang. Mijn schoonouders Piet en Ineke wil ik graag bedanken voor hun interesse in dat vreemde langdurige onderzoek van mij. Ik ben blij dat jullie nu kunnen zien waar het allemaal om te doen was. Jozien, jij bedankt voor het nakijken van het Nederlands en je begrip voor de donkere dagen van het schrijven. Xander 
en Kristien, verder van jullie wereld kon ik niet afstaan tijdens het schrijven van dit boekje. Juist daarom bedankt dat jullie zo geïnteresseerd zijn geweest en nu wéér zo hebben geholpen met de organisatie van het feest.

Tenslotte wil ik graag mijn ouders en mijn man bedanken voor ook hun toewijding aan mijn proefschrift. Mama, papa, jullie rotsvaste vertrouwen dat deze dag er ging komen blijkt gelukkig gegrond. Harm, jij juist bedankt voor het serieus nemen van mijn zorgen als ik dacht dat ik het nooit af zou krijgen. 



\section{Curriculum Vitae}

Fleur Hasaart is geboren op 11 juli 1983 in Maastricht. In 2001 behaalde zij haar gymnasium- $\beta$ diploma op het Trichter College eveneens te Maastricht. Hierna heeft ze International Economics and Finance gestudeerd aan de Universiteit van Tilburg.

Haar scriptie heeft ze geschreven over 'Upcoding binnen het Nederlandse DBC systeem' met een gecombineerde stageperiode bij het Centraal Plan Bureau en zorgverzekeraar OZ. Deze scriptie was het startpunt van dit proefschrift.

$\mathrm{Na}$ haar afstuderen is ze bij CZ (toen nog OZ zorgverzekeringen) gaan werken in een deeltijdfunctie bij de afdeling Business Intelligence om daarnaast bij de vakgroep BEOZ van Maastricht University te starten met haar promotieonderzoek. Vanuit de vakgroep BEOZ heeft ze onderwijs gegeven in de vakken Health Economics en Financial Management.

Sinds oktober 2010 is ze werkzaam bij de afdeling Projectbureau Zorg, eveneens bij $\mathrm{CZ}$, en daar onder andere bezig met het opzetten van een Expertisecentrum ten behoeve van de zorginkoop. 